1d Universidad Nacional de La Plata - Facultad de Ciencias Médicas Dto. de Posgrado Instituto de Desarrollo e Investigaciones Pediátricas (IDIP) "Dr. Fernando Viteri"

Hospital de Niños de La Plata/Min. Salud- Comisión de Investigaciones Científicas /PBA MAESTRÍA EN NUTRICIÒN HUMANA | Director Dr. Horacio F. González

\title{
- TESIS DE MAESTRÍA
}

"EVALUACIÓN DE FACTORES DE RIESGO QUE SE ASOCIAN A LA REGANANCIA DE PESO DE PACIENTES OPERADOS DE CIRUGÍA BARIÁTRICA POR EQUIPOS QUIRÚRGICOS PRIVADOS ESPECIALIZADOS DE LA REPÚBLICA ARGENTINA".
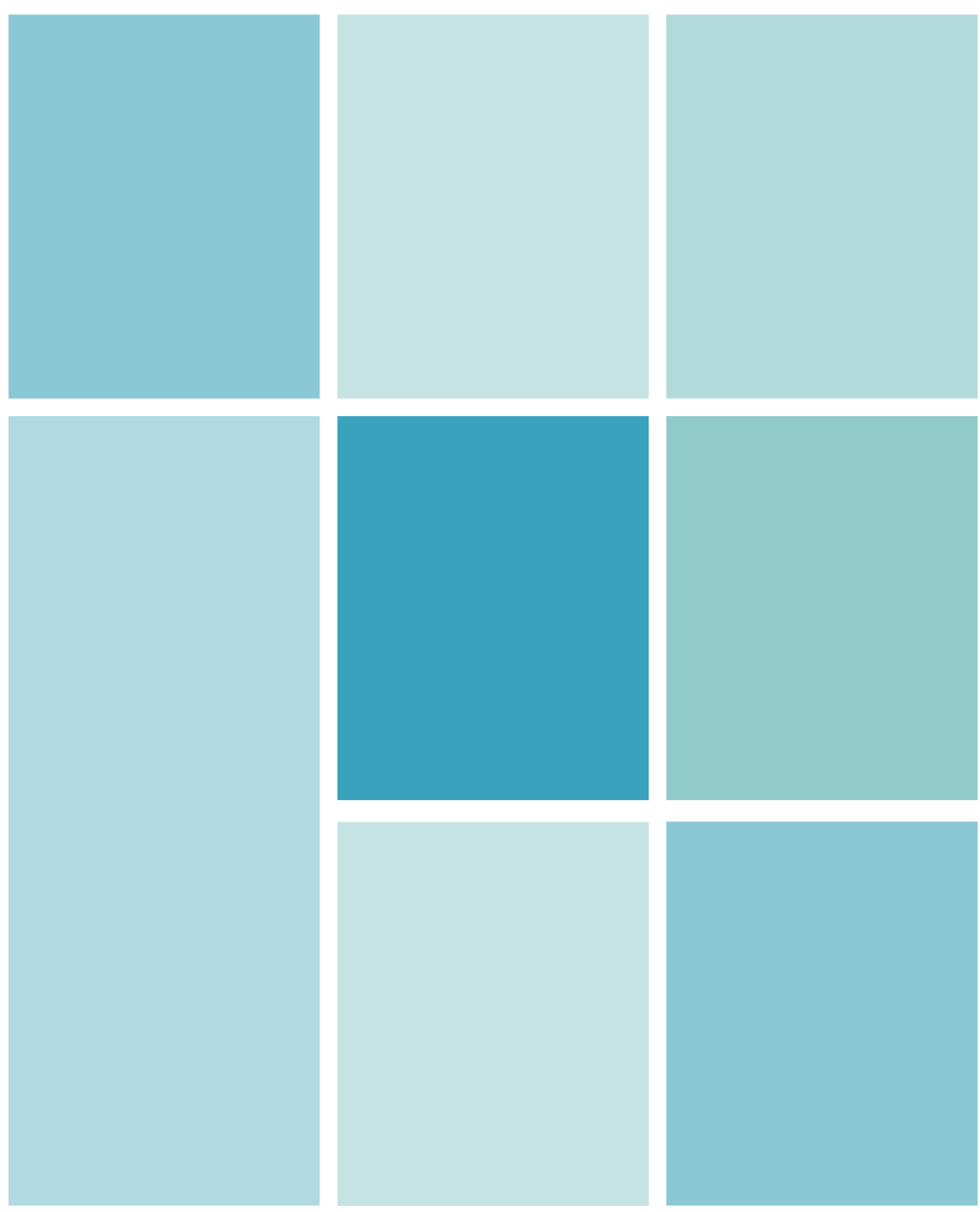

Tesis que para obtener el grado de magister presentan:

Autor: Lic. Laura Fantelli Pateiro, Nutricionista. Director: Mg. Fabián Melamed, Psicólogo. Co-director: Dr. En Medicina Horacio F. González. Análisis Estadístico: Mg. Santiago Cueto. 


\section{Dedicatorias y agradecimientos}

Esta tesis para obtener el grado de magister está dedicada primeramente a mi familia por su apoyo, al Dr. Felipe Eduardo Fiolo por confiar en mi para ser parte de su equipo de cirugía bariátrica e iniciarme en esta especialidad; a mis colegas y amigas de NUCIBA la Lic. Mónica Coqueugniot, la Lic. Patricia De Rosa, la Lic. Natalia Pampillón, la Lic. Clarisa Reynoso y la Lic. Carolina Pagano; a mis tutores el Mg. Lic. Fabián Melamed por nuestras tardes reunidos en post de esta tesis, al Mg. Santiago Cueto por colaborar con el asesoramiento metodológico y estadístico y al Dr. Horacio González por ser el director de la maestría, por su calidez y conocimiento brindado en cada clase; y a mis amigos de la maestría por los grandes momentos vividos.

Deseo agradecer principalmente a cada una de mis colegas que participaron en este estudio multicéntrico: Lic. Rita Baragiola, Lic. Natalia Bonzi, Lic. Natalia Pampillón, Lic. Mariela Abaurre, Lic. Camila Luna, Lic. Carolina Pagano, Lic. María de los Ángeles Blanco Camelino, Lic. María Sánchez Mariño, Lic. Laura Andriani, Dra. Marianela Aguirre Ackerman, Dr. Mariano Palermo, Lic. Mónica Coqueugniot, Lic. Clarisa Reynoso, Lic. Patricia De Rosa, Lic. Lucrecia Martín, Lic. Eugenia Mamone, Lic. Giselle Martínez, Dr. Eduardo Fiolo. Al Lic. Fabián Melamed y al Mg. Santiago Cueto por su colaboración y asesoramiento. $\mathrm{Y}$ por supuesto a todos nuestros pacientes que desinteresadamente participaron en el estudio. 


\section{Resumen}

\section{Título}

Evaluación de factores de riesgo que se asocian a la reganancia de peso de pacientes operados de cirugía bariátrica por equipos quirúrgicos privados especializados de la República Argentina.

\section{Resumen}

La reganancia de peso es un efecto no deseado a largo plazo que ocurre después de la cirugía bariátrica y podría comprometer muchos de los beneficios para la salud que se logran con la misma. Los mecanismos y los factores relacionados con la recuperación de peso aún no se conocen por completo.

\section{Objetivo}

Explorar las posibles variables que se asociarían a la reganancia de peso de pacientes luego de 5 años de ser sometidos a cirugía bariátrica por equipos quirúrgicos privados de la República Argentina.

\section{Hipótesis}

Las mujeres solteras jóvenes tienen un porcentaje menor de recuperación de peso a largo plazo después de la cirugía bariátrica.

Los sujetos que tienen sobrepeso después de la edad adulta logran una mayor pérdida de peso postoperatoria (> 50\% de porcentaje de pérdida de peso) con tasas más bajas de recuperación de peso a largo plazo.

Los pacientes con súper obesidad (IMC > 50) tienen una mayor prevalencia de recuperación de peso después de la cirugía.

Los pacientes que realizan un mínimo de 150 minutos de actividad física aeróbica semanal con una intensidad promedio alta logran mantener su peso más fácilmente que aquellos que no realizan actividad física o no logran alcanzar este tiempo.

Existe una asociación entre aquellos sujetos que no presentan un trastorno psicológico y que reciben apoyo psicológico durante más de 6 meses durante el período postoperatorio y una tasa más baja de reganancia. 
Las personas que tienen un buen cumplimiento de las recomendaciones médicas, no abusan del alcohol y descansan durante al menos 7 horas al día tienen un porcentaje menor de recuperación de peso después de la cirugía bariátrica.

Los sujetos con hábitos de picoteo o atracones, son comedores nocturnos, comen dulces o comen en respuesta a sus emociones después de la cirugía, tienen mayores tasas de recuperación de peso. Por el contrario, aquellos que realizan de 5 a 6 comidas y consumen una dieta saludable al día no muestran recuperación de peso. Las personas que mantienen su peso tienen una mejor calidad de vida en comparación con aquellos que recuperan peso.

\section{Metodología}

Se realizó un estudio de tipo descriptivo, exploratorio, retrospectivo y multicéntrico.

Para tal fin se revisó en forma exhaustiva, estudios con similares objetivos, seleccionando las variables asociadas a la reganancia de peso post cirugía bariátrica que mostraron mayor presencia.

La muestra se diseñó seleccionando una cohorte de 254 pacientes bariátricos operados de bypass gástrico en $Y$ de Roux o manga gástrica con seguimiento postoperatorio durante 5 años o más. Se seleccionó para tal fin 11 equipos quirúrgicos de 8 ciudades de 6 provincias de la Argentina.

El criterio de recuperación se definió como $\geq 15 \%$ del nadir de peso y se agruparon como "reganadores", y los individuos por debajo de este porcentaje se categorizaron como "mantenedores".

Los participantes fueron contactados telefónicamente para citarlos en consultorio donde respondieron una encuesta presentada por un profesional nutricionista, previa firma del consentimiento informado.

La encuesta se compone por datos filiatorios, datos en relación a la evolución de su peso, a sus hábitos alimentarios post cirugía, acceso a servicios de apoyo junto a un cuestionario validado de calidad de vida (BAROS).

En una primera etapa, los datos fueron procesados en análisis tanto descriptivos como inferenciales, utilizando test paramétricos y no paramétricos para comparaciones de registros.

En una segunda etapa, considerando el status de "reganador de peso" o "no reganador de peso", se utilizaron test no paramétricos de asociación de variables. En 
los casos donde estos test resultaron significativos, se procedió a realizar el cálculo de los Odds Ratios y sus intervalos de confianza correspondientes.

\section{Resultados}

Se observaron diferencias significativas y no significativas a lo largo de todas las categorías encuestadas con comportamiento diferencial de las variables.

Se encontró diferencias significativas entre los "reganadores" y los "mantenedores" con respecto a frecuencia de control nutricional ( $\sin$ control $p=0,005)$, hábito de almorzar $(p=0,004)$, hábito de cenar $(p=0,021)$, comida principal antes de las $15 \mathrm{~h}(\mathrm{p}=0,016)$, desayuno o almuerzo como comida principal $(p=0,005)$, hábitos alimenticios saludables $(p<0,0001)$, picoteo $(p<0,0001)$, comedor de dulces $(p=$ $0,037)$, consumo de alcohol $(p=0,024)$, ejercicio físico habitual $(p=0,006)$, diagnóstico de enfermedad psiquiátrica después de la cirugía $(p=0,0002)$, evento traumático post cirugía ( $p=0,0002$ ), y por último según el cuestionario de calidad de vida relacionado con la salud después de la cirugía bariátrica (BAROS) que valora la autoestima del paciente como mejor $(p=0,001)$, tener más relaciones sociales $(p=$ $0,019)$, más trabajo $(p=0,019)$, y mejor sexualidad $(p=0,012)$.

\section{Conclusión}

En la muestra estudiada la cirugía bariátrica mostró un alto grado de efectividad medida por el peso perdido alcanzado entre los 6 y los 24 meses postoperatorios con una adecuada reducción del exceso de peso corporal. Observados en un período mayor a 5 años, estos porcentajes de pérdida de peso se reducen en diferentes proporciones, así un $44 \%$ de la muestra regana un promedio de $16,5 \%$ de peso.

Las variables más destacadas fueron la frecuencia de consulta nutricional, los hábitos alimenticios saludables, no picotear, realizar ejercicio, no presentar una enfermedad psiquiátrica o un evento traumático después de la cirugía.

Es por ello que podemos concluir que después de un procedimiento quirúrgico para la obesidad es necesario mantener a lo largo del tiempo una alimentación saludable, ejercicio físico y estabilidad emocional. El peso perdido no logra ser mantenido si el paciente no sostiene hábitos saludables de por vida. 


\section{Abstract}

Title:

Evaluation of risk factors associated with the weight reganance of patients undergoing bariatric surgery by specialized private surgical teams of the Argentine Republic.

\section{Background:}

Weight regain is a long-term unwanted effect that occurs after bariatric surgery and could compromise many of the health benefits that are achieved with it. The mechanisms and factors related to weight recovery are not yet fully understood.

\section{Objective:}

To explore the possible variables that would be associated with the weight regnancy of patients after 5 years post bariatric surgery by private surgical teams of the Argentine Republic.

\section{Hypothesis:}

Young single women have a lower percentage of long-term weight recovery after bariatric surgery.

Subjects who are overweight after adulthood achieve greater postoperative weight loss (> $50 \%$ percentage of weight loss) with lower rates of long-term weight recovery.

Patients with super obesity $(\mathrm{BMI}>50)$ have a higher prevalence of weight recovery after surgery.

Patients who perform a minimum of 150 minutes of weekly aerobic physical activity with a high average intensity manage to maintain their weight more easily than those who do not perform physical activity or fail to achieve this time.

There is an association between those subjects who do not present a psychological disorder and who receive psychological support for more than 6 months during the postoperative period and a lower rate of reganancy.

People who have good adherence to medical recommendations, do not abuse 
alcohol and rest for at least 7 hours a day have a lower percentage of weight recovery after bariatric surgery.

Subjects with snacking habits or binge eating, nocturnal eaters, sweets eaters or eat in response to their emotions after surgery, have higher rates of weight recovery. Conversely, those who perform 5 to 6 meals and consume a healthy diet a day do not show weight recovery.

People who maintain their weight have a better quality of life compared to those who regain weight.

\section{Methodology}

A descriptive, exploratory, retrospective and multicentric study was carried out.

For this purpose, studies with similar objectives were reviewed exhaustively, selecting the variables associated with the weight reganance after bariatric surgery that showed greater presence.

The sample was designed by selecting a cohort of 254 bariatric patients operated on Roux-en-Y gastric bypass or gastric sleeve with postoperative follow-up for 5 years or more. For this purpose, 11 surgical teams from 8 cities in 6 provinces of Argentina were selected.

The recovery criterion was defined as $\geq 15 \%$ of the weight nadir and grouped as "reganadores", and individuals below this percentage were categorized as "maintainers".

The participants were contacted by telephone to call them in the office where they answered a survey presented by a nutritionist professional, after signing the informed consent.

The survey consists of filial data, data regarding the evolution of their weight, post-surgery eating habits, access to support services together with a validated quality of life questionnaire (BAROS).

In a first stage, the data were processed in both descriptive and inferential analyzes, using parametric and nonparametric tests for comparisons of records.

In a second stage, considering the status of "weight regaser" or "non-weight reliever", nonparametric variables association tests were used. In the cases where these tests were significant, the calculation of the Odds Ratios and their corresponding confidence intervals were carried out. 


\section{Results}

Significant and non-significant differences were observed throughout all the categories surveyed with differential behavior of the variables.

Significant differences were found between the "reganadores" and the "maintainers" with respect to frequency of nutritional control (without control $p=0,005$ ), habit of having lunch $(p=0,004)$, habit of having dinner $(p=0,021)$, main meal before from 3 p.m. ( $p=0.016)$, breakfast or lunch as main meal $(p=0.005)$, healthy eating habits ( $p<0.0001)$, snacking $(p<0.0001)$, sweet eater $(p=0.037)$, alcohol consumption $(p=0.024)$, habitual physical exercise $(p=0.006)$, diagnosis of psychiatric illness after surgery $(p=0.0002)$, post-surgery traumatic event $(p=0.0002)$, and finally according to the quality of life questionnaire related to health after bariatric surgery (BAROS) that assesses the patient's self-esteem as better $(p=0.001)$, having more social relationships $(p=0.019)$, more work $(p=0.019)$, and better sexuality $(p=0.012)$.

\section{Conclusión}

In the studied sample, bariatric surgery showed a high degree of effectiveness measured by the lost weight achieved between 6 and 24 months postoperatively with an adequate reduction of excess body weight.

Observed in a period greater than 5 years, these percentages of weight loss are reduced in different proportions, thus $44 \%$ of the sample recovers $16.5 \%$ of body weight on average.

The most important variables were the frequency of nutritional consultation, healthy eating habits, not snacking, exercising, not presenting a psychiatric illness or a traumatic event after surgery.

That is why we can conclude that after a surgical procedure for obesity it is necessary to maintain a healthy diet, physical exercise and emotional stability over time. The lost weight can not be maintained if the patient does not maintain healthy habits for life. 


\section{Índice General}

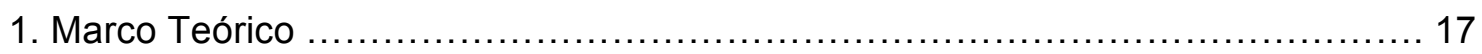

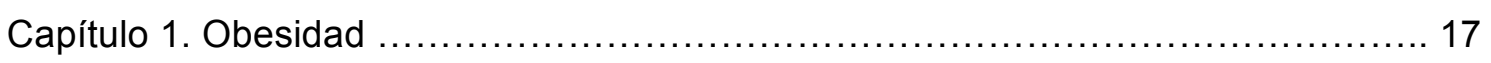

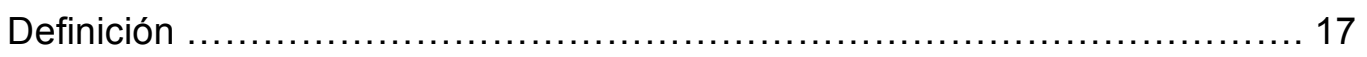

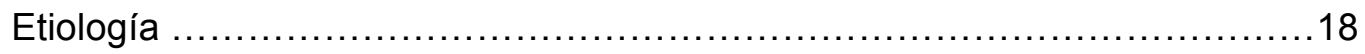

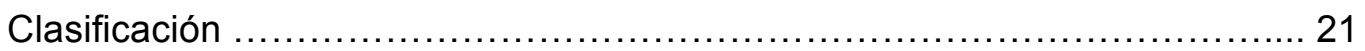

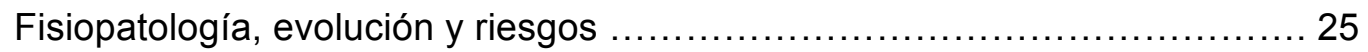

Riesgos y diagnóstico de enfermedades asociadas. ......................... 25

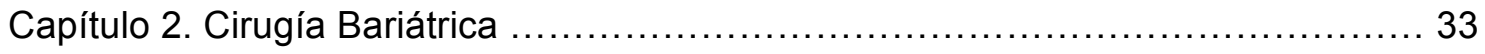

Técnicas Quirúrgicas por Videolaparoscopía ........................... 33

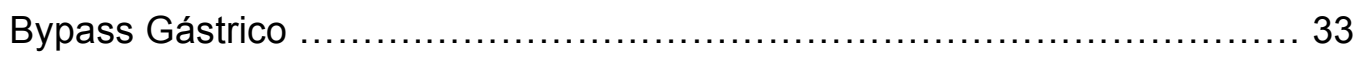

Gastrectomía Vertical en Manga ..................................... 35

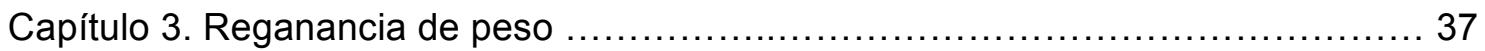

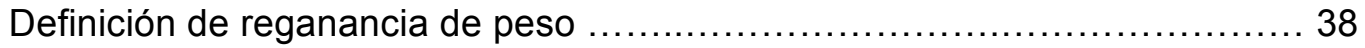

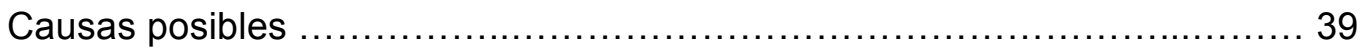

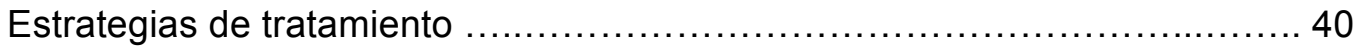

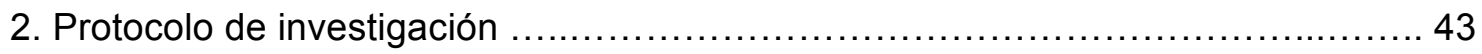

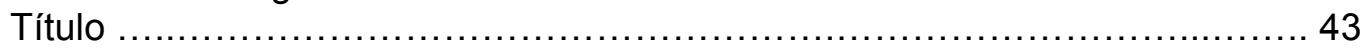

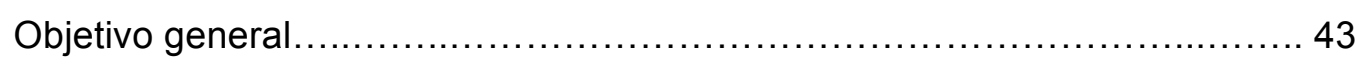

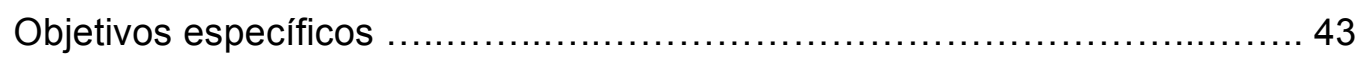

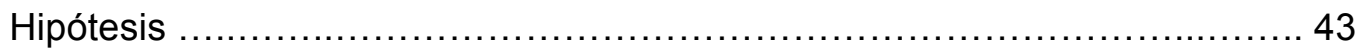

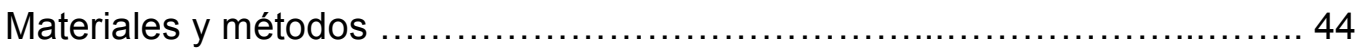

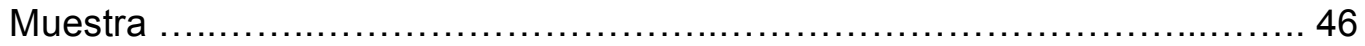

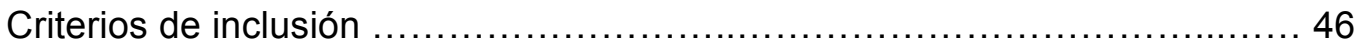

Criterios de exclusión ...................................................... 46

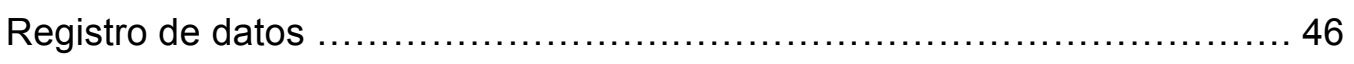

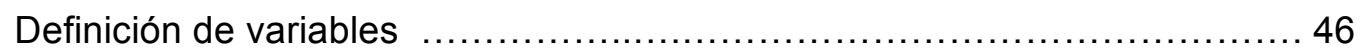

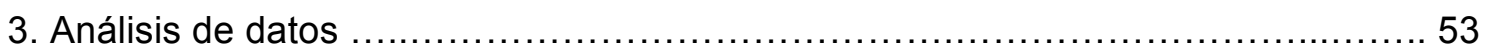

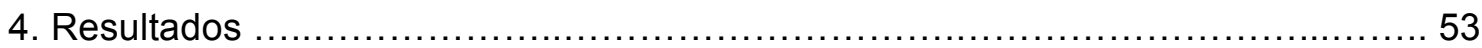

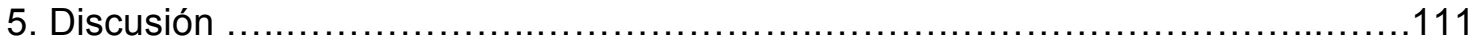

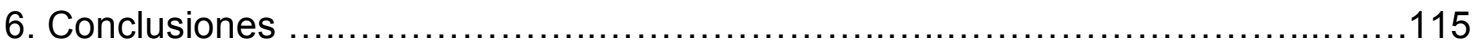

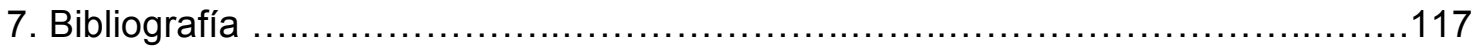




\section{Lista de tablas}

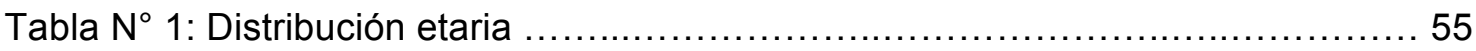

Tabla $N^{\circ}$ 2: Prueba $Z$ de comparación de proporciones (técnica quirúrgica) ........... 56

Tabla $N^{\circ}$ 3: Estado civil al momento de la cirugía y en la actualidad .................. 57

Tabla $N^{\circ} 4:$ Valores de IMC en las distintas instancias ........................... 65

Tabla $N^{\circ}$ 5: Porcentaje de aumento respecto del peso mínimo posoperatorio .........6 67

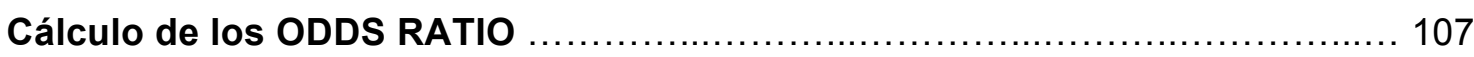

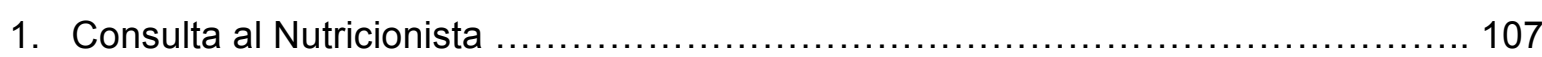

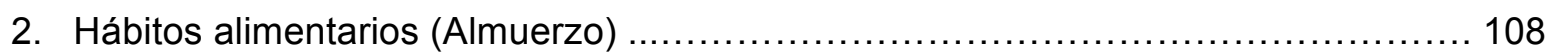

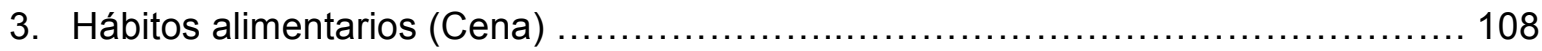

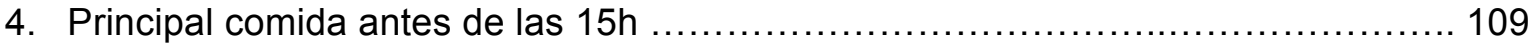

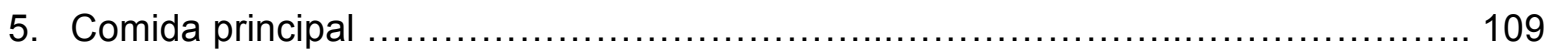

6. Picotea o realiza ingestas continuamente acompañadas de la sensación de pérdida de

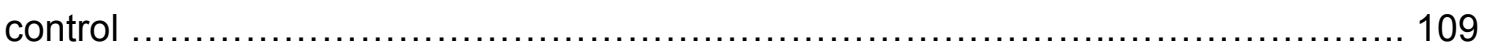

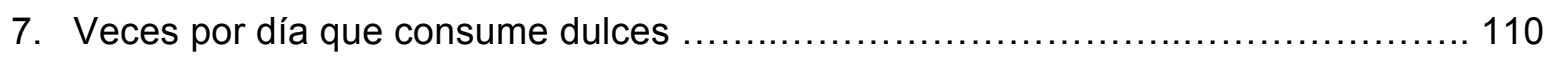

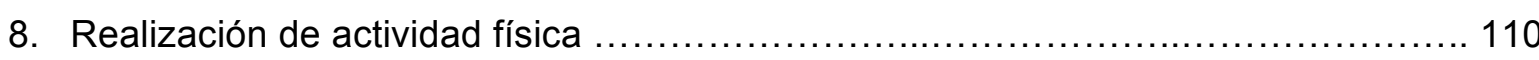

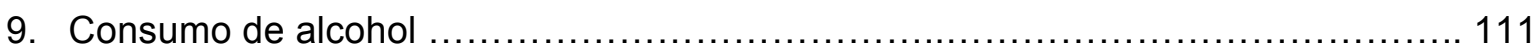

10. Presencia de enfermedades mentales, detectadas en la etapa posoperatoria ....... 111

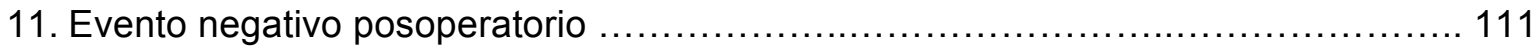

\section{Lista de gráficos}

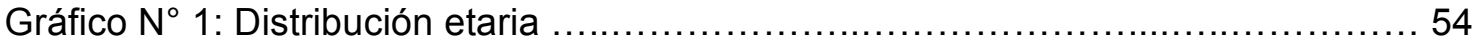

Gráfico $\mathrm{N}^{\circ}$ 2: Tiempo desde la realización de la cirugía ............................ 56

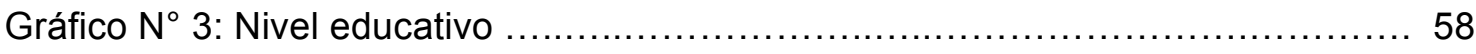

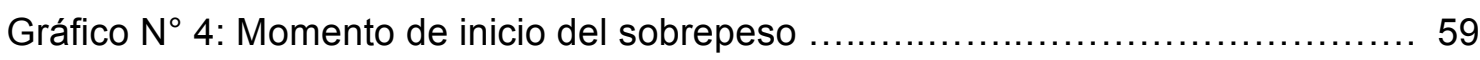

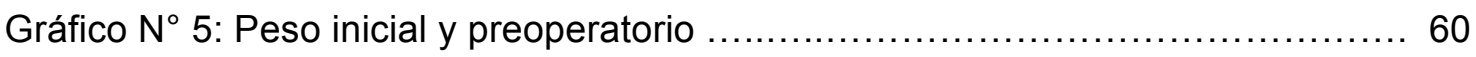

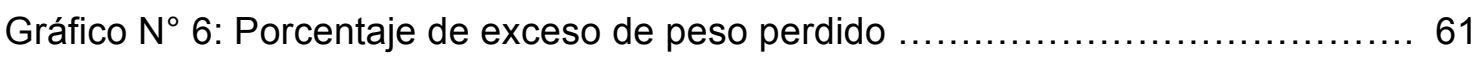

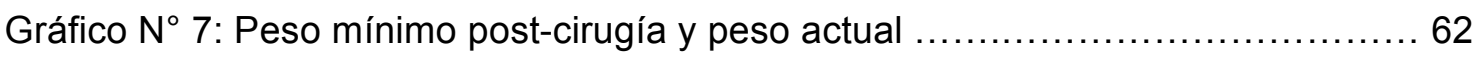

Gráfico $N^{\circ}$ 8: Tiempo transcurrido hasta el peso mínimo post-cirugía ..................6 63

Gráfico $N^{\circ}$ 9: Índice de Masa Corporal ........................................ 64

Gráfico No 10: Porcentaje de aumento respecto del peso mínimo posoperatorio ....... 66

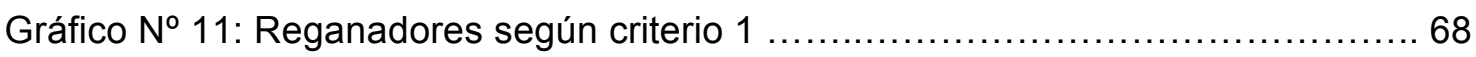

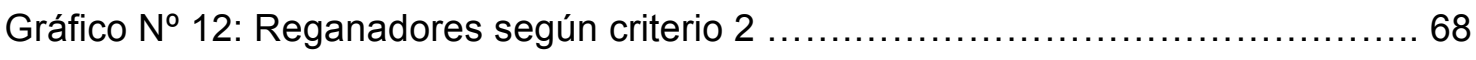

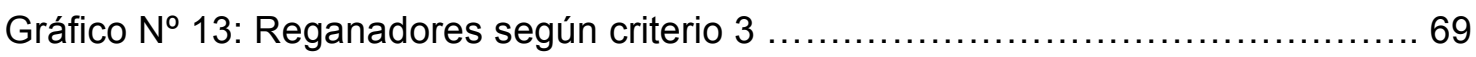

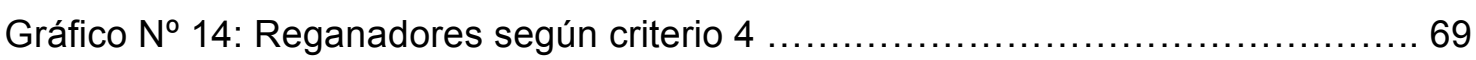

Lie. Laura Fantelli Pateito INumbenista $\quad 14$ 


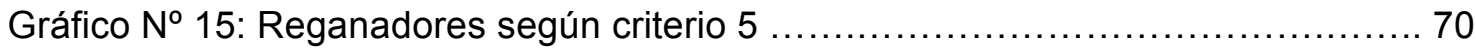

Gráfico $N^{\circ}$ 16: Cantidad de criterios cumplidos por paciente ....................... 70

Gráfico No 17: Motivos por los cuales son reganadores. ............................ 71

Gráfico $N^{\circ}$ 18: Motivos por los cuales son mantenedores o no reganadores .......... 72

Gráfico $\mathrm{N}^{\circ}$ 19: Edad diferenciada por grupos ................................... 73

Gráfico $\mathrm{N}^{\circ} 20$ : Distribución por sexo diferenciada por grupos ........................ 73

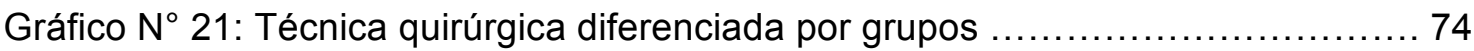

Gráfico $N^{\circ} 22:$ Nivel Educativo diferenciado por grupos ............................ 75

Gráfico $\mathrm{N}^{\circ}$ 23: Inicio del exceso de peso diferenciado por grupos $\ldots \ldots \ldots \ldots \ldots \ldots \ldots \ldots$

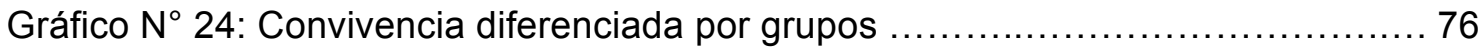

Gráfico $N^{\circ}$ 25: Objetivo de descenso de peso preoperatorio diferenciado por grupos 77

Gráfico $\mathrm{N}^{\circ} 26$ : Control de peso (frecuencia) diferenciado por grupos $\ldots \ldots \ldots \ldots \ldots \ldots \ldots \ldots$

Gráfico $N^{\circ}$ 27: Control de peso (controlador) comparativo por grupos ................. 79

Gráfico $N^{\circ}$ 28: Consulta al nutricionista (frecuencia) comparativo por grupos ......... 80

Gráfico $N^{\circ}$ 29: Concurrencia a grupos de apoyo con nutricionistas, médicos o psicólogos durante el primer año después de operado, comparativo por grupos ...... 81

Gráfico $\mathrm{N}^{\circ}$ 30: Concurrencia actual a grupos de apoyo, comparativo por grupos ...... 82

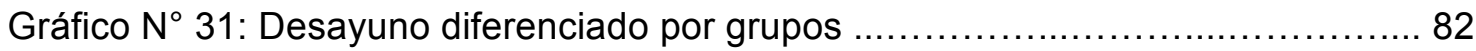

Gráfico No 32: Almuerzo diferenciado por grupos ................................... 83

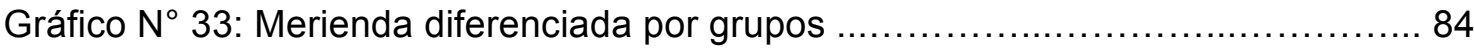

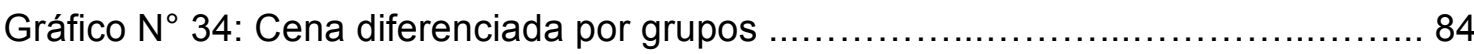

Gráfico $\mathrm{N}^{\circ}$ 35: Colación de media mañana diferenciado por grupos .................. 85

Gráfico $N^{\circ} 36$ : Colación de media tarde diferenciado por grupos ..................... 85

Gráfico $N^{\circ} 37$ : Realización de ingestas a media noche diferenciado por grupos ...... 86

Gráfico $N^{\circ} 38$ : ¿Su comida más importante o principal es antes de las $15 \mathrm{~h} ? \ldots \ldots \ldots 86$

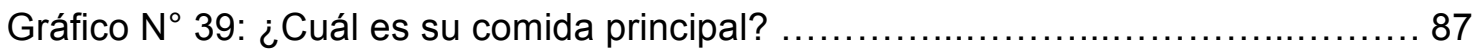

Gráfico $\mathrm{N}^{\circ}$ 40: ¿Considera que lleva una alimentación saludable después de la

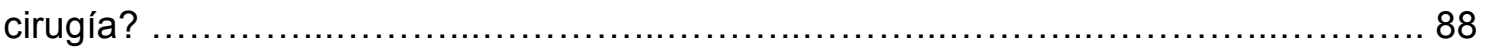

Gráfico $\mathrm{N}^{\circ}$ 41: ¿Picotea o realiza ingestas continuamente acompañadas de la sensación de pérdida de control con frecuencia? .................................... 88

Gráfico $\mathrm{N}^{\circ}$ 42: De quienes reconocieron hacer picoteo, ¿con qué frecuencia la

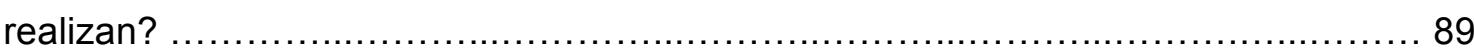

Gráfico $N^{\circ}$ 43: ¿Hace atracones o considera que come más de lo que debería comer en un tiempo menor al debido con sensación de pérdida de control?

Gráfico $\mathrm{N}^{\circ}$ 44: De quienes reconocieron hacen atracones, ¿con qué frecuencia la

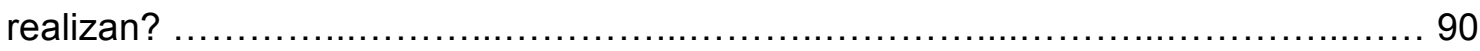

Gráfico $N^{\circ}$ 45: Si tiene atracones, ¿son desde hace más de 3 meses? ................ 90

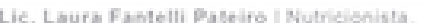


Gráfico $N^{\circ} 46$ : Siente que come en respuesta a. 91

Gráfico № 47: ¿Cuántas veces por día consume alimentos ricos en azúcar como golosinas, facturas, helados, tortas, galletitas dulces, etc.? 92

Gráfico $N^{\circ}$ 48: ¿Siente mucho apetito por las noches, dificultad para dormir y se despierta para comer por las noches? 93

Gráfico $N^{\circ} 49$ : ¿Realiza actividad o ejercicio físico? 94

Gráfico $N^{\circ}$ 50: Si realiza actividad o ejercicio, ¿cuántas veces por semana? 94

Gráfico $\mathrm{N}^{\circ}$ 51: ¿Cuántos minutos dura la actividad o ejercicio? 95

Gráfico $N^{\circ} 52$ : Tipo de actividad física 95

Gráfico $N^{\circ}$ 53: Intensidad de la Actividad que realiza 96

Gráfico $\mathrm{N}^{\circ}$ 54: ¿Duerme al menos 7 horas promedio por noche? 96

Gráfico $N^{\circ}$ 55: ¿Trabaja en relación con alimentos? (kiosco, gastronomía, panadería, rotisería, etc.) 97

Gráfico $\mathrm{N}^{\circ}$ 56: ¿Toma diariamente la suplementación de vitaminas y minerales sugerida por el equipo quirúrgico? 98

Gráfico $N^{\circ}$ 57: ¿Consume alcohol? 98

Gráfico $N^{\circ} 58$ : Si consume alcohol, ¿con qué frecuencia lo hace? 99

Gráfico N59: ¿Realizó después de operado psicoterapia durante 6 meses o más? 100

Gráfico N 60: ¿Recibió medicación psiquiátrica durante 6 meses o más? 100

Gráfico N61: ¿Le habían diagnosticado antes de la cirugía algún trastorno mental? 101

Gráfico $N^{\circ}$ 62: ¿Le diagnosticaron algún trastorno mental después de la cirugía? . 102 Gráfico $N^{\circ}$ 63: ¿Hubo algún evento que considera que pudo haber influido en su peso después de la cirugía, como una mudanza, separación, muerte de un familiar, robo, hacerse cargo de un familiar u otro? ........................................... 103

Gráfico N 64: Después de la operación me siento ................................... 104

Gráfico N 65: Participo en actividades físicas .................................... 104

Gráfico $N^{\circ}$ 66: Participo en actividades sociales ................................... 105

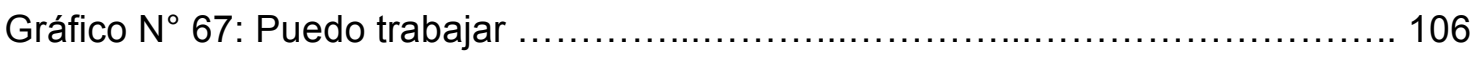

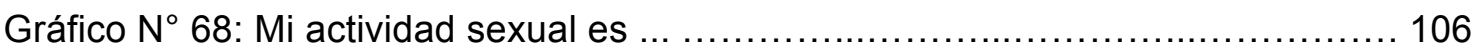




\section{Marco Teórico}

\section{Capítulo 1. Obesidad}

\section{Definición}

La obesidad es una enfermedad crónica de origen multifactorial, con implicancia de factores ambientales y genéticos que se manifiestan por una alteración de la composición corporal con aumento de tejido adiposo. Es definida clásicamente a partir del exceso de grasa corporal (no del peso corporal). La importancia de este concepto radica en que identifica al componente del organismo (grasa corporal) que centraliza la patología de la enfermedad. (1)

El Dr. Braguisnky postuló la siguiente definición: "Un incremento en el porcentaje del tejido adiposo corporal, frecuentemente acompañado de aumento de peso, cuya magnitud y distribución condicionan la salud del individuo". (1)

Aquí aparece entonces, la variable riesgo. O sea, no solo el hecho anatómico de aumento de la grasa corporal sino el hecho clínico de cómo su cuantía y donde se ubica ese tejido adiposo, implican riesgo.

Entonces la obesidad es el resultado de las alteraciones originadas por el aumento del tejido adiposo, sobre todo de tipo hipertrófico, lo que determina: aumento de la salida de ácidos grasos libres, aumento de adipocinas procuagulatorias e inflamatorias y depósito extra adiposo de las grasas (músculo, hígado, etc.) (2)

Braguinsky completa la definición de obesidad como un grupo de cuadros clínicos de tipo crónico, caracterizados por el aumento de grasa corporal, frecuentemente acompañado de un incremento del peso corporal. La magnitud del exceso de grasa corporal, su distribución, su posible carácter hipertrófico y el eventual depósito ectópico de la grasa determinan el grado de enfermedad de estos cuadros.(1)

En el año 2014 la asociación americana de endocrinología clínica (AACE) y el colegio americano de endocrinología (ACE) definen la obesidad como una enfermedad crónica caracterizada por procesos fisiopatológicos que resultan en un aumento del tejido adiposo y que puede aumentar la morbilidad y la mortalidad.(3) 


\section{Etiología}

En la obesidad hay un desequilibrio entre la ingesta calórica y el gasto de energía. Este balance energético positivo llega a un aumento del tejido adiposo. Una continua alteración regulatoria de los mecanismos de ingreso y de gasto participan en este proceso.

La obesidad está determinada por la interacción de factores:

Genéticos: a partir de un genoma de tipo que se expresa en un medio obesogénico en diversas hormonas, enzimas y otras sustancias de acción metabólica.

Interactuando con:

Factores del medio (social, económico, cultural):

- Alimentación hipercalórica/hipergrasa, con exceso de grasas, azúcares concentrados, pobre en fibras, vegetales y frutas.

- Un marcado sedentarismo. Es el síndrome de inactividad física. Enfermedad por carencia de actividad que debería ser considerado "sedentarismo obligado" ya que está impuesto por las características del actual modo de vida.

- Una notable censura social, generadora de culpas en las personas y desadaptación.

Otros factores que pueden intervenir: alcohol, supresión del tabaquismo, factores virósicos y tóxicos.(2)

\section{Factores genéticos:}

Estudios sugieren que el desarrollo de la obesidad podría tener su origen en las etapas más precoces de la vida, durante el período fetal. En ese período tendrá lugar un mecanismo de programación, que activará numerosos procesos nutricionales, hormonales, físicos y psicológicos, que van a actuar en períodos críticos de la vida configurando ciertas funciones fisiológicas. La existencia de uno o varios miembros en una misma familia con obesidad severa ha planteado la probable implicación de factores genéticos en la aparición de este cuadro a edades tempranas, implicación que ya ha sido verificada por diferentes estudios. Así, se ha podido determinar cómo el riesgo de padecer obesidad extrema a lo largo de la vida (IMC>45), se multiplica por 7 cuando uno de los progenitores la padece. (4) (5) (6) (7)

El mapa de la obesidad indica que, excepto en el cromosoma $\mathrm{Y}$, en todos los cromosomas hay genes con una potencial implicación en la aparición y desarrollo de la obesidad. En base a los resultados realizados sobre genes y obesidad, existe evidencia científica suficiente como para establecer el número de genes identificados 
como posibles inductores en la aparición de la obesidad.(8) (9)

Se conocen mutaciones en determinados genes humanos responsables de la aparición de efectos pleiotrópicos que cursan con cuadros de obesidad mórbida como manifestación clínica. Entre ellos podemos destacar el síndrome de Prader-Willi, de carácter autosómico dominante. En un $70 \%$ de los casos, el paciente muestra anomalías en varios genes localizados a su vez en el cromosoma 15 paterno. Desde un punto de vista clínico, dicho síndrome en el niño se caracteriza por el desarrollo de un cuadro de obesidad, hipotonía muscular, retraso mental, hipogonadismo, criptorquidia y baja talla acompañada de manos y pies pequeños.(10) (11)

Otras mutación de genes que puede causar obesidad, ocurre en el síndrome de Alström-Hallgren, caracterizado por la aparición de ceguera por distrofia retiniana, sordera nerviosa, miocardiopatía, diabetes mellitus e insuficiencia renal, aunque sin polidactilia ni retraso mental. En dicho síndrome, la obesidad suele aparecer a partir de los 2 años de edad, con un incremento de peso que puede superan en un $100 \%$ los valores normales para la edad y sexo del niño. (12) Su transmisión hereditaria es de tipo autosómico recesiva, y es causada por una mutación en el gen ALMS1 situado en el cromosoma 2. (12) (13) (14)

Microbiota intestinal y su influencia en el desarrollo de obesidad

El desarrollo de la obesidad está determinado por una compleja interacción entre factores genéticos, ambientales, culturales, sociales, gasto calórico e ingesta calórica.

La microbiota intestinal se considera un factor más recientemente descripto que participa en la obesidad y los trastornos metabólicos asociados. (15). Desarrolla tareas bioquímicas esenciales tales como la obtención de energía a través de la dieta, síntesis de vitaminas y otros compuestos absorbibles. Desequilibrios en su composición se han asociado con el desarrollo de resistencia insulínica y aumento del peso corporal.(16) (17)

La microbiota puede afectar ambos lados del balance energético:

- Influencia el aprovechamiento energético de la dieta

- Afecta la expresión de los genes del huésped que regulan cómo la energía es gastada y almacenada.

Uno de los primeros reportes en humanos fue descripto por Tumbaught quien muestra por primera vez que los sujetos obesos presentan alterada su microbiota intestinal de manera similar a lo observado en ratones obesos, predominando el grupo 
de los firmicutes sobre los bacteroidetes lo que les permite ser más eficiente en la extracción de calorías desde los alimentos y su almacenamiento en tejido adiposo.(18)

Ley Re muestra que la reducción de peso corporal después de 1 año en un grupo de sujetos obesos, tienden a normalizar la microbiota intestinal, independiente de la dieta seguida (alta o baja en grasas).(19)

En el estudio desarrollado por Sato et al. se comprobó cómo la administración de leche fermentada con Lactobacillus gasseri reducía el tamaño de los adipocitos del tejido adiposo mesentérico al mismo tiempo que reducía los niveles de leptina en suero. Ello evidenció el potencial efecto regulador que dichas bacterias tenían sobre el crecimiento del tejido adiposo y, en este sentido, sobre la obesidad. En otro estudio desarrollado por Ma et al, en el que se trabajó con ratones alimentados mediante una dieta rica en grasas, la administración en la dieta de Lactobacillus, Bifidobacterium y Streptococcus, mejoró la esteatosis y resistencia a la insulina inducida en estos ratones por el exceso de grasas.(20) (21)

Una de las bacterias con efectos benéficos sobre la microbiota es la Akkermansia municiphila. El tratamiento con esta bacteria, en ratones, revierte el desorden metabólico inducido por dieta alta en grasa (masa grasa, endotoxemia metabólica, inflamación TA e IR). También aumenta niveles de endocanabinoides (controlan la inflamación, barrera intestinal y secreción de péptidos intestinales).(12)

Cambios en los hábitos alimentarios y sedentarismo

En la actualidad, la biotecnología alimentaria, ha posibilitado consumir durante todo el año cualquier tipo de alimento. Esto, unido a una accesibilidad casi ilimitada a los alimentos por gran parte de la población, ha generado toda una serie de modificaciones en la dieta habitual de los sujetos.

Se ha producido un incremento en el consumo de alimentos de origen animal, así como de bebidas gaseosas de elevado contenido de azúcar. Ciertos trabajos evidencian cómo un consumo excesivo de jugos de frutas (mayor a 350ml/día) en preescolares puede favorecer el desarrollo de obesidad, llegando incluso a limitar el crecimiento de los niños.(23) (24)

González et al. (2010), por su parte, plantean que el total de calorías, la composición, la palatabilidad de los alimentos, variedad de los mismos, tamaño y número de comidas diarias representan también factores estrechamente vinculados con la obesidad.(25)

Existen otros factores a tener en cuenta como es el estilo de vida actual, en el 
que los horarios laborales de los padres a menudo dificultan la tarea diaria de elaboración de los alimentos, optando en un gran número de casos por comidas precocinadas y bebidas ricas en azúcares en lugar de agua.(26) (27)

El hábito de comer fuera de casa de manera permanente contribuye también al incremento progresivo de tejido adiposo ya que dichas comidas suelen ser ricas en grasas y con un elevado contenido calórico.

El aumento de la prevalencia de obesidad en los últimos años responde también a una reducción en los niveles de actividad física.(28)

La actividad física diaria es el factor preponderante en el mantenimiento del peso corporal, y por consiguiente, importante para la pérdida ponderal. (29)

\section{Clasificación}

Según el índice de masa corporal (IMC) distintas organización y sociedades científicas clasifican el estado nutricional:

Criterios de clasificación de la OMS (1998) según el IMC, peso y riesgo:

\begin{tabular}{|c|c|c|}
\hline PESO & IMC & RIESGO \\
\hline Bajo Peso & $<18,5$ & $\begin{array}{l}\text { Bajo (aumento de riesgo de otros } \\
\text { problemas) }\end{array}$ \\
\hline Normal & $18.5-24.9$ & Peso normal (peso saludable) \\
\hline Preobesidad & $25-29.9$ & Aumentado \\
\hline Obesidad grado I & $30-34.9$ & Moderado \\
\hline Obesidad grado II & $35-39.9$ & Severo \\
\hline Obesidad grado III & $\geq 40$ Muy severo & (Obesidad mórbida) \\
\hline $\begin{array}{l}\text { Categorias } \\
\text { Sobrepeso: incluye } \\
\text { Preobesidad: deno } \\
\text { Obesidad: cuando }\end{array}$ & $\begin{array}{l}\text { personas con IMC } \\
\text { personas con IMC } \\
\geq 30\end{array}$ & \\
\hline
\end{tabular}

En Estados Unidos los datos del segundo Nacional Health and Nutrition Examination Survey (NHANES II) usó los siguientes puntos de corte para definir obesidad en adultos:

- IMC $\geq 27.3 \mathrm{~kg} / \mathrm{m} 2$ en mujeres y

- IMC $\geq 27.8 \mathrm{~kg} / \mathrm{m} 2$ en hombres. 
Esta definición se basó en el percentilo 85 de IMC para personas de 20 a 29 años de edad.(30)

La Sociedad Española para el Estudio de la Obesidad (SEEDO) en su consenso del año 2007, presenta dos diferencias importantes con respecto a la clasificación de la OMS del año 1998: el rango que abarca el sobrepeso lo divide en dos categorías, calificando al sobrepeso de grado II como preobesidad e introduce un nuevo grado de obesidad: obesidad grado IV u obesidad extrema) para aquellos pacientes con un IMC $=50 \mathrm{~kg} / \mathrm{m} 2 .(23)$

Clasificación de Sobrepeso y Obesidad según SEEDO 2007

\begin{tabular}{|c|c|}
\hline IMC (KG/M2) & DIAGNÓSTICO \\
\hline$<18,5$ & Peso insuficiente \\
\hline 18,5 a 24,9 & Normopeso \\
\hline 25,0 a 26,9 & Sobrepeso grado I \\
\hline 27,0 a 29,9 & Sobrepeso grado II (Preobesidad) \\
\hline 30,0 a 34,9 & Obesidad Grado I \\
\hline 35,0 a 39,9 & Obesidad Grado II \\
\hline 40,0 a 49,9 & Obesidad Grado III ó Mórbida \\
\hline$>50$ & Obesidad Grado IV o Extrema \\
\hline
\end{tabular}

Clasificación de Obesidad Mórbida según Sociedad Americana de Cirugía Bariátrica y Metabólica

En el año 1997, la Sociedad Americana de Cirugía Bariátrica (actualmente Sociedad Americana de Cirugía Bariátrica y Metabólica), define obesidad mórbida cuando el individuo presenta un peso mayor o igual a dos veces su peso ideal, o cuando tiene cien libras de peso por encima de su peso ideal (definido de acuerdo con los estándares de talla y peso determinados en 1983 por la Compañía Metropolitana de Seguros de Vida). También puede ser definida en función a la grasa corporal total, considerándola cuando se presenta un $40 \%$ o más del peso corporal total en grasa. Se establece categorías para el IMC y clasifica distintos tipos de obesidad extrema. 
Grados de Obesidad Mórbida según el IMC(32)

\begin{tabular}{|c|c|}
\hline IMC (KG/M2) & DIAGNÓSTICO \\
\hline $40-50$ & Obesidad Mórbida \\
\hline $50-60$ & Super Obesidad \\
\hline Más de 60 & Super/ Super Obesidad \\
\hline
\end{tabular}

Para el diagnóstico de la obesidad no es suficiente conocer el IMC, se debe incluir el grado de exceso de adiposidad que afecta negativamente la salud de cada individuo.(33)

En un ambiente que interactúa con genes de susceptibilidad para promover el aumento de peso (es decir, genes obesogénicos), muchas personas con IMC $\geq 25 \mathrm{~kg}$ /m2, tienen mayor probabilidad de tener obesidad con sus complicaciones relacionadas y riesgo progresivo de obesidad.

El diagnóstico completo de la obesidad no solo depende del nivel de IMC sino también del impacto del aumento de peso en la salud. Las personas con IMC $\geq 25$ $\mathrm{kg} / \mathrm{m} 2$ (o en ciertas poblaciones un IMC de $23-25 \mathrm{~kg} / \mathrm{m} 2$ ) requieren evaluación especifica de la presencia y gravedad de las complicaciones relacionadas a la obesidad.

Cada complicación se evalúa en función de la gravedad y de la salud del paciente como Etapa 0 (no hay complicación presente), Etapa 1 (la complicación es leve a moderada), o Etapa 2 (la complicación es grave) utilizando criterios específicos de complicaciones.(3)

AACE y ACE en la Conferencia de Consenso sobre Obesidad establecieron un plan de acción global para combatir la obesidad. Incluyen las intervenciones primarias, secundarias y terciarias.

- IMC $<25 \mathrm{~kg} / \mathrm{m} 2$ (y la circunferencia de la cintura no está aumentado), estos pacientes tienen pesos normales y son candidatos a intervenciones primarias para prevenir la obesidad a través de educación y correcciones de estilo de vida saludable en la naturaleza obesogénica de su entorno.

- Pacientes que tienen sobrepeso u obesidad, sin complicaciones (Etapa 0), son elegibles para intervenciones secundarias para prevenir el aumento progresivo de peso y la aparición de complicaciones relacionadas a la obesidad.

- En individuos que tienen sobrepeso u obesidad y complicaciones que afectan adversamente la salud, las intervenciones terciarias son necesarias para prevenir el empeoramiento de la enfermedad. 
Plan de acción global para combatir la obesidad según la AACE y ACE

\begin{tabular}{|l|l|l|l|}
\hline Diagnostico & IMC & Componentes clínicos & $\begin{array}{l}\text { Prevención/ } \\
\text { Tratamiento }\end{array}$ \\
\hline Normo peso & IMC $<25$ & & Primaria \\
\hline Sobrepeso & IMC 25 -29.9 & Sin complicaciones relacionadas a la obesidad & Secundaria \\
\hline Obesidad & IMC $\geq 30$ & Sin complicaciones relacionadas a la obesidad & Secundaria \\
\hline $\begin{array}{l}\text { Obesidad } \\
\text { Estado 1 }\end{array}$ & IMC $\geq 25$ & $\begin{array}{l}\text { Presencia de una o más complicaciones de } \\
\text { leves a moderada }\end{array}$ & Terciaria \\
\hline $\begin{array}{l}\text { Obesidad } \\
\text { Estado 2 }\end{array}$ & IMC $\geq 25$ & $\begin{array}{l}\text { Presencia de una o más complicaciones } \\
\text { severas }\end{array}$ & Terciaria \\
\hline
\end{tabular}

Se entiende por prevención primaria: hábitos alimentarios saludables, educación para la salud, ejercicio físico, sueño adecuado.

Prevención secundaria: tratamiento con plan de alimentación adecuado, ejercicio físico, tratamiento cognitivo conductual, sueño adecuado, medicación para perder peso.

Prevención terciaria tratamiento con plan de alimentación adecuado, ejercicio físico, tratamiento cognitivo conductual, sueño adecuado, medicación para perder peso.

Considerar la cirugía bariátrica. Puede necesitar terapia específica para complicaciones.

Se consideran complicaciones relacionadas con el exceso de peso:

- Prediabetes

- Síndrome metabólico

- Diabetes tipo 2

- Dislipidemia

- Hipertensión

- Enfermedad cardiovascular

- Enfermedad hepática grasa no alcohólica

- Síndrome de ovario poliquístico

- Infertilidad femenina

- Hipogonadismo masculino

- Apnea obstructiva del sueño

- Asma / Enfermedad Reactiva de las Vías Respiratorias

- Osteoartritis

- Incontinencia urinaria por estrés

- Reflujo gastroesofágico 
- Depresión

Por lo expresado anteriormente es necesario establecer el grado y tipo de obesidad que tiene un individuo, para poder valorar el nivel de riesgo de morbimortalidad que tiene.

Existen diferencias entre los dos tipos de obesidad (androide y ginoide) determinadas fundamentalmente por los esteroides sexuales. (35)

- Androide o central: de mayor riesgo metabólico. Aumento de adiposidad abdominal o intraabdominal. Se asocia con tejido adiposo hipertrófico y disfuncional.

- Ginoide o periférica: es probable que no tenga riesgo metabólico.

Según esta distribución grasa, desde la perspectiva anatómica Bouchard y col. reconocieron 4 tipos de obesidad de acuerdo con el fenotipo.(35) (36)

Tipo de obesidad según Bouchard

\begin{tabular}{|l|l|l|}
\hline Tipo de Obesidad & Denominación & Localización exceso de grasa \\
\hline Tipo I & Difusa & Generalizada por todo el cuerpo \\
\hline Tipo II & Androide & Central o troncoabdominal \\
\hline Tipo III & Visceral o visceroportal & Abdominovisceral \\
\hline Tipo IV & Ginoide & Femoroglútea \\
\hline
\end{tabular}

Fuente: Bouchard. 1990

La importancia de la ubicación del tejido adiposo radica en la variación de la velocidad y el comportamiento con que los diferentes tejidos reciben a los ácidos grasos liberados por el tejido adiposo.

Desde el punto de vista metabólico, el tejido adiposo visceral es considerado como el más activo, por un lado por la mayor respuesta a los estímulos lipolíticos y lipogénicos, y además por la mayor concentración de receptores $B$ adrenérgicos y la disminución de los receptores insulínicos en sus adipocitos.(8)

\section{Fisiopatología, evolución y riesgos}

Sea cual sea la etiología de la obesidad, el camino para su desarrollo es el mismo, un aumento de la ingestión y/o una disminución del gasto energético. Los lípidos procedentes de la dieta o sintetizados a partir de un exceso de carbohidratos 
de la dieta, son transportados al tejido adiposo como quilomicrones o lipoproteínas de muy baja densidad (VLDL). Los triglicéridos de estas partículas son hidrolizados por la lipoproteinlipasa localizada en los capilares endoteliales, introducidos en el adiposito y reesterificados como triglicéridos tisulares. Durante los períodos de balance positivo de energía, los ácidos grasos son almacenados en la célula en forma de triglicéridos; por eso, cuando la ingestión supera el gasto, se produce la obesidad. En la medida en que se acumulan lípidos en el adipocito, este se hipertrofia y en el momento en que la célula ha alcanzado su tamaño máximo, se forman nuevos adipocitos a partir de los preadipocitos o células adiposas precursoras, y se establece la hiperplasia. El paciente muy obeso que desarrolla hiperplasia y comienza a adelgazar, disminuirá el tamaño de los adipocitos, pero no su número. Este hecho tiene una relevancia especial en la obesidad de temprano comienzo, en la niñez o la adolescencia, en la cual prima la hiperplasia sobre la hipertrofia, y como resultado es más difícil su control, pues hay una tendencia a recuperar el peso perdido con gran facilidad y de ahí la importancia de la vigilancia estrecha en el peso de los niños y adolescentes, porque las consecuencias pueden ser graves. (2) (12)

En el caso de la obesidad de comienzo en la adultez, predomina la hipertrofia sobre la hiperplasia, por lo cual su tratamiento suele ser más agradecido, pero no por eso fácil. Por otra parte, se sabe que la distribución de los adipocitos y su capacidad de diferenciación, está condicionada genéticamente, por eso, mientras mayor sea la fuerza genética para la obesidad, mayor será la probabilidad de que este proceso se desarrolle con el menor esfuerzo y la mayor rapidez. (2) (12)

Tomando en cuenta la leyes de la termoenergética, el paciente obeso debe comer más para mantener su peso, porque además de que su gasto energético es mayor porque el tejido magro también se incrementa con la obesidad, la actividad adrenérgica está estimulada por vía de la leptina, y este aspecto parece ser importante en el mantenimiento de la obesidad. Y es que la mayoría de los obesos tienen en realidad una hiperleptinemia con resistencia a la acción de la leptina de forma selectiva, es decir, solo en su capacidad para disminuir la ingestión, pero no en su acción con mediación simpática, y por eso el obeso está expuesto no solo a un incremento del gasto mediado por el sistema neurovegetativo, sino también a efectos neuroendocrinos amplificados, con devastadoras consecuencias clínicas. Por eso, cuando se pierde peso a partir de un estado de sobrepeso y/o obesidad, el GEB disminuye, tanto por la misma ley de la termoenergética, como por la disminución de la actividad simpática. De ahí que la pérdida de solo unos pocos kilogramos de peso represente un beneficio multiplicado, por las positivas consecuencias clínicas que esto condiciona, y que las acciones contra la obesidad sean siempre de inestimable 
utilidad. Los obesos con hipoleptinemia, aleptinémicos o con alteraciones en la acción de los receptores de la leptina, que son el grupo menos numeroso, tienen, por su parte, un gasto energético disminuido con desregulación de los mecanismos controladores de la ingestión que da origen y perpetúa la obesidad, y se ha demostrado que se corrige con la administración de leptina recombinante en el caso de las alteraciones de la leptina, no así en los problemas del receptor. (2) (12)

Otro hecho importante lo constituye el envejecimiento en su amplio sentido de ganancia en años vividos, ya que cuando ocurre se pierde masa magra, que si no es balanceado con una disminución de la ingesta, lleva a la ganancia de peso lenta e irremediablemente. Además, aunque el aumento de peso está mediado por ambos tejidos (magro y graso), hay que recordar que, llegado el límite superior de crecimiento del tejido magro, todo aumento posterior depende de la grasa cuyo gasto energético es menor, por lo cual el GET tiende a estabilizarse o disminuir de acuerdo con el punto inicial, y si el ingreso energético (IE) permanece igual, habrá más ganancia de peso.(38)

De acuerdo con la primera ley de la termodinámica, la obesidad es el resultado del desequilibrio entre el gasto y el aporte de energía. Esta energía procede, en el caso de nuestro organismo, de los principios inmediatos: carbohidratos, proteínas y grasas. Los carbohidratos son el primer escalón en el suministro de energía. Cuando el consumo de carbohidratos excede los requerimientos, estos se convierten en grasas.

En ausencia, o con niveles muy bajos de glúcidos, las grasas son movilizadas siendo utilizadas para la producción de energía. A este proceso se le conoce como lipólisis, y en él, las grasas son convertidas en ácidos grasos y glicerol. De este modo, el cuerpo humano cumple las leyes físicas representadas por este primer principio de la termodinámica, según el cual la energía ni se crea ni se destruye, solo se transforma.

Todo exceso de energía introducida cambia la energía interna del organismo y se transforma en energía química, y como principal almacén está el tejido graso. Un IE mayor que el gasto o consumo energético total (CET), inevitablemente causará un aumento del tejido adiposo, que siempre se acompaña del incremento de la masa magra, así como también del peso corporal, en cuyo control el CET desempeña una función importante. (2) (12)

Según esto, el peso corporal podrá variar en relación con la ingestión y el gasto energético total (GET), que es igual al gasto energético en reposo o basal (GEB) más el gasto energético durante la actividad física (GEA) y el gasto energético derivado del proceso de termogénesis (GET). Todo ello vendría definido en la ecuación de balance 
energético:

Ahora bien, en la regulación del gasto energético y de la ingesta participan el sistema nervioso, el sistema digestivo con órganos como el hígado y el páncreas, y el adipocito. El adipocito es una célula altamente diferenciada con 3 funciones: almacén, liberación de energía y endocrino metabólica. Puede cambiar su diámetro 20 veces, y su volumen mil. Cada adipocito es capaz de almacenar en su interior un volumen máximo de 1,2 microgramos de triglicéridos. En este proceso, denominado esterificación, tendrá lugar la participación de 2 enzimas, la lipoproteinlipasa (LPL) y la proteína estimulante de acilación (ASP), ambas activadas a partir de la acción de la insulina y los quilomicrones. La cantidad de triglicéridos almacenados en el interior del adipocito no suele exceder los 0,6 microgramos por célula. Considerando que el número promedio de adipocitos presentes en cada sujeto es de 30 a $60 \times 10$, y que cada uno de estos contiene en su interior 0,5 microgramos de triglicéridos, podemos valorar o inferir un volumen graso total de $15 \mathrm{~kg}$ o lo que es I o mismo $135.000 \mathrm{kcal}$. (2) (12)

Es, sin embargo, el descubrimiento de la leptina y de los genes que regulan su producción desde el adipocito, lo que ha originado la gran revolución en el conocimiento de la regulación ingesta-gasto $y$, por lo tanto, en el estudio de la obesidad. La leptina constituye el resultado o la síntesis final del gen-ob. Dicho gen se encuentra localizado, en el caso humano, en el cromosoma $7 q$ 31,3. Cuenta con $650 \mathrm{~kb}$ y está constituido por 3 exones separados a su vez por 2 intrones, siendo los exones 2 y 3 los portadores de la región que codifica la síntesis de leptina.(12)

Por su estructura bioquímica, se trata de un péptido compuesto por 167 aminoácidos cuya secuencia resulta similar en diferentes especies. Tanto es así que la leptina del ratón y la rata mantienen un 84 y un $83 \%$ de homología con la leptina del humano, respectivamente. A través de esta hormona, el hipotálamo ejerce un efecto controlador de la homeostasis energética del organismo, modulando la ingesta y contrarrestando un potencial balance energético positivo. Para ello, la leptina provoca una activación de los sistemas efectores catabólicos. Estos van a provocar una reducción de la adiposidad por medio de una inhibición del apetito (efecto anorexígeno), estimulando con ello el gasto energético e inhabilitando los sistemas efectores anabólicos cuyo objetivo es aumentar la adiposidad corporal (vía aumento de apetito), favoreciendo así el proceso de lipolisis del tejido adiposo.(12)

Su acción anorexígena la ejerce a través de su receptor ubicado en las neuronas del núcleo infundibular del hipotálamo. Una vez activado el receptor se pondrán en marcha un complejo entramado de mecanismos. En ellos, una disminución de la secreción de neuropéptido $\mathrm{Y}$, el estimulador del apetito endógeno más potente. 
En segundo lugar, y de forma paralela, tendrá lugar una disminución en la secreción de la proteína relacionada con el agouti. Dicha proteína es un antagonista de los receptores de la melanocortina 1 y 4 , que a su vez son reguladores del apetito.

La leptina, a través del hipotálamo, utiliza el sistema nervioso simpático para estimular la liberación de tirotropina. Además, por mediación de la leptina, los receptores noradrenérgicos también modulan el peso corporal, mediante la estimulación de los receptores alfa 1 y beta 3 disminuyendo la ingesta y aumentando el gasto energético.

Por su parte, el sistema nervioso parasimpático eferente modula el metabolismo hepático, la secreción de insulina y el vaciamiento gástrico, participando de este modo en el control y regulación del peso corporal.

Asimismo, los estímulos olfatorios y gustativos producidos por el alimento participan igualmente en la regulación de la ingesta. Dichos estímulos constituyen señales periféricas que a su vez serán integradas y procesadas a nivel del sistema nervioso liberando neurotransmisores, que van a modular nuestra ingesta. De ellos el mejor estudiado es la serotonina. Los receptores de la serotonina intervienen regulando la cantidad de alimento ingerido y la selección de macronutrientes. Su estimulación a nivel hipotalámico reduce la ingestión en general, y de forma específica la de las grasas.(12)

La hormona a-melanocito estimulante ( $\mathrm{\alpha}-\mathrm{MSH}$ ) es un péptido anorexígeno estrechamente implicado en la regulación de la ingesta. Es sintetizada en al núcleo arqueado desde donde se distribuye ampliamente por el sistema nervioso central, especialmente a nivel del núcleo paraventricular. Su administración en el sistema ventricular del cerebro causa disminución del apetito y aumento de la termogénesis. Su acción se establece a nivel cerebral interaccionando con receptores tipo 3 y 4 (MC3 y MC4). Sus efectos en humanos son cada vez mejor conocidos, pudiendo constituir una de las piezas clave en el tratamiento de la obesidad.(12)

Otra biomolécula implicada en la modulación de la ingesta alimentaria es el neuropéptido $Y$. Este tiene como función principal incrementar la ingesta de alimentos, y constituye el neurotransmisor más potente de acción anabólica.(12)

Los péptidos intestinales poseen igualmente una acción moduladora respecto de la ingestión de alimentos. Así, péptidos como la colecistocinina, el péptido liberador de gastrina y la bombesina disminuyen la ingesta de alimentos. Por su parte, la insulina tiene un efecto anabólico, favoreciendo la captación de glucosa y el acúmulo de lípidos a nivel de los tejidos.

La grelina, descubierta por Jojima (1999), constituye el primer péptido de efecto orexígeno descrito. Actúa a nivel del hipotálamo mediante 3 vías: por una parte, 
accediendo al núcleo arqueado a través de la circulación sanguínea atravesando la barrera hematoencefálica. Una segunda vía mediante aferencias vagales que llegan desde el estómago hasta el hipotálamo por medio del nervio vago. O bien, mediante una síntesis intra-hipotalámica. Otros estudios han puesto de manifiesto como los niveles plasmáticos de ghrelina se elevan en períodos de balance energético negativo, esto es, en situaciones de ayuno para a continuación normalizarse al ingerir alimento.(12)

Otros péptidos gastrointestinales implicados en el proceso de saciedad son el polipéptido insulinotrópico dependiente de glucosa (GIP), con capacidad para inducir la secreción de insulina ante concentraciones elevadas de glucosa en sangre. Estudios a partir de ratones deficientes en su receptor desarrollaron un fenotipo resistente a la obesidad inducida por la dieta, por lo que GIP puede estar involucrado en la patogenia de la obesidad central. La secreción del péptido similar al glucagon tipo 1 (GLP-1) por las células L del intestino, preferentemente a nivel de íleon y colon, tiene lugar tras la ingestión de nutrientes (hidratos de carbono y ácidos grasos) y en proporción con el contenido calórico. En el estudio desarrollado por Näslund et al., se evidenció cómo en pacientes obesos la administración subcutánea de GLP-1 antes de cada comida durante 5 días reducía en hasta un 15\% su ingesta generando una pérdida de peso de $0,5 \mathrm{~kg}$. Finalmente el péptido $Y Y(P Y Y)$ o tirosina-tirosina, perteneciente a la familia del polipéptido pancreático (PP), es sintetizado por las células $\mathrm{L}$ del tracto gastrointestinal distal (colon y recto), aunque también está presente en estómago, páncreas y determinadas regiones del sistema nervioso central. Dicho péptido es secretado en función de la ingesta calórica, siendo los lípidos los responsables mayores de su secreción. En situaciones de ayuno, sus valores plasmáticos son bajos, elevándose en los 15-30 minutos previos al comienzo de la ingesta. Su secreción y liberación a la sangre posibilita la absorción de nutrientes mediante el retrasado del vaciamiento gástrico y tránsito intestinal.(12)

Otra hormona sintetizada por el páncreas e igualmente implicada en la regulación de la ingesta alimentaria es el glucagón. Dicha hormona tiene como función principal estimular la degradación del glucógeno y la puesta en marcha de la gluconeogénesis favoreciendo con ello el catabolismo. Desde un punto de vista exocrino, el páncreas sintetiza la enterostatina (señal peptídica de la colipasa pancreática) cuya función es disminuir la ingesta de grasa y producir saciedad.

En el caso de los sistemas eferentes de control del peso corporal cabe destacar por su importancia y participación el sistema endocrino y el neurovegetativo. El sistema endocrino está representado por las hormonas del crecimiento, las tiroideas, las gonadales, los glucorticoides y la insulina.(12) 
Durante la etapa del desarrollo, la hormona del crecimiento y las tiroideas trabajan al unísono para aumentar el crecimiento. La hormona del crecimiento, una vez en la sangre, estimula al hígado para que produzca otra hormona, el factor de crecimiento insulínico (IGF-1), que juega un papel clave en el crecimiento durante la niñez. Por su parte, las hormonas tiroideas actúan incrementando la síntesis de proteínas en todos los tejidos del organismo.(12)

Durante el desarrollo puberal comienzan a funcionar los esteroides gonadales. Así, la testosterona aumenta el peso corporal magro en relación con la grasa, mientras que los estrógenos realizan el efecto contrario. Por su parte, los niveles de testosterona disminuyen a medida que el varón avanza en edad, causando un aumento de la grasa visceral y corporal total así como una disminución del peso corporal magro (12). En el caso de los glucocorticoides suprarrenales, estos desarrollan una acción importante en el control neuroendocrino de la ingesta alimentaria y el consumo energético (12).

Finalmente, el sistema neurovegetativo representa el último eslabón en la cadena de procesos y biomoléculas que llevan a cabo el control del peso corporal. Su acción principal tiene lugar mediante la regulación de las secreciones hormonales y la termogénesis. (12)

Riesgos y diagnóstico de enfermedades asociadas. (33)

Existen complicaciones relacionadas con la obesidad que son causadas 0 exacerbadas por el exceso de adiposidad. Todos los pacientes con sobrepeso u obesidad y con aumento progresivo de peso deben ser evaluados para diagnosticar dichas complicaciones.

- Diabetes, síndrome metabólico y prediabetes: circunferencia de la cintura, glucemia en ayunas, hemoglobina glicosilada, tensión arterial y perfil de lípidos, incluyendo triglicéridos y HDL-C. Para evaluar el riesgo de diabetes se puede estimar pruebas de tolerancia y / o rasgos del síndrome metabólico.

- Dislipidemia: perfil lipídico que incluye triglicéridos, HDL-c, LDL-c calculado, colesterol total.

- Hipertensión: determinar la presencia de hipertensión o prehipertensión. 
- Enfermedades cardiovasculares y mortalidad por enfermedades cardiovasculares: historia de enfermedad cardiovascular por examen físico y con pruebas basadas en el estado de riesgo de enfermedad cardiovascular.

- Enfermedad hepática grasa no alcohólica y esteatohepatitis no alcohólica: con pruebas de función hepática, seguido de ultrasonido u otra modalidad.

- Síndrome de ovario poliquístico (SOP): mujeres premenopáusicas con sobrepeso u obesidad y / o síndrome de ovario poliquístico deben ser evaluadas por historia y examen físico.

- Infertilidad femenina: las mujeres con sobrepeso u obesidad deben ser informadas que tienen un mayor riesgo de infertilidad y, si buscan la reproducción asistida, deben conocer que tienen menores índices de éxito en estos procedimientos y menor capacidad de llevar el embarazo a término.

- Hipogonadismo masculino: todos los hombres que tienen un aumento de la circunferencia de la cintura o con obesidad se debe evaluar hipogonadismo.

- Apnea obstructiva del sueño: historia clínica y el examen físico. La polisomnografía y otros estudios del sueño, en casa o en un laboratorio del sueño, deben ser considerados para pacientes con alto riesgo de apnea del sueño basado en la presentación clínica, gravedad del exceso de adiposidad y sintomatología.

- Asma/enfermedad reactiva de las vías respiratorias: antecedentes médicos, sintomatología, examen físico y espirometría. (33) 


\section{Capítulo 2. Cirugía Bariátrica}

La obesidad es un problema mundial y día a día se incrementa el número de personas que la padecen. La Organización Mundial de la Salud la ha definido como la epidemia del siglo XXI que afecta más de 1.900 millones de personas.(39)

El tratamiento quirúrgico es actualmente el único tratamiento efectivo y permanente para la obesidad mórbida, incluso mejorando enfermedades comórbidas relacionadas con la obesidad.(40)

\section{Técnicas Quirúrgicas por Videolaparoscopía}

Pueden dividirse en tres grupos

1. Técnicas restrictivas: ya que reducen el tamaño del estómago permitiendo la restricción en la incorporación de alimentos.

2. Técnicas malabsortivas: si bien se reduce el tamaño del estómago, lo más importante es el puente (bypass) de más de $1,20 \mathrm{~cm}$ de intestino por donde no pasa el alimento, generando un déficit de absorción.

3. Técnicas mixtas: son generalmente restrictivas y también malabsortivas. Se reduce el tamaño del estómago y se realiza un puente del intestino que genera cierto grado de mala absorción.(41)

- Técnicas restrictivas puras

- Banda gástrica (ajustable o no)

- Gastrectomía lineal o tubular (sleeve gastrectomy)

- Técnicas mixtas (restrictivas-malabsortivas)

- By-pass gástrico

- Derivación bilio-pancreática (Scopinaro)

- Técnicas malabsortivas puras (ya no realizadas en la actualidad)

- By-pass yeyuno-cólico

- By-pass yeyuno-ileal

\section{Bypass Gástrico}

El Bypass gástrico es considerado el "gold standard" de la cirugía en términos 
de pérdida de peso a largo plazo.

El procedimiento:

Hay dos componentes para el procedimiento. En primer lugar, un pequeño estómago, de aproximadamente $30 \mathrm{ml}$ de volumen, se crea dividiendo la parte superior del estómago del resto del mismo. A continuación, se divide la primera porción del intestino delgado y se divide el extremo inferior del intestino delgado dividido y se conecta con la bolsa de estómago recién creada. El procedimiento se completa conectando la porción superior del intestino delgado dividido, al intestino delgado más abajo para que los ácidos del estómago y las enzimas digestivas del estómago y la primera porción del intestino delgado se mezclen

eventualmente con el alimento.(41) (42)

El bypass gástrico funciona por varios mecanismos. En primer lugar, similar a la mayoría de los procedimientos bariátricos, el pouch de estómago recién creado es considerablemente más pequeño y facilita comidas significativamente más pequeñas, lo que se traduce en menos calorías consumidas. Además, debido a que hay menos digestión de los alimentos por el estómago más pequeño, y hay un segmento del intestino delgado que normalmente absorbe calorías, así como nutrientes, que ya no tiene comida pasando por ella, es probable que en cierto grado se produzca menor absorción de calorías y nutrientes. Lo más importante es que el desvío de la corriente alimentaria produce cambios en las hormonas intestinales (GLP-1, Péptido Y) que promueven la saciedad, suprimen el hambre y revierten uno de los principales mecanismos por los cuales la obesidad induce la diabetes tipo 2.

Ventajas.(41) (42) (43)

- Produce una pérdida significativa de peso a largo plazo (60 a 80 por ciento de exceso de pérdida de peso).

- Restringe la cantidad de alimentos que se pueden consumir.

- Puede conducir a condiciones que aumenten el gasto energético.

- Produce cambios favorables en las hormonas intestinales que reducen el apetito y aumentan la saciedad.

- Mantenimiento típico de $>50 \%$ de exceso de pérdida de peso.

Desventajas.(41) (42) (43)

- Es técnicamente una operación más compleja que la Banda Gástrica o la Manga Gástrica y potencialmente podría dar lugar a mayores tasas de

Lie. Laura Famelli Pasteito I Nurneconista. 34 
complicaciones.

- Puede conducir a deficiencias a largo plazo de vitaminas y minerales, especialmente déficit de vitamina B12, hierro, calcio y ácido fólico.

- Requiere adherencia a las recomendaciones dietéticas, suplementos vitamínicos/minerales a lo largo de toda la vida, y cumplimiento de seguimiento.

\section{Gastrectomía Vertical en Manga}

Se realiza mediante la eliminación de aproximadamente el 80 por ciento del estómago. El estómago restante, tubular, se parece a una manga.

El procedimiento:

Este procedimiento funciona por varios mecanismos. En primer lugar, la bolsa de estómago nuevo tiene un volumen considerablemente menor que el estómago normal y ayuda a reducir significativamente la cantidad de alimentos (y por lo tanto las calorías) que se pueden consumir. El mayor impacto, sin embargo, parece ser el efecto de la cirugía en las hormonas ya que al resecar el techo gástrico se suprime la secreción de Ghrelina (encargada de estimular el apetito a nivel cerebral) y las hormonas intestinales que afectan a una serie de factores,

incluyendo el hambre, la saciedad y el control de azúcar en la sangre.(43) (44)

Los estudios a corto plazo demuestran que la manga es tan eficaz como el bypass gástrico en $Y$ de Roux en términos de pérdida del peso y de la mejoría o de la remisión de la diabetes.

También hay evidencia que sugieren que la Manga Gástrica, similar al bypass gástrico, es eficaz para mejorar la diabetes tipo 2 independientemente de la pérdida de peso.

Ventajas.(43) (44)

- Restringe la cantidad de alimentos que el estómago puede contener.

- Induce una pérdida rápida y significativa de peso que los estudios comparativos encuentran similar a la del bypass gástrico de Roux-en-Y. Pérdida de peso mayor al $50 \%$ del exceso de peso inicial para datos de 3-5 años o más y pérdida de peso comparable a la del bypass.

- Implica una estancia hospitalaria relativamente corta de aproximadamente 2 días.

- Provoca cambios favorables en las hormonas intestinales que suprimen el 
hambre, reducen el apetito y mejoran la saciedad.

Desventajas.(43) (44)

- Es un procedimiento no reversible.

- Tiene el potencial de deficiencias de vitaminas a largo plazo. 


\section{Capítulo 3. Reganancia de peso}

Son bien conocidos los beneficios que ofrece la Cirugía Bariátrica para la salud, la calidad de vida y autoestima de nuestros pacientes con obesidad mórbida sin embargo algunos no obtienen los resultados esperados por ellos mismos y por el equipo multidisciplinario.

La calidad de una técnica quirúrgica está dada por la reducción de peso, el mantenimiento del mismo a largo plazo, la curación o mejoría de las comorbilidades y la mejoría de la calidad de vida. La fase activa de reducción de peso ocurre aproximadamente hasta los 12 a 24 meses del postoperatorio. Durante este tiempo los pacientes intervenidos se ven beneficiados por todas las técnicas quirúrgicas, ya sean malabsortivas, mixtas o restrictivas, en cuanto a pérdida de peso se refiere; sin embargo son los pacientes operados con técnicas mixtas y malabsortivas los que mayor pérdida de peso obtienen y presentan menores tasas de reganancia a largo plazo.

Hollanda y col.(45) describieron tres patrones de descenso de peso postoperatorio: los buenos perdedores de peso, aquellos que logran perder más del $50 \%$ del exceso de peso y lo mantienen durante los años de seguimiento; los pobres perdedores secundarios, aquellos que pierden durante la fase activa más del $50 \%$ del exceso de peso sin embargo no sostienen una buena pérdida en el tiempo; y por último los pobres perdedores de peso, aquellos que nunca lograron tener una buena pérdida de peso definida como un descenso de por lo menos el $50 \%$ del exceso de peso. La pérdida del exceso de peso es muy variable en todas las series estudiadas. Hollanda describe un PEPP de 22 a 146\%, con posterior reganancia de peso de 0 a $64 \mathrm{~kg}$ durante más de 5 años de seguimiento. (45)

Según datos del estudio Swedish Obese Subjects (SOS) (46) la fase más activa de descenso de peso postoperatorio ocurre alrededor del primer año, con gradual reganancia principalmente hasta el sexto año de seguimiento, lo cual se enlentece entre el sexto al decimo año de seguimiento.

Es esperable que los pacientes presenten reganancia de peso de forma gradual, pero lamentablemente algunos de ellos lo hacen de forma significativa viéndose afectada su salud con la recurrencia de comorbilidades y afectando 
nuevamente su calidad de vida y autoestima.

\section{Definición de reganancia de peso}

Es difícil definir el significado como así también la prevalencia de reganancia de peso post cirugía bariátrica, dado que existe heterogeneidad de criterio. Algunos autores lo definen como:

- El aumento de un 15 \% del peso mínimo: [(Peso Actual - Peso Mínimo)/ (Peso Inicial - Peso Mínimo)] x 100, Odom y col. (47)

- El aumento del peso mantenido por lo menos durante 6 meses, Elfhag Rossner y col. (48)

- El aumento de $5 \mathrm{~kg} / \mathrm{m}^{2}$ o más del IMC, respecto del mínimo IMC posoperatorio, Stoklossa y col. (3) (49)

- El aumento de, como mínimo, $2 \mathrm{~kg}$ en pacientes con más de 2 años de operados, Leite Faria y col. (50)

- Aumento de más de $10 \mathrm{~kg}$ de peso corporal del peso mínimo alcanzado post cirugía. $(16,17,18)$

- Recuperar peso después de una pérdida exitosa superando un IMC de $35 \mathrm{~kg} / \mathrm{m}^{2}$.(19)

- Aumento de más del $25 \%$ del exceso de peso perdido después de la cirugía (recuperar más de un $25 \%$ o más del peso perdido entre la cirugía y el peso mínimo alcanzado) (22)

En la Actualización del Consenso Argentino de Nutrición y Cirugía Bariátrica publicado en el 2016 se consensuó definir reganancia de peso como el aumento del $15 \%$ del peso mínimo, mantenido por lo menos durante 6 meses . (51)

Los datos de prevalencia son limitados y muy variables entre las distintas series estudiadas. Se estudian distintas técnicas quirúrgicas, en diferentes momentos de evolución con un reducido número de pacientes que concurren a seguimiento, lo cual complica la obtención de información fidedigna respecto a la prevalencia real de recuperación ponderal. Se estima que aproximadamente entre el $10 \%$ y el $20 \%$ de los pacientes operados reganan un significativo porcentaje del peso perdido a largo plazo.

Otros autores con criterios menos exigentes han reportado reganancias de peso de $20 \%$ a $50 \%$, según la técnica empleada. El período de estudio tras la intervención también es variable en las diferentes publicaciones, lo que supone un factor que complica la comparación, ya que en general la recuperación ponderal aumenta con la longitud del período de observación desde el $14 \%$ a los 2 años al $70 \%$ 
a I os 5 años.

Es por ello que al momento de comparar resultados se debe:

1) Conocer el criterio de reganancia de peso.

2) Considerar el momento en que se estudian a los pacientes operados.

3) Observar el tipo de técnica quirúrgica que se está evaluando.

\section{Causas posibles}

Muchos investigadores hoy en día ponen su atención en conocer las causas de aumento de peso para identificarlas antes y después de la cirugía y prevenir que esto ocurra, o en su defecto, que impacte lo menos posible en el paciente.

Las causas de reganancia de peso son de origen multifactorial. Si bien existen causas relacionadas a la cirugía, como dilatación de la anastomosis o del pouch, y adaptación gastrointestinal; son los factores relacionados al paciente, aspectos conductuales y psicológicos, los que más que influyen en este hecho.(52)

La recuperación ponderal no se produce con similar magnitud tras la aplicación de las distintas técnicas quirúrgicas. Mientras los procedimientos restrictivos, como la gastroplastía vertical o la banda gástrica ajustable se asocian a recuperación ponderal significativa, cuanto mayor es el componente malabsortivo, la probabilidad de desarrollar recuperación ponderal es menor. Es decir, que los pacientes intervenidos de bypass gástrico tienen mayor riesgo de recuperación ponderal que los operados de derivación biliopancreática o cruce duodenal. (53)

Algunos autores estiman que el aumento en el diámetro de la anastomosis puede provocar una pérdida de la contención y un rápido vaciamiento del pouch gástrico, con disminución de la saciedad postprandial, lo que promovería una mayor ingesta de alimentos.(54) En estudios sobre gastrectomía tubular encontraron que el tamaño del tubo gástrico es el único factor que influye en la pérdida de peso.

La falta de adherencia a las recomendaciones como retomar hábitos de comedor de dulces o picoteador, un volumen de ingesta inadecuado, preferir alimentos de alto índice glucémico, un consumo de bebidas altas en calorías (bebidas azucaradas y alcohólicas), una alimentación rica en grasa, un bajo consumo de proteínas magras, horarios desordenados de comidas, y falta de ejercicio físico son 
predictores de reganancia

de peso. (55) (56)

El sedentarismo en pacientes con antecedentes de cirugía bariátrica es una variable predictora de reganancia de peso. Es importante resaltar la importancia de la actividad física como forma de contrarrestar la disminución en la tasa metabólica.(57) (59) (59) Según Yanos y col. es la recomendación que nuestros pacientes menos adhieren. Si bien son más activos para las actividades no programadas, son pocos los que logran como mínimo 150 a 300 minutos por semana de ejercicio moderado como se sugiere para una buena pérdida y mantenimiento de peso.

Se ha demostrado una relación positiva entre el número de enfermedades psiquiátricas diagnosticadas después de la cirugía y la magnitud del aumento de peso $(60)$.

Los trastornos ansiosos motivados por eventos de estrés, como duelos, divorcios, pérdida de trabajo, y las enfermedades psiquiátricas, como la depresión o la adicción al alcohol, son causa frecuente de la pérdida de control y autocuidado que experimentan los pacientes que reganan peso.(52)

Un número importante de pacientes no sostienen el seguimiento a largo plazo. Shen y col.(61) sostienen que sólo el $40 \%$ cumple con las 4 consultas anuales. Algunos autores detectaron que las principales razones de la falta de adherencia eran: cuestiones vinculadas al trabajo, problemas relacionados con la familia, lejanía del centro de seguimiento, reganancia de peso, embarazo, el hecho de considerar que el seguimiento no era necesario o el haberse olvidado de efectuar los controles. Algunos autores consideran que el hecho de que el paciente no se realice ningún control por más de 6 meses implica no adherencia y que el intento por perder peso después de la cirugía bariátrica ha fracasado cuando el EPP es $<50 \%$ en cualquier control de seguimiento después de al menos 1 año de la cirugía.

Según Odom, los sujetos comprometidos con el automonitoreo tienen menos probabilidades de recuperar peso después de la cirugía bariátrica.(47) Por su parte, Oliveira Magro observó que de los pacientes en los que la cirugía no resultó exitosa, el $60 \%$ no se había sometido a un seguimiento nutricional y el $80 \%$ no se había sometido a un seguimiento psicológico.(65)

Existe una población de riesgo para un descenso de peso subóptimo y posible reganancia de peso durante el postoperatorio en la que se debe poner especial atención al momento de la evaluación preoperatoria: aquellos pacientes superobesos (IMC >50); pacientes con DMT2 preoperatoria; aquellos sujetos con peor respuesta 
ponderal en estadíos precoces tras la cirugía bariátrica (pérdidas menores al $50 \%$ del exceso de peso); pacientes con alteraciones del comportamiento alimentario durante el preoperatorio (picoteo, atracón), con funciones cognitivas alteradas y aquellos con baja adherencia a los controles durante el postoperatorio. Se requieren más investigaciones para comprender aún mejor la asociación entre la respuesta postoperatoria y factores clínicos, genéticos, hormonales, nutricionales y psicológicos.(45)

Se considera exitoso a aquel paciente bien entrenado con buen nivel de conocimiento y buena adherencia a las recomendaciones brindadas por el equipo multidisciplinario.

Según Colleen M. Cook y col. los hábitos de sujetos exitosos intervenidos de BPGYR son:(54)

1) Realizar tres comidas bien balanceadas y dos colaciones al día.

2) Beber agua y evitar las bebidas carbonatadas de cualquier tipo.

3) Tomar suplementos multivitamínicos.

4) Dormir un mínimo de 7 horas diarias.

5) Hacer actividad física en forma regular, cuatro veces por semana, durante al menos 40 minutos.

6) Mostrar responsabilidad personal en el control del peso; hacerlo semanalmente.

\section{Estrategias de tratamiento}

Un paciente que presenta recuperación ponderal debe ser reevaluado por todo el equipo multidisciplinario de cirugía bariátrica.(62) (55) Es necesario conocer su condición clínica (reaparición o deterioro de las comorbilidades asociadas), examinar sus hábitos alimentarios, su actividad física, optimizar el comportamiento alimentario y promover la ayuda psicológica y psiquiátrica.

Recomendaciones para profesionales y pacientes (3) (50)

- Individualizar las recomendaciones nutricionales para facilitar la adherencia: proponer un plan alimentario hipocalórico (aproximadamente de 1200 a $1500 \mathrm{Kcal}$ ) con control de hidratos de carbono con preferencia de bajo índice glucémico y limitando en hidratos de carbono simples, un aporte proteico de 1,2 g/kg/día, y selección de grasas (menos de $7 \%$ saturadas, $10 \%$ poliinsaturadas, y $13 \%$ mono insaturadas) y rico en fibras (frutas, verduras, legumbres, cereales integrales y legumbres, y suplementos de fibras). Sugerir 5 a 6 comidas al día (desayuno, 
almuerzo, merienda, cena y una colación) de baja densidad calórica (Kcal/g < 1) y mayor volumen $(\mathrm{g} / \mathrm{cal}>1)$.

- Suplementar con multivitamínico, hierro, calcio, vitaminas B 12 y D, y ácido fólico para evitar deficiencias.

- Sugerir un registro semanal de los alimentos consumidos y utilizar fotografías de porciones estandarizadas como herramienta de educación nutricional.

- Tener un contacto periódico con el especialista en nutrición con formación y experiencia en cirugía bariátrica, ya sea en la consulta individual como en grupos de apoyo para pacientes operados. También se puede incluir al entorno del paciente para una intervención más eficaz si así lo requiere.

- Realizar ejercicio físico aeróbico moderado, partiendo de un mínimo de 150 minutos por semana y con una meta de 300 minutos por semana, que incluya entrenamiento de fuerza, de las capacidades del paciente.

- Recibir apoyo psicológico individual y asistir a talleres psicoterapéuticos con especialistas con experiencia en la materia. Pacientes que participan en programas de educación nutricional y reciben consejería nutricional durante el pre y postoperatorio de cirugía bariátrica incrementaron la pérdida de peso y el mantenimiento a largo plazo.

La cirugía bariátrica no es una panacea, y el éxito a corto y largo plazo depende de la habilidad del paciente de incorporar cambios de estilo de vida. La identificación de factores asociados a la reganancia de peso post cirugía bariátrica es clave a la hora de indicar un tratamiento, ya que el adecuado manejo preoperatorio de dichos factores podría ayudar a disminuir ese riesgo de reganancia y aumentar el rendimiento a largo plazo de la cirugía bariátrica.

Los factores involucrados en la reganancia de peso confirman que el tratamiento quirúrgico de la obesidad debe ser realizado en centros de excelencia, con cirujanos y un equipo multidisciplinario de profesionales capaces de enfrentar todos los aspectos del paciente candidato a cirugía bariátrica. Será tarea de este equipo el asesoramiento, la contención y el desarrollo de herramientas útiles que contribuyan al logro y al mantenimiento del cambio de estilo de vida a largo plazo.(51) 


\section{Protocolo de investigación}

\section{Título:}

"Evaluación de factores de riesgo que se asocian a la reganancia de peso de pacientes obesos operados de cirugía bariátrica por equipos quirúrgicos privados especializados de la República Argentina".

\section{Objetivo general:}

Explorar las posibles variables que se asociarían a la reganancia de peso de pacientes obesos luego de 5 años de ser sometidos a cirugía bariátrica por equipos quirúrgicos privados de la República Argentina.

\section{Objetivos específicos:}

1. Evaluar la asociación entre el nivel educativo y la reganancia de peso.

2. Evaluar la edad, estado civil, convivencia y edad de inicio del sobrepeso y su asociación con la reganancia de peso.

3. Evaluar la frecuencia de control nutricional de los pacientes sometidos a cirugía bariátrica y su asociación con la reganancia de peso.

4. Evaluar tipo y frecuencia de actividad física de la población en estudio.

5. Evaluar la relación entre tratamiento psicológico y reganancia de peso.

6. Evaluar la asociación entre el cumplimiento de las indicaciones del equipo de salud y la reganancia de peso.

7. Analizar los hábitos de la conducta alimentaria post cirugía.

8. Evaluar la calidad de vida después de 5 años de operados.

\section{Hipótesis:}

Los pacientes superobesos intervenidos quirúrgicamente presentan mayor prevalencia de reganancia de peso post cirugía.

Las mujeres jóvenes solteras, con estudios terciarios o universitarios completos tienen menor porcentaje de reganancia de peso a largo plazo.

Los sujetos que registran sobrepeso a partir de la edad adulta logran un mayor descenso de peso postoperatorio con menores tasas de reganancia de peso a largo plazo.

Los pacientes que concurren regularmente a la consulta nutricional y que mantienen una cantidad mínima de controles individuales o grupales logran mantener su peso. 
Los pacientes que realizan un mínimo 150 minutos de actividad física aeróbica semanal con una intensidad media alta logran mantener su peso con mayor facilidad que aquellos que no realizan actividad física.

Existe una asociación entre aquellos sujetos que no presentan un trastorno psicológico y los que reciben apoyo psicológico por más de 6 meses durante el postoperatorio y menor tasa de reganancia.

Las personas que tienen buena adherencia a las recomendaciones médicas tienen menor porcentaje de reganancia de peso post cirugía bariátrica.

Los sujetos que tienen buenos hábitos de la conducta alimentaria post cirugía no presentan reganancia de peso.

Aquellas personas que mantienen su peso estable tienen mejor calidad de vida a comparación de las que reganan peso.

\section{Materiales y métodos:}

Es un tipo de estudio descriptivo, retrospectivo, observacional, analítico, de casos y controles.

Para tal fin se realizó una revisión exhaustiva de estudios con similares objetivos, seleccionando las variables asociadas a la reganancia de peso post cirugía bariátrica que mostraron mayor presencia.

Se seleccionaron 17 profesionales nutricionistas y médicos nutricionistas de 11 equipos quirúrgicos de 6 provincias de la Argentina. Los mismos contactan telefónicamente, por mail o en consultorio externo a todos aquellos pacientes operados hasta el año 2011 inclusive que actualmente concurren o no a consultorio externo. Se los cita en consultorio para completar una encuesta y medir su peso actual. En caso de no estar en la ciudad responderán telefónicamente la misma. Los datos son recolectados desde julio a diciembre 2016.

Los pacientes fueron intervenidos en 14 centros quirúrgicos diferentes: 


\begin{tabular}{|l|}
\hline Centros de Salud: \\
\hline Clínica Bazterrica CABA \\
\hline CETOS Centro de Estudio y Tratamiento de la Obesidad Severa, CABA \\
\hline $\begin{array}{l}\text { CITOmet Centro Integral del tratamiento de la obesidad y enfermedades metabólicas } \\
\text { Neuquen }\end{array}$ \\
\hline CRQO Centro de Rehabilitación Quirúrgica de la Obesidad CABA \\
\hline Centro CIEN Centro integral de endocrinología y nutrición Corrientes \\
\hline Centro Quirúrgico de la Obesidad Mendoza \\
\hline Cilap Mar del Plata \\
\hline HAO Hospital de alta complejidad de Formosa \\
\hline HE Hospital Español Mendoza \\
\hline HPC Hospital Privado de Comunidad de Mar del Plata \\
\hline Hospital Británico de CABA \\
\hline OC Obesity Care Rosario \\
\hline SANATORIO BRITANICO Rosario \\
\hline TINO Mar del Plata Tratamiento Interdisciplinarios en Nutrición y Obesidad \\
\hline
\end{tabular}

La muestra se diseñó seleccionando una cohorte de 254 pacientes bariátricos operados de bypass gástrico en $\mathrm{Y}$ de Roux o manga gástrica con seguimiento postoperatorio durante 5 años o más.

El criterio de recuperación se definió como $\geq 15 \%$ del nadir de peso y se agruparon como "reganadores", y los individuos por debajo de este porcentaje se categorizaron como "mantenedores".

La profesional encuesta, previa firma del consentimiento informado.

La encuesta se compone por datos filiatorios, datos en relación a la evolución de su peso, a sus hábitos alimentarios post cirugía, acceso a servicios de apoyo junto a un cuestionario validado de calidad de vida (BAROS).

En una primera etapa, los datos fueron procesados en análisis tanto descriptivos como inferenciales, utilizando test paramétricos y no paramétricos para comparaciones de registros.

En una segunda etapa, considerando el status de "reganador de peso" o "no reganador de peso", se utilizaron tests no paramétricos de asociación de variables. En los casos donde estos test resultaron significativos, se procedió a realizar el cálculo de los Odds Ratios y sus intervalos de confianza correspondientes.

La encuesta es cargada en una plataforma de Google forms para su posterior análisis. 


\section{Muestra:}

Se realizó una lista de los pacientes operados hasta el 2011 inclusive de BPGYR o Manga gástrica con una antigüedad mayor de 5 años. De la lista de pacientes operados en cada centro se tomaron los primeros 4 pacientes de cada 10 .

\section{Criterios de inclusión:}

Hombres y mujeres mayores de 18 años operados hace más de 5 años de cirugía bariátrica (bypass gástrico o manga gástrica) que aceptan participar en el estudio y concurren a los consultorios de los equipos de cirugía bariátrica de centros de referencia seleccionados.

\section{Criterios de exclusión:}

Aquellos sujetos que:

- Tengan una cirugía de revisión.

- Presenten enfermedades que influyan en su peso como cáncer.

- Mujeres que se hayan embarazado post cirugía.

- Otros procedimientos quirúrgicos (Derivación biliopancreática, banda gástrica)

- No acepten participar.

- No firmen el consentimiento informado.

\section{Registro de datos:}

Registrar en la planilla de registro de pacientes por centro aquellos que responden a la encuesta y los que no responden. La información recabada se volcará en el sitio google forms:

https://docs.google.com/forms/d/1Y-

4xSuQs3KUFIITq6DOiG4pjLNLhnZF8Lee5fr2DLAg/viewform?c=0\&w=1

\section{Las variables se definirán en el siguiente apartado:}

\section{Definición de variables:}

Edad: edad que presenta el paciente al momento de la encuesta expresada en años.

Sexo: conjunto de las peculiaridades que caracterizan los individuos de una especie dividiéndolos en masculino y femenino.

Tipo de cirugía: conjunto de procedimientos quirúrgicos usados para tratar la obesidad, buscando disminución del peso corporal y como alternativa al tratamiento con otros medios no quirúrgicos. Como criterio de inclusión se consideran el bypass gástrico y manga gástrica, ambos por vía laparoscópica. 
Tiempo desde la realización de la cirugía: cantidad de años y meses desde que fue realizado el procedimiento.

Estado civil: condición de una persona según el registro civil en función de si tiene o no pareja y su situación legal respecto a esto (soltero, casado, divorciado y viudo al momento de la cirugía y al momento de la encuesta).

Escolaridad: máximo nivel de educación formal adquirido (primario, secundario y terciario o universitario).

Edad de inicio del sobrepeso: etapa de la vida del paciente donde se registra por primera vez un sobrepeso considerando al mismo como un peso excesivo tomando en cuenta valores normales o aceptables, siendo estas niñez (menor a 12 años), adolescencia (entre 12 y 20 años) o adultez (más de 20 años).

Convivencia: acción de convivir (vivir en compañía de otro u otros).

Peso corporal: Cantidad de masa corporal de un individuo. Para la medición del peso al momento de la entrevista se utiliza Balanza CAM con precisión de 0,1 kg para sujetos de hasta $150 \mathrm{~kg}$ con tallímetro incorporado o similar. Para sujetos con un peso superior a los $150 \mathrm{~kg}$ se utiliza báscula electrónica (Tanita o Inbody o marca similar). El pesaje es sin zapatos, con la menor cantidad de ropa posible. Se ubica en el centro de la misma, con los hombros relajados a los costados del cuerpo, parándose derecho para distribuir uniformemente el peso. (68)

Peso máximo preoperatorio: peso máximo registrado el primer día de la evaluación preoperatoria con el equipo de cirugía.

Peso preoperatorio: peso registrado durante el último control pre cirugía o al ingreso a quirófano expresado en kilos.

La finalidad de registrar peso máximo preoperatorio y peso preoperatorio es constatar si ha perdido el $5 \%$ del exceso de peso durante la preparación pre cirugía mediante una dieta de muy bajo valor calórico como requisito para disminuir el volumen hepático. (1)

Porcentaje de Exceso de Peso Perdido (PEPP): cociente entre las diferencias de pesos máximo y preoperatorio, y máximo e ideal, y se utiliza para calcular el exceso de peso perdido utilizando la fórmula de: (peso inicial máximo-peso preoperatorio)/(peso inicial máximo-peso ideal) $x$ 100. (2)

Peso ideal: peso definido por tablas de peso ideal en función de la talla, como las de la Metropolitan Life Insurance Company de 1956, utilizando la fórmula de peso Teórico $\mathrm{kg}: 50+0.75 \times\left(\right.$ talla $\left._{\mathrm{cm}}-150\right)$. (2)

Peso mínimo postoperatorio: peso mínimo expresado en kilos post cirugía registrado en la historia clínica o el peso mínimo que el paciente refiera a pesar de no estar registrado en la historia clínica. 
Mes en que registró su peso mínimo post cirugía: número de meses en los que el sujeto ha alcanzado su menor peso después de la intervención bariátrica.

Peso actual: peso actual post cirugía registrado en la historia clínica durante algún control con integrantes del equipo de cirugía en consultorio externo.

Talla: altura de un individuo, expresada en metros constatada en la historia clínica. Para la medición de la talla se utiliza el tallímetro incorporado a la balanza o de pared. El sujeto se ubica de frente al medidor, erguido, con los pies juntos, y los brazos relajados colgando a los costados del cuerpo. Se debe mantener la cabeza del sujeto firme, en plano de Frankfort (línea imaginaria trazada desde el extremo inferior de la órbita hasta el borde superior del conducto auditivo externo; paralelo al piso cuando se va a medir talla parada). Se solicita al sujeto que haga una inspiración profunda y se debe apoyar la tabla firmemente sobre el vértex (parte más alta del cráneo), aplastando el pelo tanto como sea posible y observando que los talones no se separen del piso y que la cabeza se mantenga en su plano. La medición será tomada antes de que el sujeto exhale. (68)

Índice de Masa Corporal (IMC): la Organización Mundial de la Salud define el IMC como la relación entre el peso (en kilogramos) divido por el cuadrado de la talla (en metros) $(\mathrm{kg} / \mathrm{m} 2)$. (69) Este índice es utilizado frecuentemente para clasificar el sobrepeso y diferentes grados de obesidad en los adultos. Según la OMS define sobrepeso como un IMC igual o superior a 25, la obesidad como un IMC igual o superior a 30 , siendo obesidad de clase I entre 30 a 34,9; obesidad de clase II entre 35 a 39,9 y obesidad de clase III mayor o igual a 40 .

Índice de Masa Corporal (IMC) máximo preoperatorio al momento de la evaluación inicial, preoperatorio y actual: es la relación entre el peso (en kilogramos) divido por el cuadrado de la talla (en metros) $(\mathrm{kg} / \mathrm{m} 2)$ máximo al momento de la primera entrevista inicial, antes del ingreso a quirófano y el actual postoperatorio.

Pérdida de peso: se considera como criterio de éxito a aquellos casos en los que la pérdida de peso es superior o igual al $50 \%$ del exceso de peso o presentan un IMC menor a 35 , mientras que se considera como criterio de fracaso a aquellos casos en los que la pérdida de peso es inferior al $50 \%$ del exceso de peso o presentan un IMC superior a 35. Operacionalmente se considera buena pérdida de peso o pobre pérdida de peso en función del registro obtenido al ser encuestados después de 5 años de operados.

Reganador de peso: aquella persona operada de cirugía bariátrica que después de cinco años tiene una reganancia de peso $\geq 15 \%$ del peso mínimo alcanzado o peso nadir. (3) 
Mantenedor o exitoso en el mantenimiento de peso: se considera que un sujeto ha mantenido su peso exitosamente al ser evaluado después de 5 años de ser operado de cirugía bariátrica y no presenta reganancia de peso o la misma es $<15 \%$ del peso mínimo alcanzado.

Frecuencia de monitoreo de peso: acto de medir el peso corporal y definir su frecuencia: menos de 1 vez al mes, 1 vez al mes (mensual), 2 veces al mes (quincenal), 4 veces al mes (semanal), más de 4 veces al mes.

Responsable de monitoreo de peso: persona encargada de medir el peso corporal (el mismo sujeto, un profesional o ambos).

Frecuencia de visitas a la nutricionista durante el último año: número de veces que el paciente ha tenido controles con un licenciado en nutrición o médico nutricionista, siendo las opciones a responder anual, semestral, trimestral, mensual, o sin control.

Concurrencia a grupos de apoyo para paciente durante el postoperatorio: sujeto que concurre a grupos de apoyo, talleres o encuentros de pacientes operados con profesionales como médicos, nutricionistas y/o psicólogos de algún equipo de cirugía bariátrica con la finalidad de realizar educación relacionada a la cirugía, nutrición y salud en general postoperatoria.

Frecuencia de comidas que realiza en el día: frecuencia con la que realiza las comidas a lo largo del día, siendo las opciones: todos los días, 5-6/semana, 34/semana, 1-2/semana, menos de 1 /semana.

Horario en que realiza la comida principal: hora del día en que realiza la comida más importante del día que podría incluir preparaciones elaboradas, plato principal o similar.

Comida principal: comida más importante del día que podría incluir preparaciones elaboradas, plato principal con guarnición, sándwich completo, ensalada completa con pan y sopa o similar comparada con comidas más livianas como leche con cereales, sopas, ensaladas simples, frutas.

Alimentación saludable post cirugía bariátrica: nivel de adhesión a una dieta rica en proteínas, baja en grasas saturadas y azúcares simples, con cereales integrales. Prefiriendo leche y yogur descremado, quesos descremados, carnes magras, frutas y verduras a diario, panes blancos o integrales, aceite crudo, legumbres; consumiendo porciones razonables para alguien operado, comiendo variado, cocinando de manera saludable; omitiendo grasas, frituras, azúcares y todos aquellas preparaciones que contienen alta densidad calórica y son pobres en nutrientes.

Picoteador: sujeto que ingiere snacks entre cortos períodos de tiempo, o que constantemente come pequeñas porciones de comida a lo largo del día con sensación 
de pérdida de control, o come permanentemente. Según la American Psychiatric Association, Manual Diagnóstico y Estadístico de los trastornos Mentales, DSM 5 ( $5^{\text {ta }}$ edición), se lo define al sujeto que ingiere más de 2 veces por día, pequeñas porciones de alimentos de manera no planeada, en forma compulsiva o no compulsiva.

Binge eating desorder (BED) o desorden por atracón: Según la American Psychiatric Association, Manual Diagnóstico y Estadístico de los trastornos Mentales, DSM 5 (5ta edición), se lo define como la ingestión en un corto período, de una cantidad de alimentos superior a lo que la mayoría de las personas ingerirían en un período similar con sensación de falta de control, al menos una vez por semana durante 3 meses, sin comportamiento compensatorio.

Si respondió que estos episodios ocurren con una frecuencia superior a una vez por semana, responder si la antigüedad de los mismos es superior a tres meses.

Depresión: trastorno mental frecuente, que se caracteriza por la presencia de tristeza, pérdida de interés o placer, sentimientos de culpa o falta de autoestima, trastornos del sueño o del apetito, sensación de cansancio y falta de concentración.

Ansiedad: condición de una persona que experimenta una conmoción, intranquilidad, nerviosismo, preocupación, estado angustioso que no permite la relajación y el descanso del paciente.

Soledad: carencia voluntaria o involuntaria de compañía. Pesar y melancolía que se siente por la ausencia, muerte o pérdida de alguien o de algo.

Disgusto: impresión o sentimiento en el ánimo de una persona producidos por algo que no se ajusta a lo que se desea o espera.

Hambre: sensación que indica la necesidad de alimentos.

Emociones: reacciones psicofisiológicas que representan modos de adaptación a ciertos estímulos del individuo cuando percibe un objeto, persona, lugar, suceso, o recuerdo importante.

Consumo de alimentos ricos en azúcares: consumo de alimentos ricos en azúcares simples como golosinas, azúcar, helados y todas aquellas preparaciones que contengan azúcar con la finalidad de determinar si es un comedor de dulces.

Comedor nocturno o Night Eating Syndrome (NES): falta de apetito por la mañana, hiperfagia por la noche y dificultades para dormir que en algunas oportunidades se puede acompañar con despertarse para comer.

Actividad física y ejercicio físico: todo movimiento corporal producido por los músculos esqueléticos y que ocasiona un gasto energético.

Tiempo y frecuencia promedio semanal de actividad física: medición temporal que el paciente le dedica a la realización de actividad o ejercicio físico. 
Tipo de actividad física: caracterización de la actividad física (natación, trote, caminata, entre otros).

Intensidad de la actividad física: nivel de intensidad que el paciente manifiesta respecto a la actividad que realiza (suave, moderada o intensa).

Tiempo de sueño: tiempo que en el que el paciente está en un estado de reposo en el cual queda totalmente suspendida cualquier actividad consciente y todo movimiento voluntario.

Trabajar en relación con alimentos: estar vinculado a alimentos, comida y gastronomía como kiosco, restaurante, panadería, confitería, rotisería, industria de elaboración de productos alimenticios.

Consumo de suplementos de vitaminas y minerales: consumo de aquellos suplementos que contienen una combinación de vitaminas y minerales $\mathrm{y}$, a veces, otros ingredientes indicados por los equipos de cirugía bariátrica durante el postoperatorio.

Consumo de alcohol: consumo de bebidas que presentan en su composición al compuesto químico etanol, también nombrado como alcohol etílico.

Frecuencia de consumo de alcohol: cantidad de veces que una persona consume alcohol (todos los días, 5-6/semana, 3-4/semana, 1-2/semana, menos de 1 /semana).

Cantidad de alcohol consumida: cantidad promedio de alcohol que una persona consume manifestada en la encuesta.

Psicoterapia después de operado: proceso terapéutico que se produce entre un psiquiatra o un psicólogo con una formación en psicología clínica y una persona que acude a consultarlo que se da con el propósito de una mejora en la calidad de vida en este último, a través de un cambio en su conducta, actitudes, pensamientos y/o afectos.

Medicación psiquiátrica durante 6 meses o más: fármacos utilizados por 6 meses 0 más para el tratamiento y control de los trastornos mentales como clorpromazina, flufenazina, haloperidol (medicamentos utilizados en los trastornos psicóticos); amitriptilina, fluoxetina (medicamentos utilizados en los trastornos depresivos); carbamazepina, carbonato de litio, ácido valproico (medicamentos utilizados en los trastornos bipolares); diazepam (medicamento utilizado en la ansiedad generalizada y los trastornos del sueño); clomipramina (medicamento utilizado en los trastornos obsesivo-compulsivos y los ataques de pánico); metadona y buprenorfina (medicamentos utilizados en los programas de tratamiento de la dependencia de sustancias psicotrópicas).

Diagnóstico de trastorno mental o psicopatología: síndrome caracterizado por una alteración clínicamente significativa del estado cognitivo, la regulación emocional o el 
comportamiento de un individuo, que refleja una disfunción de los procesos psicológicos, biológicos o del desarrollo que subyacen en su función mental.

Eventos que hayan influido en su peso post cirugía: aquellas situaciones que hayan generado stress y malestar en el sujeto y en consecuencia influyeron en su peso y su modo de alimentarse o ejercitarse.

Calidad de vida post cirugía: valoración de resultados tras la cirugía bariátrica que percibe el paciente de si mismo en todos sus hábitos (físico, mental y social) utilizando el cuestionario validado BAROS (Bariatric Analisys and Reporting Outcome System) que valora la pérdida ponderal y la resolución/mejoría de las comorbilidades preoperatorias, morbimortalidad del procedimiento a corto y largo plazo, evalúa la calidad de vida postoperatoria analizando la autoestima del paciente, la actividad física, social, laboral y sexual. (70) 


\section{Análisis de datos}

Este trabajo se divide en dos etapas. Por un lado analiza el perfil, la prevalencia de reganancia y las características generales de las personas que participan de este trabajo. Para esto realizan análisis tanto descriptivos como inferenciales, utilizando test paramétricos y no paramétricos para comparaciones de registros. Se informan los resultados correspondientes a las medias o proporciones, indicando los intervalos correspondientes donde resulta pertinente hacerlo.

Por otro lado, considerando el status de "reganador de peso" o "no reganador de peso", se realiza un estudio epidemiológico de casos y controles que permite analizar cuáles son las posibles características que generan que los pacientes se ubiquen en cada una de las anteriores categorías. En esta segunda etapa se utilizan test no paramétricos de asociación de variables. En los casos donde estos test resultan significativos, se procede a realizar el cálculo de los Odds Ratios y sus intervalos de confianza correspondientes. El análisis de datos se realiza mediante el software estadístico R, versión 3.3.1 (2016) ${ }^{1}$.

Para el diseño, realización y análisis del trabajo se siguieron los principios éticos de la declaración de Helsinki en donde se resguardó la identidad de las personas.

\section{Resultados}

Para la presente investigación se desarrolló un trabajo de campo que consistió en el registro sobre datos e historia personal, evolución de peso, datos antropométricos, hábitos, monitoreo y seguimiento del equipo quirúrgico, en pacientes que registraban una antigüedad mínima de cinco años de haber sido sometidos a cirugía bariátrica.

Este trabajo se divide en dos etapas, por un lado analizar el perfil, la prevalencia de reganancia y las características generales de las personas que participaron de este trabajo, y por otro lado, considerando el status de "reganador de peso" o "no reganador de peso", se realiza un estudio epidemiológico de casos y

\footnotetext{
${ }^{1} \mathrm{R}$ Core Team (2016). R: A language and environment for statistical computing. R Foundation for Statistical Computing, Vienna, Austria. URL https://www.R-project.org/.

2 World Medical Assembly. Declaration of Helsinki. Geneva, Switzerland: World Health

${ }^{2}$ World Medical Assembly. Declaration of Helsinki. Geneva, Switzerland: World Health

Organization; 1964
} 
controles que permita analizar cuáles son las posibles características que generan que los pacientes se ubiquen en cada de las anteriores categorías.

Se encuestaron a 254 pacientes con una antigüedad mayor o igual a cinco años de realizada su cirugía bariátrica, provenientes de 11 centros de diversas ciudades de la República Argentina que fueron encuestados en consultorio externo mediante un cuestionario estándar implementado por 17 profesionales de las ciencias médicas (nutricionistas y médicos especialistas en nutrición).

Inicialmente se presenta un perfil de los pacientes que participaron en este trabajo. Respecto de su composición por sexo se obtuvieron los datos que se presentan a continuación.

En cuanto a la composición por sexo de la muestra el $79,13 \%$ son mujeres y $20,87 \%$ hombres. Existe una notoria mayoría de pacientes de sexo femenino representando casi un $80 \%$ de la muestra, lo cual resulta coherente respecto de la bibliografía consultada donde en general la proporción de mujeres siempre resulta ampliamente mayoritaria.

Seguidamente se analiza la edad actual de los pacientes encuestados. La distribución resultante se presenta en el siguiente gráfico:

Gráfico $\mathbf{N}^{\circ}$ 1: Distribución etaria $(n=254)$

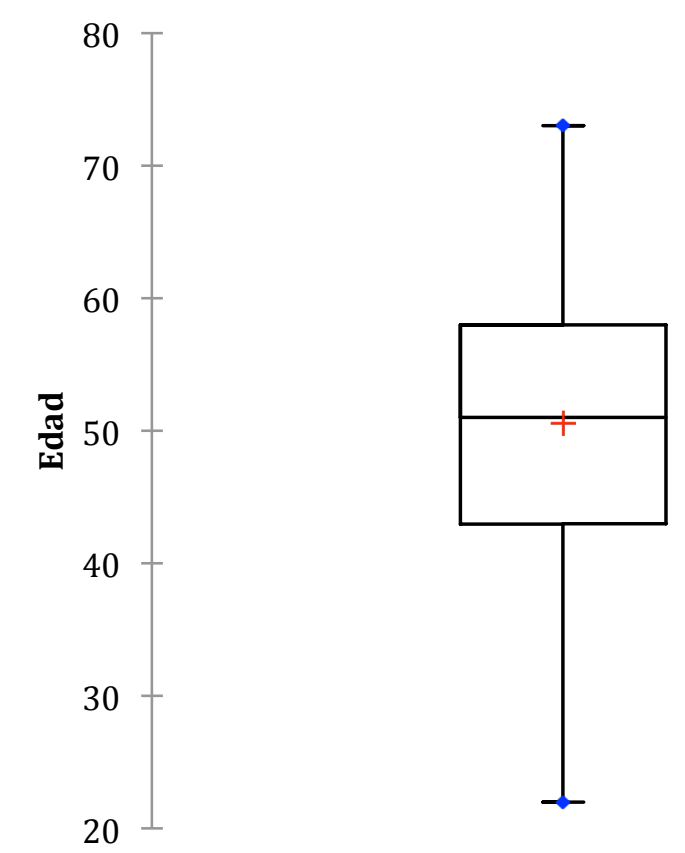


Tabla $N^{\circ}$ 1: Distribución etaria

\begin{tabular}{|l|l|}
\hline Estadística & Edad \\
\hline No. de observaciones & 254 \\
\hline Mínimo & 22,000 \\
\hline Máximo & 73,000 \\
\hline $\mathbf{1}^{\circ}$ Cuartil & 43,000 \\
\hline Mediana & 51,000 \\
\hline $\mathbf{3}^{\circ}$ Cuartil & 58,000 \\
\hline Media & 50,551 \\
\hline Desviación típica (n-1) & 10,320 \\
\hline Coeficiente de variación & 0,204 \\
\hline Límite inferior de la media (95\%) & 49,276 \\
\hline Límite superior de la media (95\%) & 51,826 \\
\hline
\end{tabular}

Las edades oscilan entre 22 y 73 años no registrándose valores atípicos. La distribución resulta levemente asimétrica, ubicándose el $50 \%$ central entre los 43 y 58 años. La media se ubica en 50,5 años y la mediana en 51 años. El coeficiente de variación en el orden del $20,4 \%$ sustenta la concentración en torno a los valores centrales.

Al analizar la técnica mediante la cual los pacientes fueron operados, se obtienen los resultados que siguen. El 59,45\% de la muestra tiene un bypass gástrico y el resto una manga gástrica o gastrectomía tubular en manga. Los resultados indican una mayor prevalencia de bypass gástrico, respecto de manga gástrica. Para el contraste de dos proporciones se empleará la prueba $Z$, que mediante la aproximación a la distribución normal, calculará el estadístico de contraste para la diferencia de proporciones $^{2}$. Como resultado de esta prueba se obtienen los siguientes resultados:

\footnotetext{
2 A través de esta prueba se determina si existe una diferencia estadísticamente significativa entre los porcentajes obtenidos por cada una de las dos categorías de una variable. Esta prueba se basa en la aproximación normal de la distribución binomial. La hipótesis nula de esta prueba plantea que ambas proporciones son iguales.
} 
Tabla $N^{\circ}$ 2: Prueba $Z$ de comparación de proporciones (técnica quirúrgica)

\begin{tabular}{|l|l|}
\hline Diferencia: & 0,095 \\
\hline p-value: & 0,003 \\
\hline IC: & $(0,033 ; 0,156)$ \\
\hline
\end{tabular}

Un p-value menor a 0,05 , indica que existe evidencia significativa en contra de la hipótesis nula, es decir, existe evidencia que indica que la diferencia de proporciones en las técnicas quirúrgicas utilizadas resulta significativa. En la mayoría de los estudios consultados para este trabajo de investigación aparecen estás dos técnicas como las más utilizadas, aunque el objetivo que persiguen es el mismo.

Al analizar la antigüedad de la cirugía, independientemente del tratamiento utilizado, se encuentran los siguiente resultados.

Gráfico $\mathbf{N}^{\circ}$ 2: Tiempo de realización de la cirugía $(n=254)$

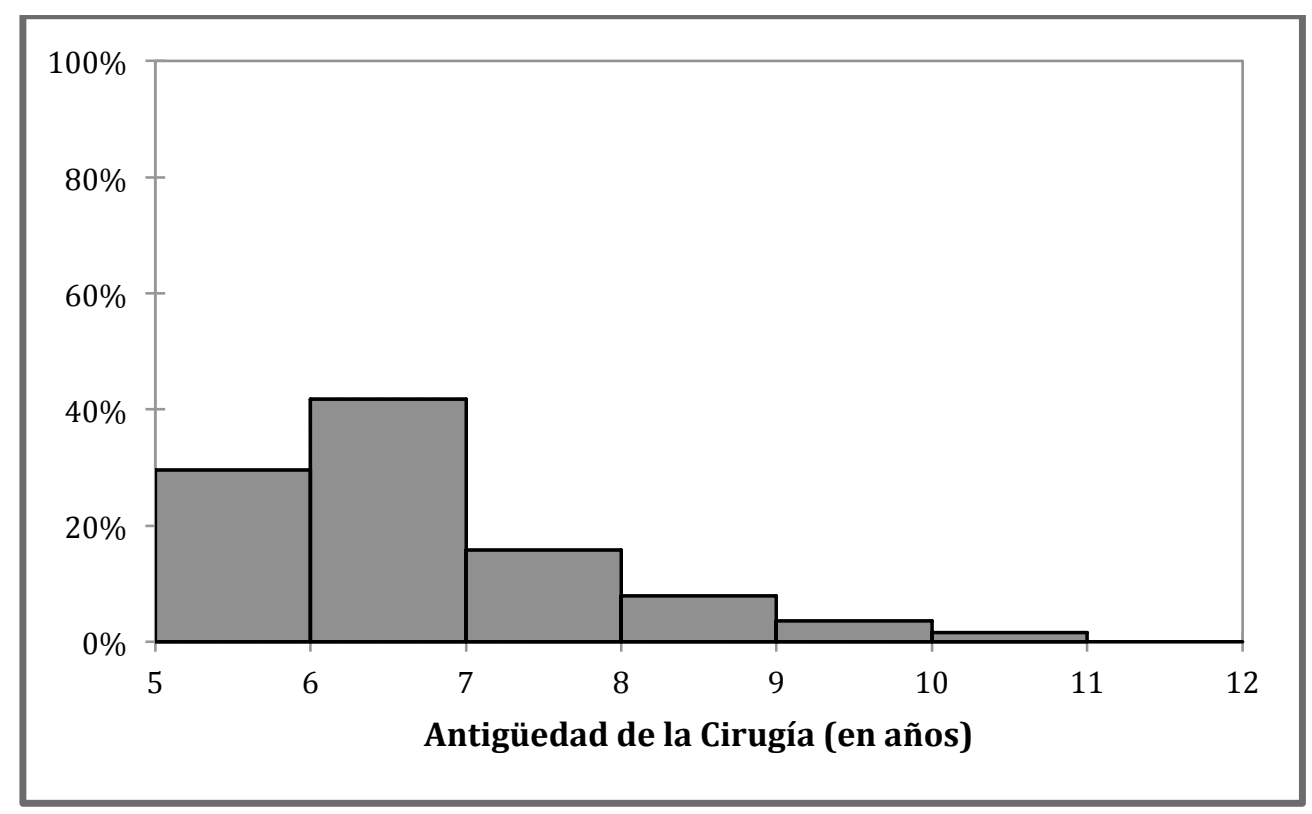

Los registros de antigüedad de la cirugía muestran, tal como era de esperar, que los porcentajes de pacientes que responden a una convocatoria como la de este trabajo decrecen con el correr del tiempo. Aproximadamente el $70 \%$ de los pacientes presentan una antigüedad menor a los siete años, mientras que no se registran antecedentes mayores a los 11 años de antigüedad.

Seguidamente se presenta el estado civil de los pacientes, tanto al momento de la cirugía como actualmente. Este dato resultaría relevante para establecer el nivel de acompañamiento que presentan los pacientes a lo largo de este tratamiento. 
Tabla $\mathbf{N}^{\circ}$ 3: Estado civil al momento de la cirugía y en la actualidad

\begin{tabular}{|c|c|c|c|c|c|}
\hline \multirow{2}{*}{ Estado civil } & & \multicolumn{4}{|c|}{ Actualmente } \\
\hline & & Casado & Divorciado & Soltero & Viudo \\
\hline \multirow{4}{*}{$\begin{array}{l}\text { Al momento } \\
\text { de la cirugía }\end{array}$} & Casado & 150 & 13 & 0 & 4 \\
\hline & Divorciado & 2 & 19 & 0 & 0 \\
\hline & Soltero & 12 & 1 & 46 & 0 \\
\hline & Viudo & 1 & 0 & 0 & 6 \\
\hline
\end{tabular}

Se observa que más de la mitad de la muestra se encontraba casado al momento de la cirugía y aún mantiene el mismo estado civil, mientras que 13 pacientes, cambiar su estado civil de casado a divorciado. Por su parte, de los 59 pacientes que eran solteros al momento de la cirugía, actualmente 12 se encuentran casados. Como un dato de resumen, se observa que solo 33 pacientes han cambiado su estado civil entre la cirugía y el momento de responder la encuesta.

Como información complementaria al estado civil, se indaga sobre el estado de convivencia de la persona, considerando las categorías "Vive solo" o "Vive acompañado". El 88,19\% vive acompañado (pareja, hijos, padres, otro) y la diferencia restante solo.

A continuación se analiza el nivel educativo alcanzado por los pacientes encuestados, considerando en cada caso si el nivel alcanzado estaba completo o incompleto. 
Gráfico $N^{\circ}$ 3: Nivel educativo $(n=254)$

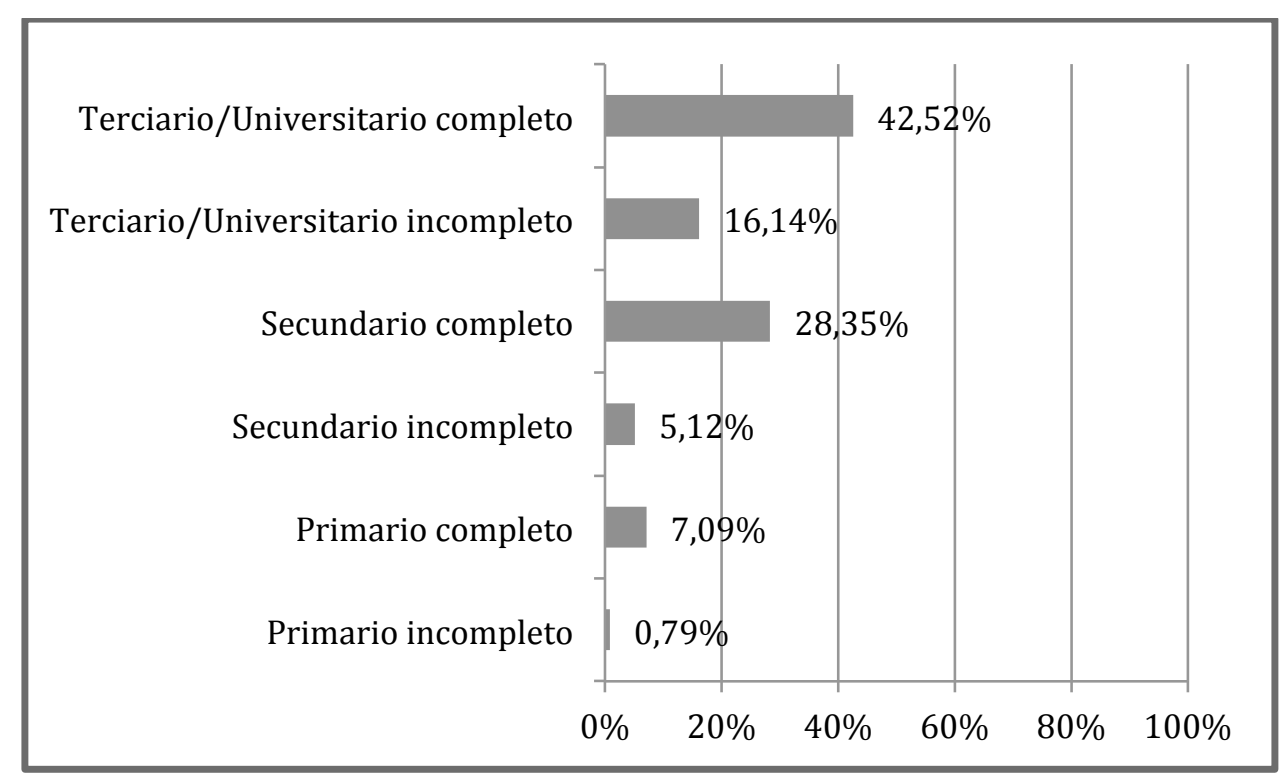

Se observa que si bien no se encuentra un porcentaje mayoritario en ninguna de las categorías, algo más del $85 \%$ de la muestra tiene, al menos, el nivel secundario completo. El porcentaje más alto corresponde a quienes tienen título terciario o universitario, siendo algo menor de la mitad de la muestra.

Niveles educativos como los encontrados en esta muestra podrían estar vinculados a dos cuestiones centrales entre quienes toman la decisión de someterse a un tratamiento quirúrgico como el estudiado. Por un lado la cuestión económica, dado que el elevado costo del tratamiento no resulta accesible para cualquier persona y en general se encuentra cubierto por obras sociales o empresas de medicina prepaga, que implican estar ante personas con un nivel de ingreso medio o alto. Por otro lado se encuentra la cuestión sanitaria dado que niveles superiores de formación podrían estar vinculados a una concientización mayor de los problemas que podría implicar un estado de exceso de peso sostenido en el tiempo.

Como parte del perfil e historia de vida de los pacientes, se indaga sobre el momento de su vida en el que se inició el sobrepeso, registrándose las siguientes respuestas. 
Gráfico $\mathbf{N}^{\circ}$ 4: Momento de inicio del sobrepeso $(n=254)$

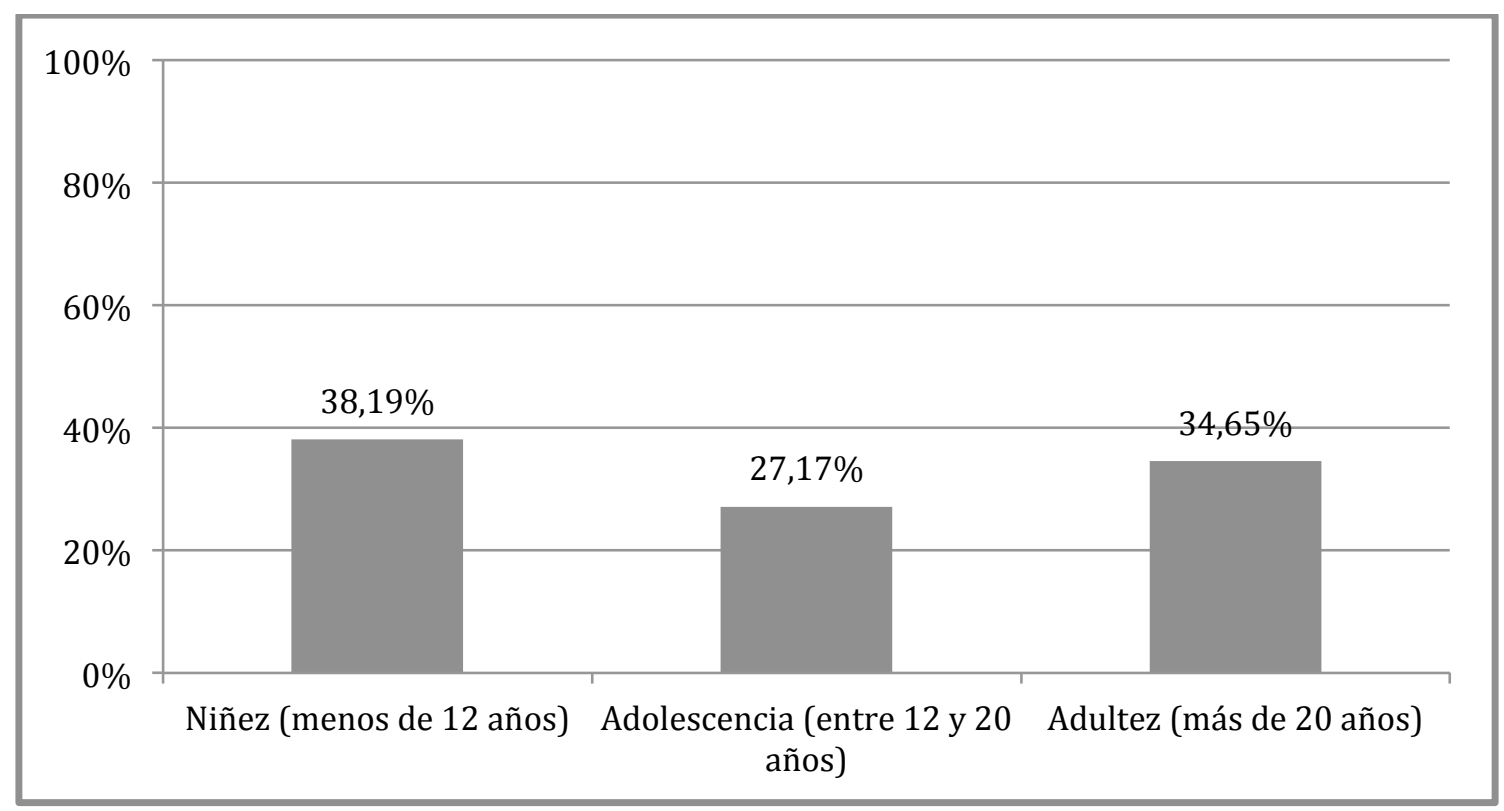

En función de los resultados es posible afirmar que tanto la niñez como la adultez son las etapas de la vida donde se registran los mayores porcentajes de comienzo de las situaciones de sobrepeso.

Al aplicar una prueba de comparación de k-proporciones Chi-Cuadrado se obtiene un p-value: 0,027 .

En la comparación de k-proporciones un p-value menor a 0,05, indica que se debe rechazar la hipótesis nula, es decir, que existe evidencia que indica que las kproporciones son significativamente diferentes entre sí. El resultado global indica que existe una diferencia significancia entre las diferentes etapas consideradas (niñez, adolescencia y adultez).

Seguidamente se analizan cuestiones relacionadas con la evolución del peso de los pacientes. En primer lugar se consideran los pesos registrados tanto al momento de la evaluación inicial como al momento del ingreso a quirófano, previo a la cirugía. 
Gráfico $N^{\circ}$ 5: Peso inicial y preoperatorio $(n=254)$

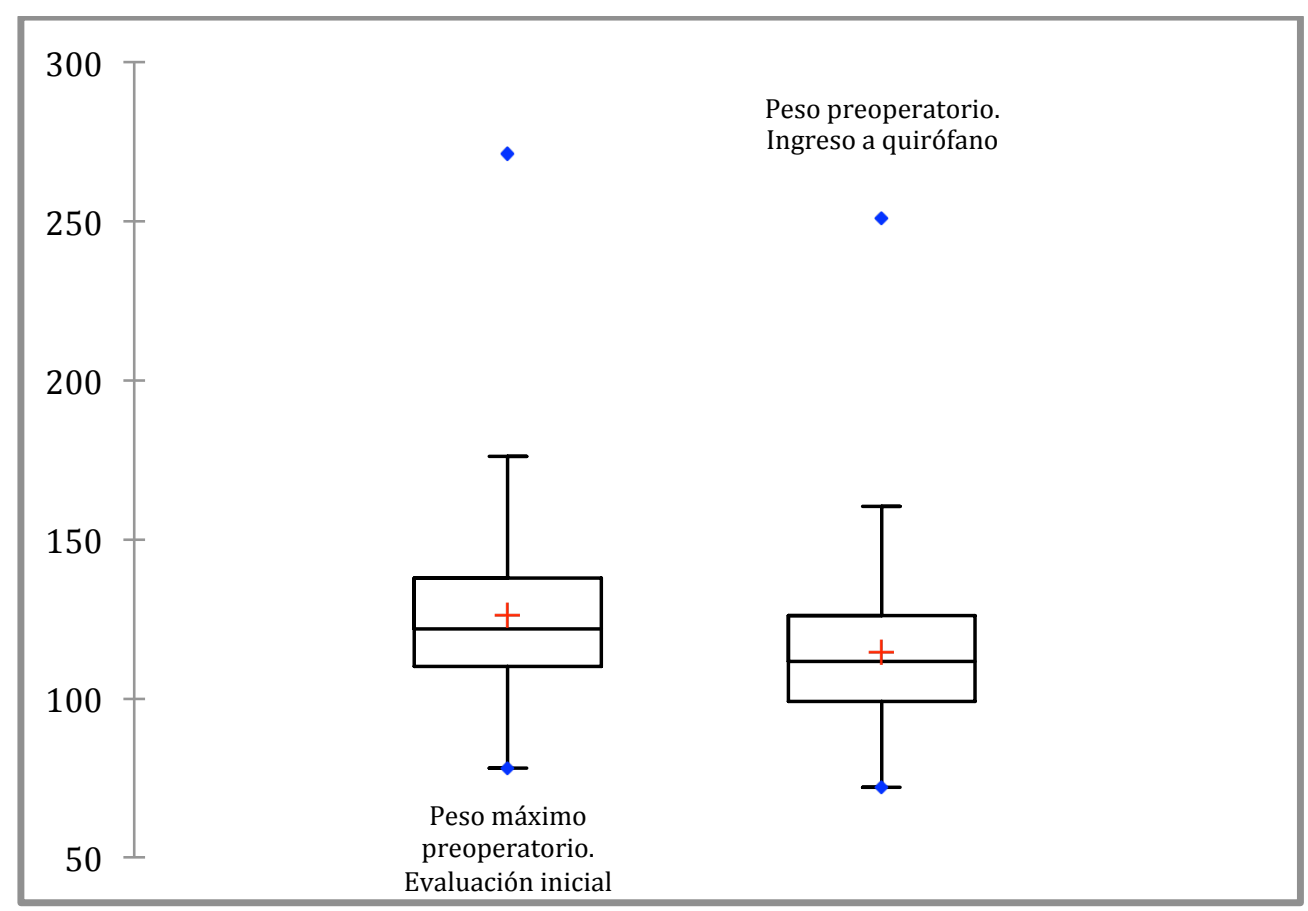

Como se puede observar en el anterior gráfico, los pesos registrados en las evaluaciones iniciales oscilan entre $78 \mathrm{~kg}$ y $176 \mathrm{~kg}$, aunque se registraban valores atípicos o outliers de hasta $271 \mathrm{~kg}$. En esta instancia el peso promedio resulta de $126 \mathrm{~kg}$. Por su parte, los pesos registrados al momento de ingreso al quirófano oscilan entre $72 \mathrm{~kg}$ y $160 \mathrm{~kg}$, registrando también outliers de hasta $251 \mathrm{~kg}$. El peso promedio en esta instancia resulta de $114 \mathrm{~kg}$.

Al realizar una prueba t-Student de comparación de medias para datos apareados $^{3}$, se obtiene un $p$-valor de $<0,0001$. Los resultados obtenidos en la prueba $t$ indican que la diferencia entre el peso al momento de la evaluación inicial y el peso de ingreso a quirófano es significativamente diferente de cero, es decir, el descenso promedio observado entre ambas instancias resulta estadísticamente significativo.

A partir de esta notoria disminución, se debe evaluar si los pacientes han perdido el $5 \%$ del exceso de peso durante la preparación previa a la cirugía mediante una dieta de muy bajo valor calórico como requisito para disminuir el volumen hepático.

\footnotetext{
${ }^{3}$ La prueba t-Student o simplemente t para muestras relacionadas calcula las diferencias entre los valores de dos variables o una variable medida en dos ocasiones y contrasta si la media de estas diferencias es significativamente diferente de 0 . Las pruebas $t$ para muestras de este tipo se utiliza generalmente con grupo de unidades que han sido evaluadas en dos ocasiones diferentes. Un ejemplo típico de prueba t para mediciones repetitivas sería por ejemplo que los sujetos sean evaluados antes y después de un tratamiento.
} 
Al analizar el porcentaje de exceso de peso perdido, definido como el cociente entre las diferencias de pesos máximo y preoperatorio, y máximo e ideal ${ }^{4}$, se obtienen los resultados que siguen:

Gráfico $N^{\circ}$ 6: Porcentaje de exceso de peso perdido $(n=254)$

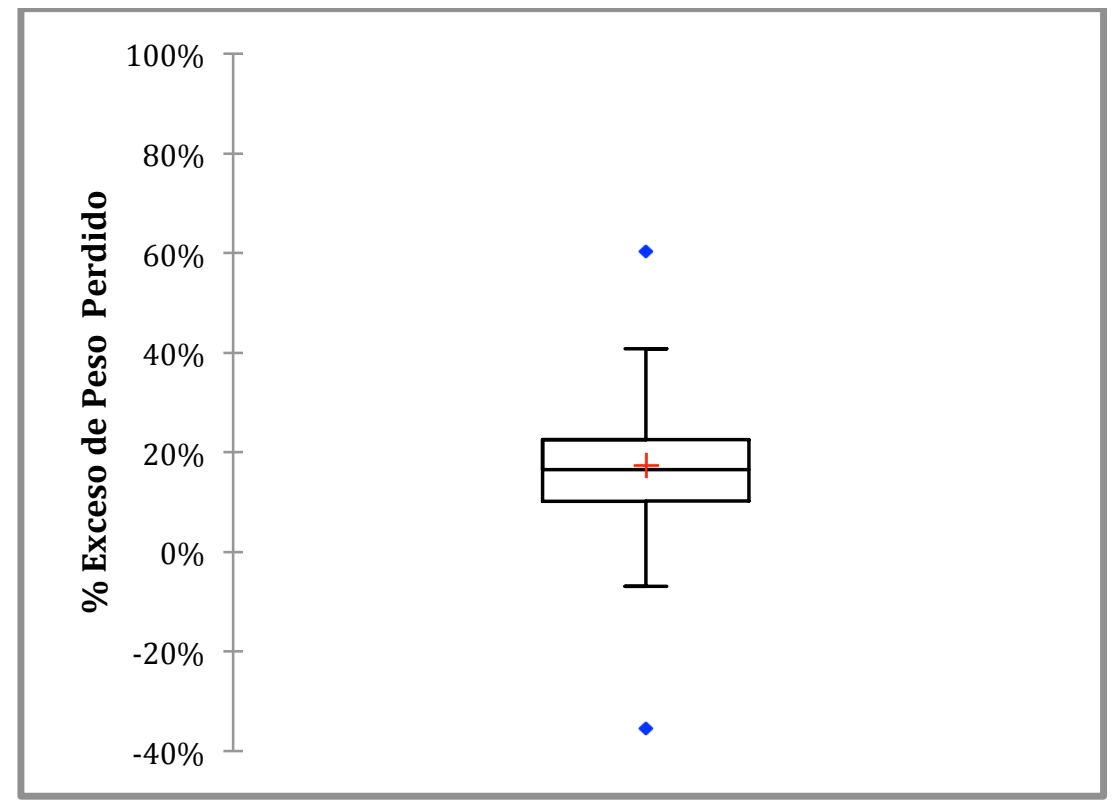

Como se puede observar los porcentajes de exceso de peso perdido oscilan entre $-6 \%$ y $41 \%$, registrándose outliers superiores de hasta $60 \%$ e inferiores de hasta $-35 \%$. Valores negativos indican un incremento de peso desde la evaluación inicial hasta el momento de la cirugía. El 50\% central de los valores se ubica entre un $10 \%$ y un $23 \%$, con una media de $17 \%$, generando una distribución aproximadamente simétrica.

Como se mencionó previamente, el objetivo era lograr una pérdida de al menos un $5 \%$ del exceso de peso durante la preparación previa a la cirugía, mediante una dieta, para disminuir el volumen hepático. Al analizar el cumplimiento de este objetivo se observa que la gran mayoría de los pacientes, un 92,55\%, ha logrado cumplimentarlo, pero el porcentaje que no lo ha logrado alcanza un no despreciable $7,45 \%$.

Seguidamente se analiza el peso mínimo que alcanza un paciente después de la cirugía y el peso actual de cada uno de los mismos.

\footnotetext{
${ }^{4}$ Peso ideal se lo considera como el peso definido por tablas de peso en función de la talla, como las de la Metropolitan Life Insurance Company de 1956. Operacionalmente se utiliza la fórmula: PesoTeórico $(\mathrm{kg})=50+0,75 \times($ talla $(\mathrm{cm})-150)$.
} 
Gráfico $\mathbf{N}^{\circ} 7$ : Peso mínimo post-cirugía y peso actual $(n=254)$

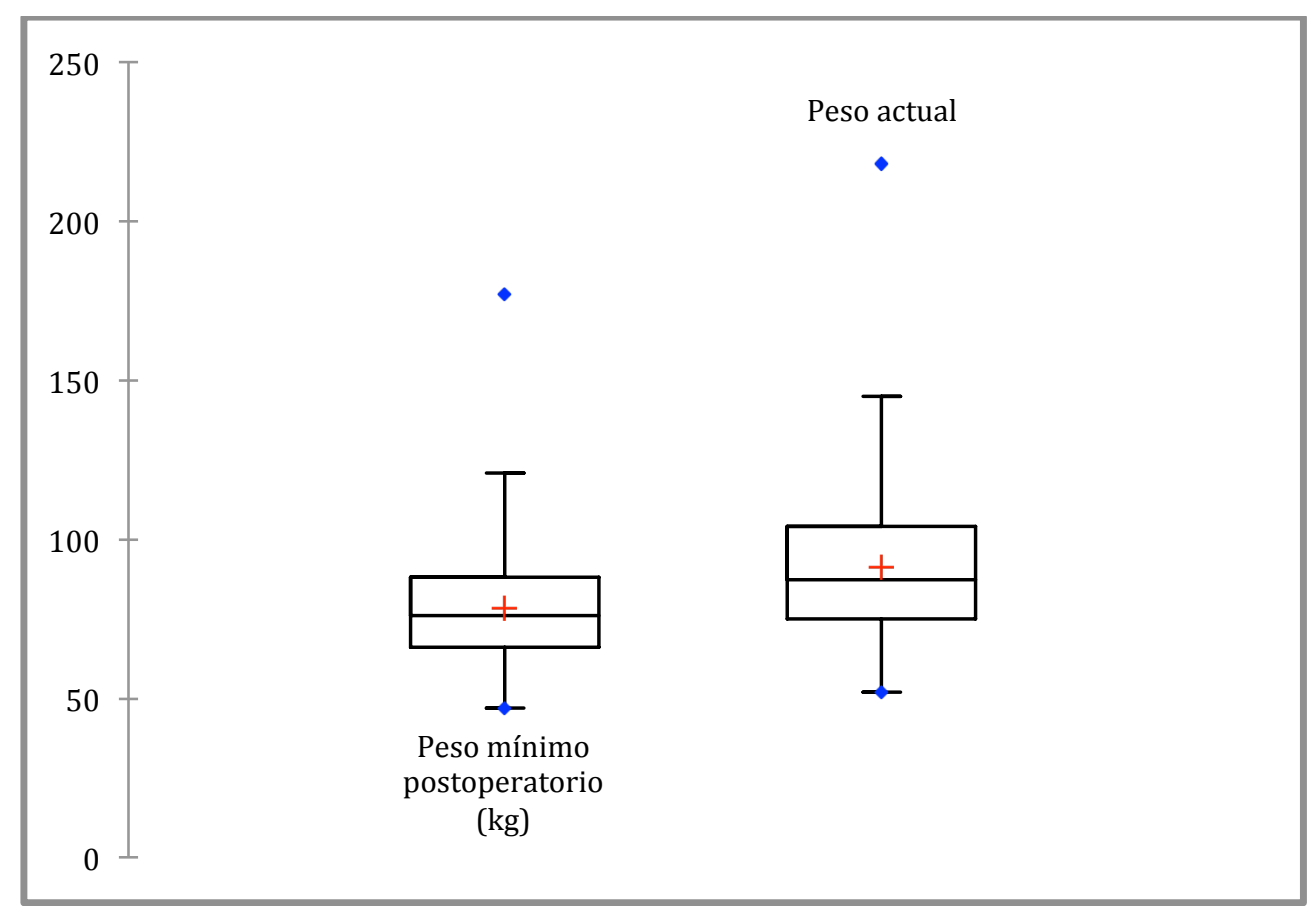

Se puede observar que los pesos mínimos alcanzados por los pacientes oscilan entre $47 \mathrm{~kg}$ y $121 \mathrm{~kg}$, con un promedio de $78 \mathrm{~kg}$ y quedando las tres cuartas partes de la muestra por debajo de los $88 \mathrm{~kg}$, marcando una cierta concentración de valores. En los pesos mínimos se observa outliers superiores de hasta $177 \mathrm{~kg}$.

Respecto de los pesos actuales se observa un aumento en los valores, oscilando entre $52 \mathrm{~kg}$ y $145 \mathrm{~kg}$, con un promedio de $91 \mathrm{~kg}$ o un promedio de aumento de peso de $16,5 \%$. Se observa una mayor dispersión de los datos y nuevamente se registran outliers superiores de hasta $218 \mathrm{~kg}$.

Al realizar una prueba t-Student de comparación de medias para datos apareados, se obtiene un $p$-valor de $<0,0001$. Los resultados obtenidos en la prueba $t$ indican que la diferencia entre el peso mínimo alcanzado después de la cirugía y el peso actual de los pacientes es significativamente diferente de cero, es decir, el aumento de peso promedio observado entre ambas instancias resulta estadísticamente significativo.

Se analiza también el momento después de la cirugía donde se registró el mínimo peso, encontrándose los valores que se presentan a continuación. 
Gráfico $N^{\circ}$ 8: Tiempo transcurrido hasta el peso mínimo post-cirugía $(n=254)$

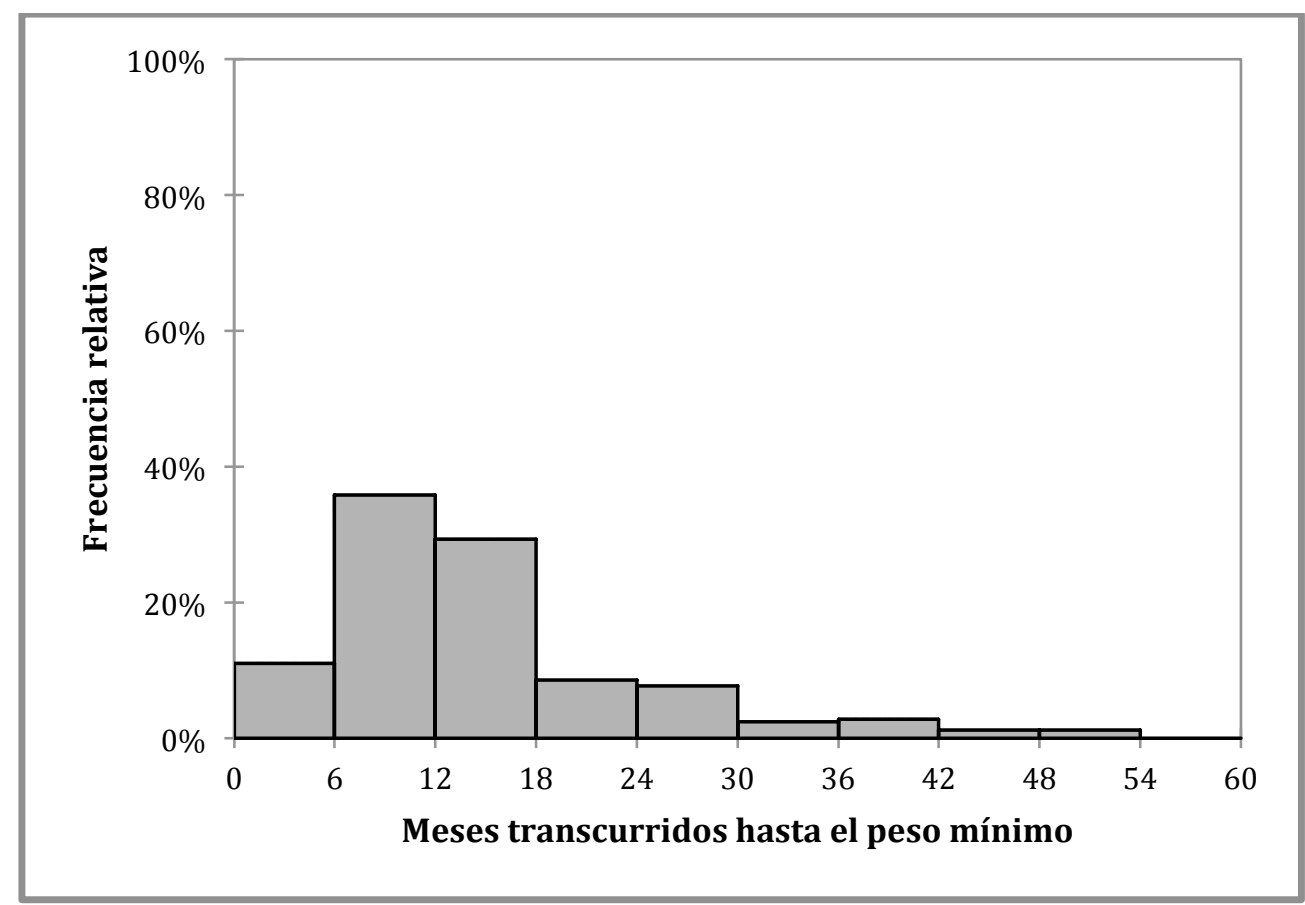

En función de los datos obtenidos se observa que entre los 6 y los 18 meses, aproximadamente un $65 \%$ de los pacientes alcanzan su peso mínimo, marcando una notoria concentración de datos en este rango de tiempo. Cabe mencionar que algunos pacientes han alcanzado su peso mínimo luego de transcurridos cuatro años de la operación.

Más allá de las fluctuaciones de los valores registrados de los pesos de los pacientes en las distintas instancias, resulta necesario contextualizar esos valores de peso respecto de la talla de los mismos, comparando valores de Índice de Masa Corporal $(\mathrm{IMC})^{5}$. Se presentan a continuación los valores de IMC en la evaluación inicial, al momento de registrar el peso mínimo posoperatorio y al momento de responder al cuestionario.

\footnotetext{
${ }^{5}$ El Índice de Masa Corporal (IMC) es un indicador simple de la relación entre el peso y la talla que se utiliza frecuentemente para identificar el sobrepeso y la obesidad en los adultos. Se calcula dividiendo el peso de una persona en kilos por el cuadrado de su talla en metros $(\mathrm{kg} / \mathrm{m} 2)$.
} 
Gráfico N²: Índice de Masa Corporal $(n=254)$

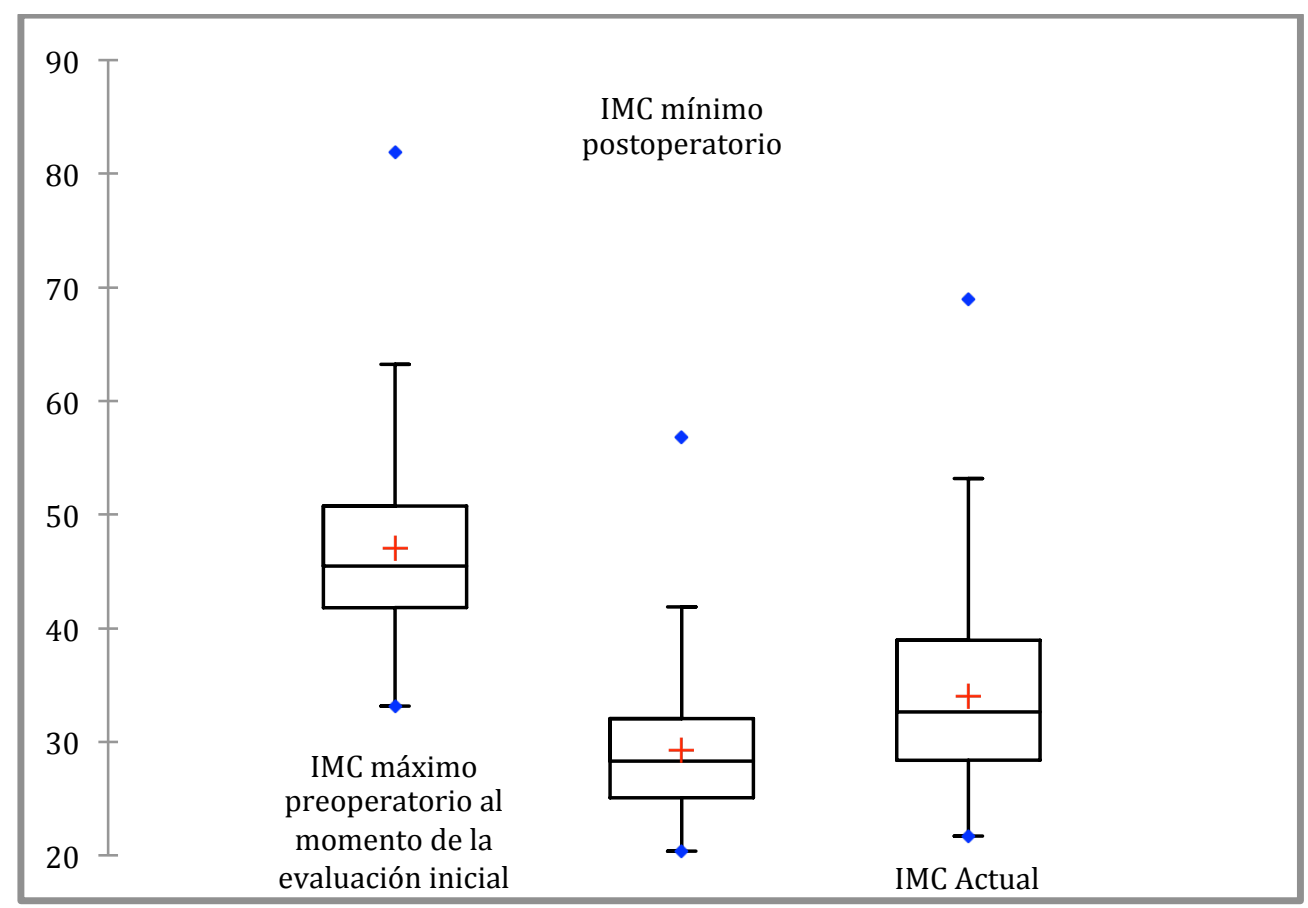

De este gráfico se desprende como la distribución en los valores de IMC se ve notoriamente disminuida entre la evaluación inicial y la instancia donde se registra el peso mínimo postoperatorio. De la misma forma, respecto de la valoración actual se observa un incremento en los valores de IMC en comparación con la instancia anterior, registrándose una mayor dispersión de los mencionados valores. Resulta destacable observar que la media fluctúa de manera similar a la distribución a la que pertenece, manteniéndose un comportamiento, más allá de las diferencias en las dispersiones. Por su parte en las tres instancias se registran valores atípicos superiores.

Considerándose que a partir de los valores de IMC se establece una clasificación del estado nutricional del paciente, se presentan los valores numéricos específicos para las anteriores distribuciones. 
Tabla $N^{\circ}$ 4: Valores de IMC en las distintas instancias

\begin{tabular}{|l|l|l|l|}
\hline Estadística & $\begin{array}{l}\text { IMC } \\
\text { evaluación } \\
\text { inicial }\end{array}$ & $\begin{array}{l}\text { IMC mínimo } \\
\text { postoperatorio }\end{array}$ & IMC actual \\
\hline Mínimo & 33,150 & 20,375 & 21,719 \\
\hline Máximo & 81,904 & 56,797 & 68,968 \\
\hline $\mathbf{1}^{\circ}$ Cuartil & 41,829 & 25,091 & 28,399 \\
\hline Mediana & 45,515 & 28,305 & 32,659 \\
\hline $\mathbf{3}^{\circ}$ Cuartil & 50,735 & 32,029 & 38,968 \\
\hline Media & 47,060 & 29,257 & 34,051 \\
\hline Desviación típica (n-1) & 7,708 & 5,811 & 7,388 \\
\hline Coeficiente de variación & 0,163 & 0,198 & 0,217 \\
\hline
\end{tabular}

Se considera que los puntos de corte en la escala de IMC indican que valores comprendidos entre 25 y $30 \mathrm{~kg} / \mathrm{m}^{2}$ corresponden a la clasificación de sobrepeso y valores por encima de $30 \mathrm{~kg} / \mathrm{m}^{2}$ se corresponden con la clasificación de obesidad. Por lo tanto, las medias en las tres instancias cambian su clasificación de obesidad a sobrepeso y nuevamente a obesidad. Sin embargo, el primer cuartil cambia de obesidad a sobrepeso y se mantiene en esa calificación, mostrando que un $25 \%$ de los pacientes encuestados no vuelve a su clasificación inicial luego del descenso.

Seguidamente se analiza el porcentaje de aumento de peso registrado por los pacientes al momento de responder la encuesta, respecto del mínimo postoperatorio alcanzado. Los resultados se presentan a continuación. 
Gráfico No 10: Porcentaje de aumento respecto del peso mínimo posoperatorio $(\mathrm{n}=$ 254)

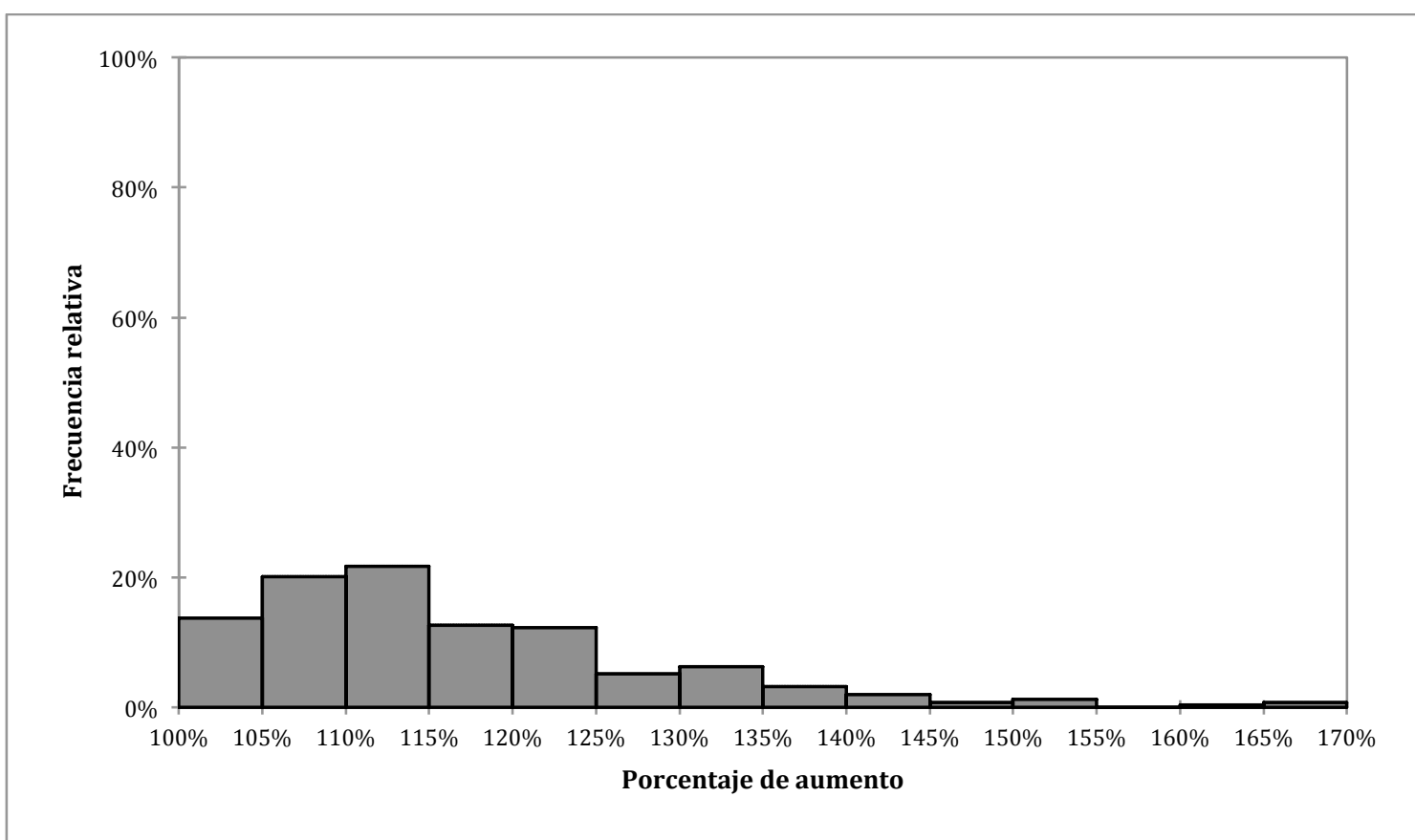


Tabla $\mathbf{N}^{\circ}$ 5: Porcentaje de aumento respecto del peso mínimo posoperatorio

\begin{tabular}{|c|c|c|c|}
\hline Límite inferior & Límite superior & Frecuencia & Frecuencia relativa \\
\hline $100 \%$ & $105 \%$ & 35 & $13,78 \%$ \\
\hline $105 \%$ & $110 \%$ & 51 & $20,08 \%$ \\
\hline $110 \%$ & $115 \%$ & 56 & $22,05 \%$ \\
\hline $115 \%$ & $120 \%$ & 31 & $12,20 \%$ \\
\hline $120 \%$ & $125 \%$ & 31 & $12,20 \%$ \\
\hline $125 \%$ & $130 \%$ & 13 & $5,12 \%$ \\
\hline $130 \%$ & $135 \%$ & 16 & $6,30 \%$ \\
\hline $135 \%$ & $140 \%$ & 8 & $3,15 \%$ \\
\hline $140 \%$ & $145 \%$ & 5 & $1,97 \%$ \\
\hline $145 \%$ & $150 \%$ & 2 & $0,79 \%$ \\
\hline $150 \%$ & $155 \%$ & 3 & $1,18 \%$ \\
\hline $155 \%$ & $160 \%$ & 0 & $0,00 \%$ \\
\hline $160 \%$ & $165 \%$ & 1 & $0,39 \%$ \\
\hline $165 \%$ & $170 \%$ & 2 & $0,79 \%$ \\
\hline
\end{tabular}

Se observa que más del $50 \%$ de los pacientes registran un aumento de peso de hasta el $15 \%$ respecto del peso mínimo posoperatorio, mientras que aproximadamente un $15 \%$ registra un aumento de entre un $30 \%$ y $70 \%$ por encima del peso mínimo posoperatorio.

Dado que existe heterogeneidad de definiciones de reganancia de peso post cirugía bariátrica surgió la inquietud de estudiar la muestra de acuerdo a los diferentes criterios para evaluar la variabilidad de la prevalencia de reganancia según cada uno. 
Gráfico No 11: Reganadores según el criterio 1 "aumento de más de $10 \mathrm{~kg}$ de peso corporal del peso mínimo alcanzado post cirugía”. $(16,17,18)(n=254)$

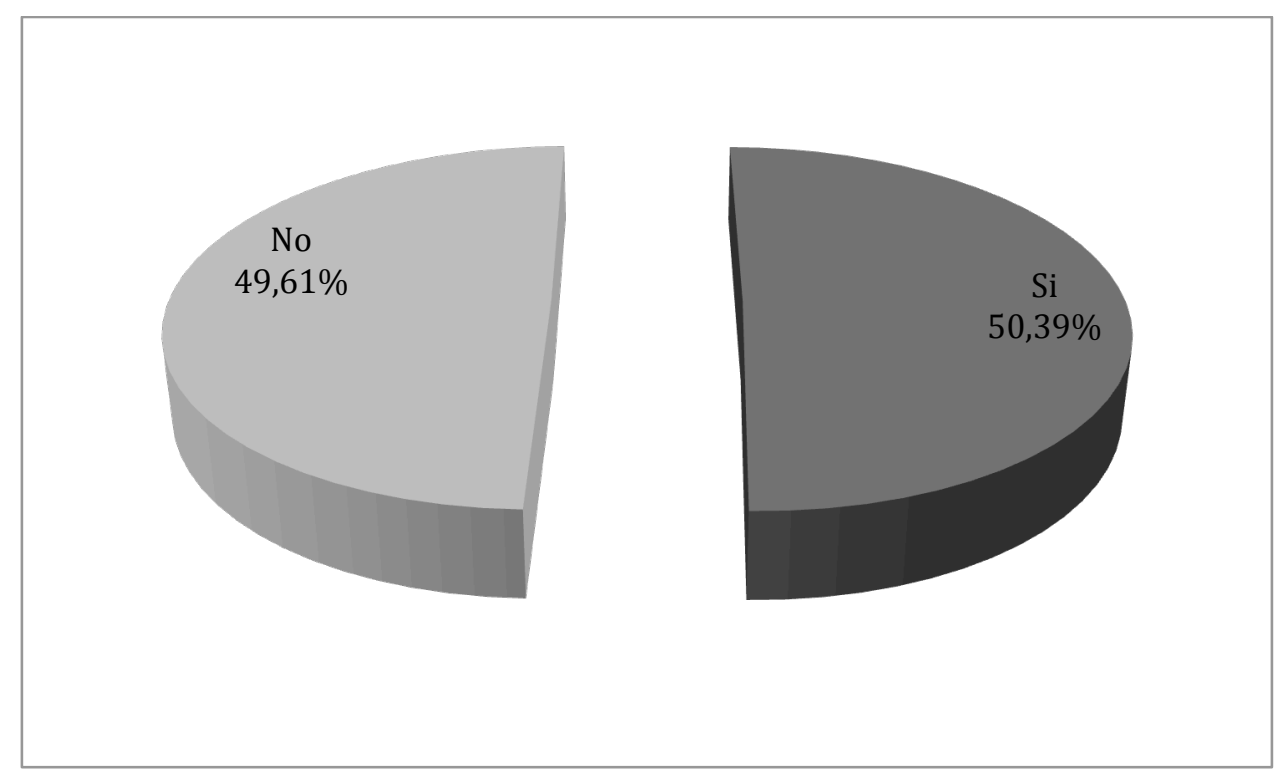

Gráfico No 12: Reganadores según criterio 2 "aumento de $5 \mathrm{~kg} / \mathrm{m}^{2}$ o más del IMC, respecto del mínimo IMC posoperatorio“. (3) $(n=254)$

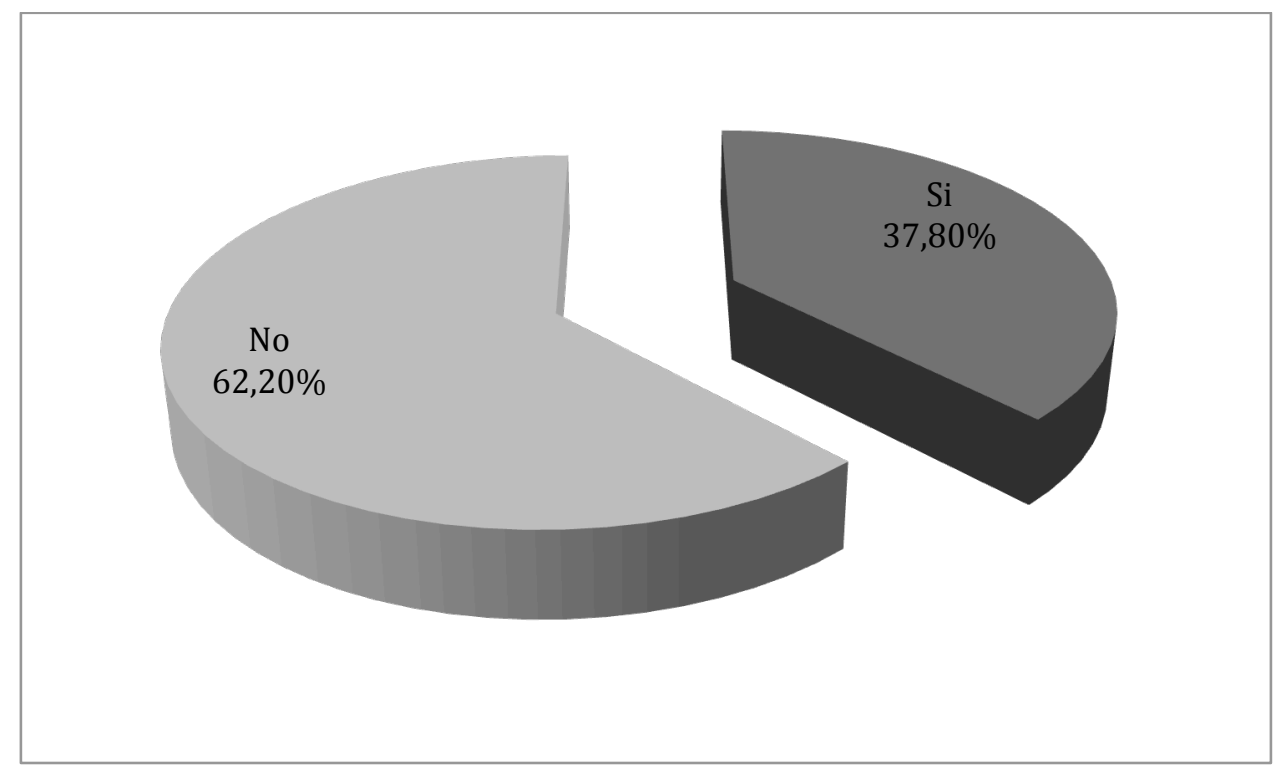


Gráfico N 13: Reganadores según criterio 3 "recuperar peso después de una pérdida exitosa superando un IMC de $35 \mathrm{~kg} / \mathrm{m}^{2}$ ". Esto genera 3 categorías: "reganador", "no reganador" y "no considerado" por no haber cumplido la pérdida exitosa. (19) (n = 254)

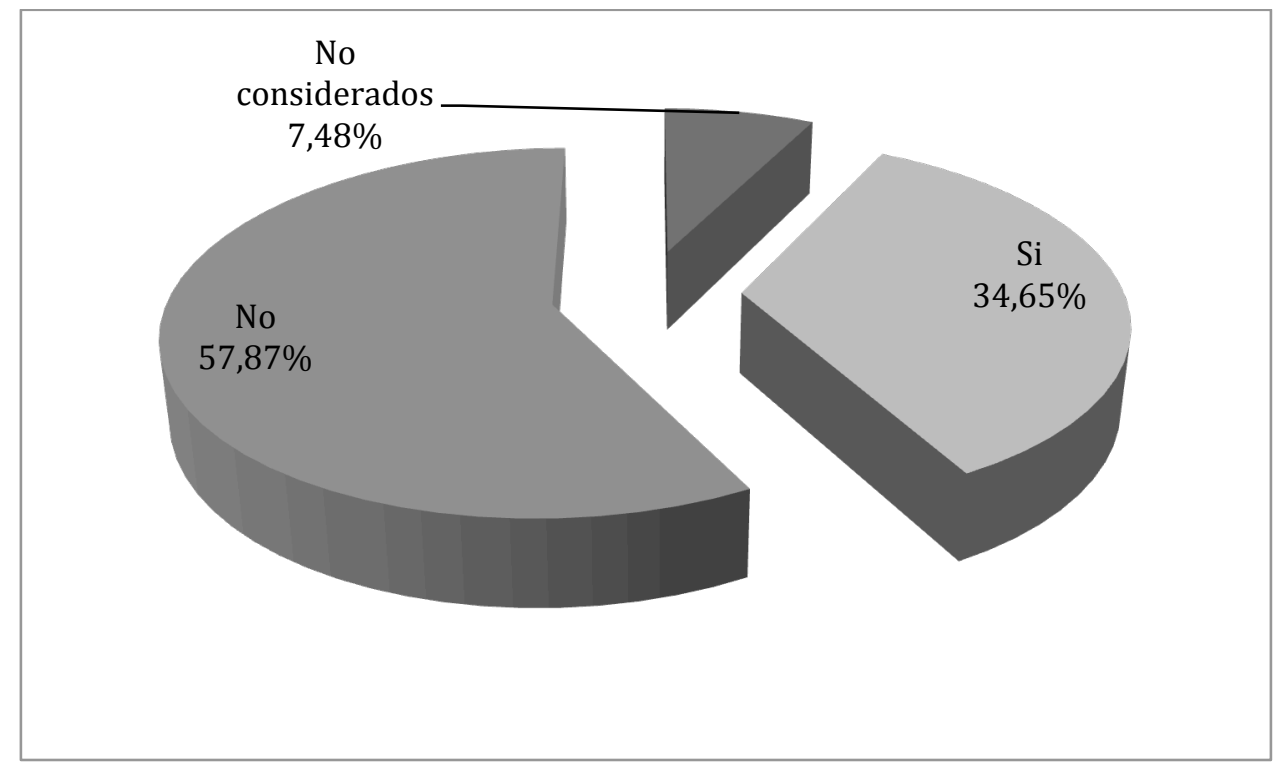

Gráfico No 14: Reganadores según criterio 4 "aumento de más del $25 \%$ del exceso de peso perdido después de la cirugía (recuperar más de un $25 \%$ o más del peso perdido entre la cirugía y el peso mínimo alcanzado)“. (22) $(n=254)$

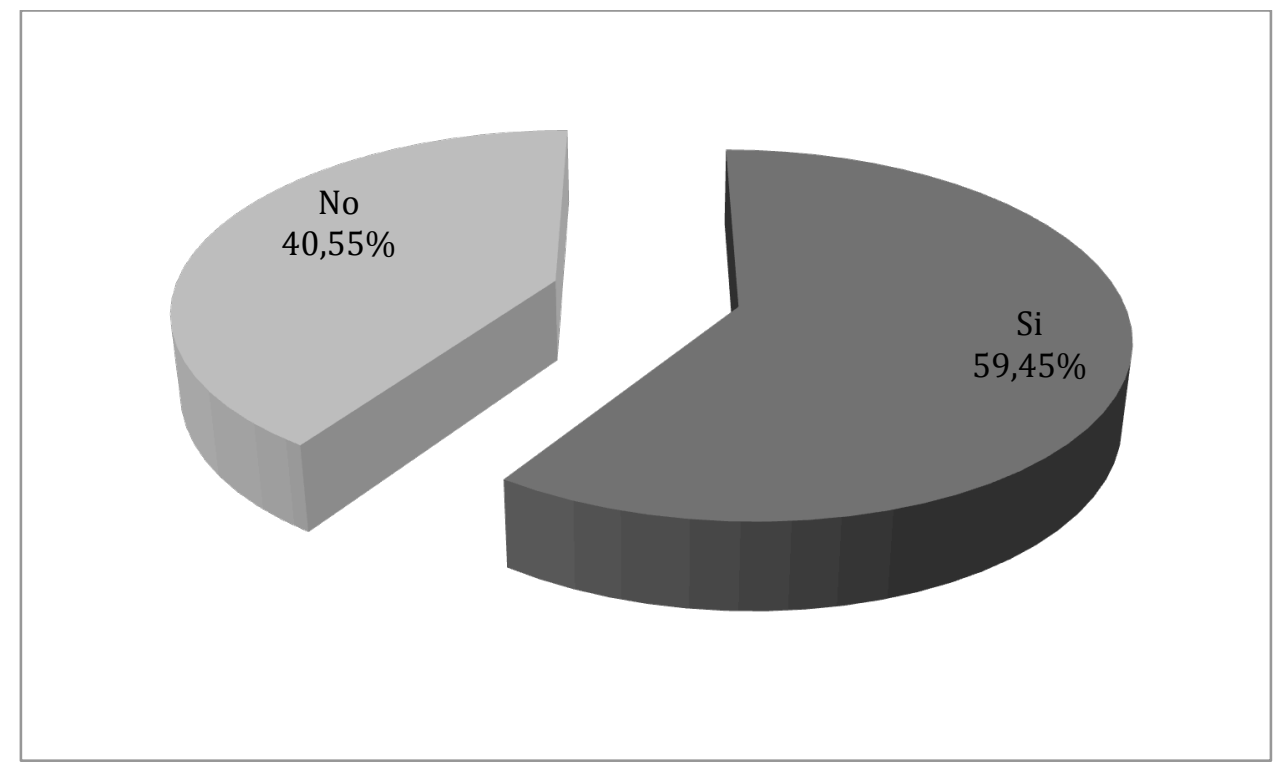


Gráfico N 15: Reganadores según criterio 5 "aumento de más del $15 \%$ respecto del peso mínimo alcanzado". $(n=254)$

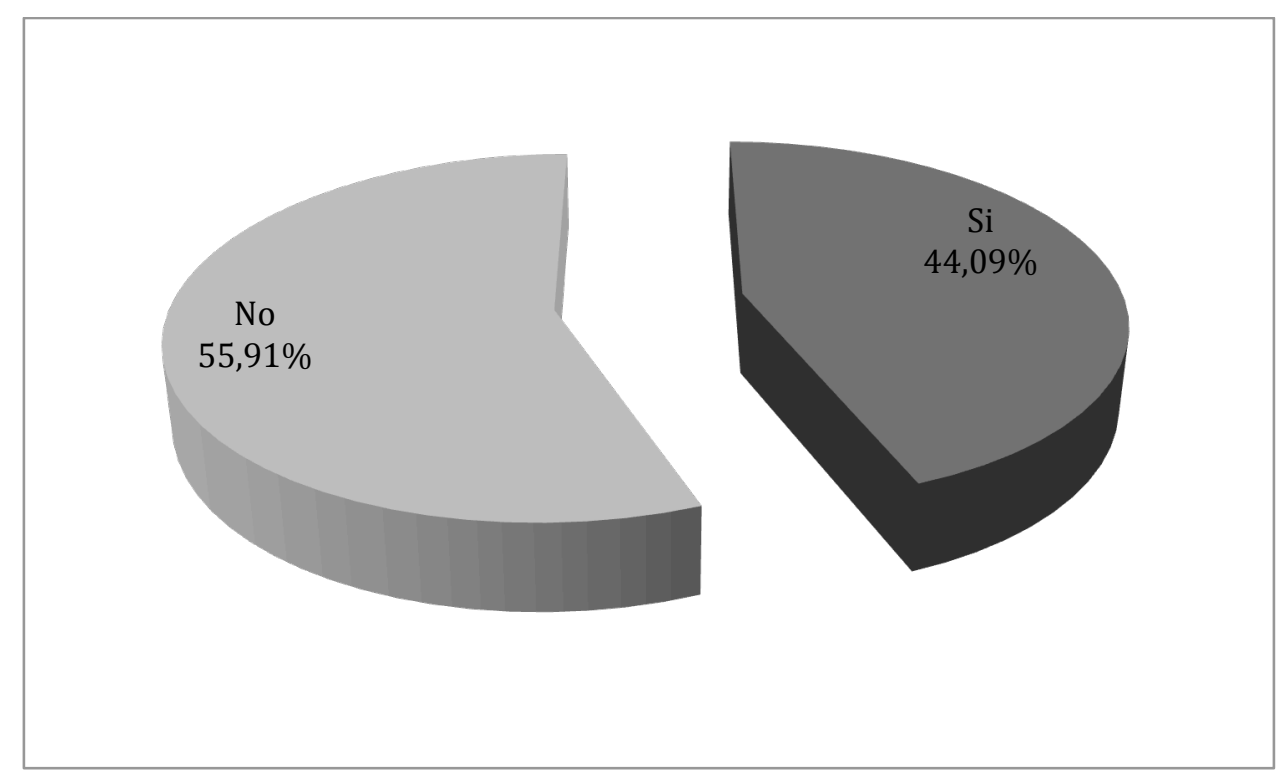

A partir de los anteriores gráficos se observa que los distintos criterios definen como reganadores a entre un $34 \%$ y un $59 \%$ de los pacientes. Por lo que resulta importante determinar la cantidad de esos criterios cumplidos por cada uno de los pacientes, en pos de analizar las coincidencias en los mismos.

Gráfico $\mathbf{N}^{\circ}$ 16: Cantidad de criterios cumplidos por paciente $(n=235$, solo los pacientes a quienes se les pudo establecer los 5 criterios).

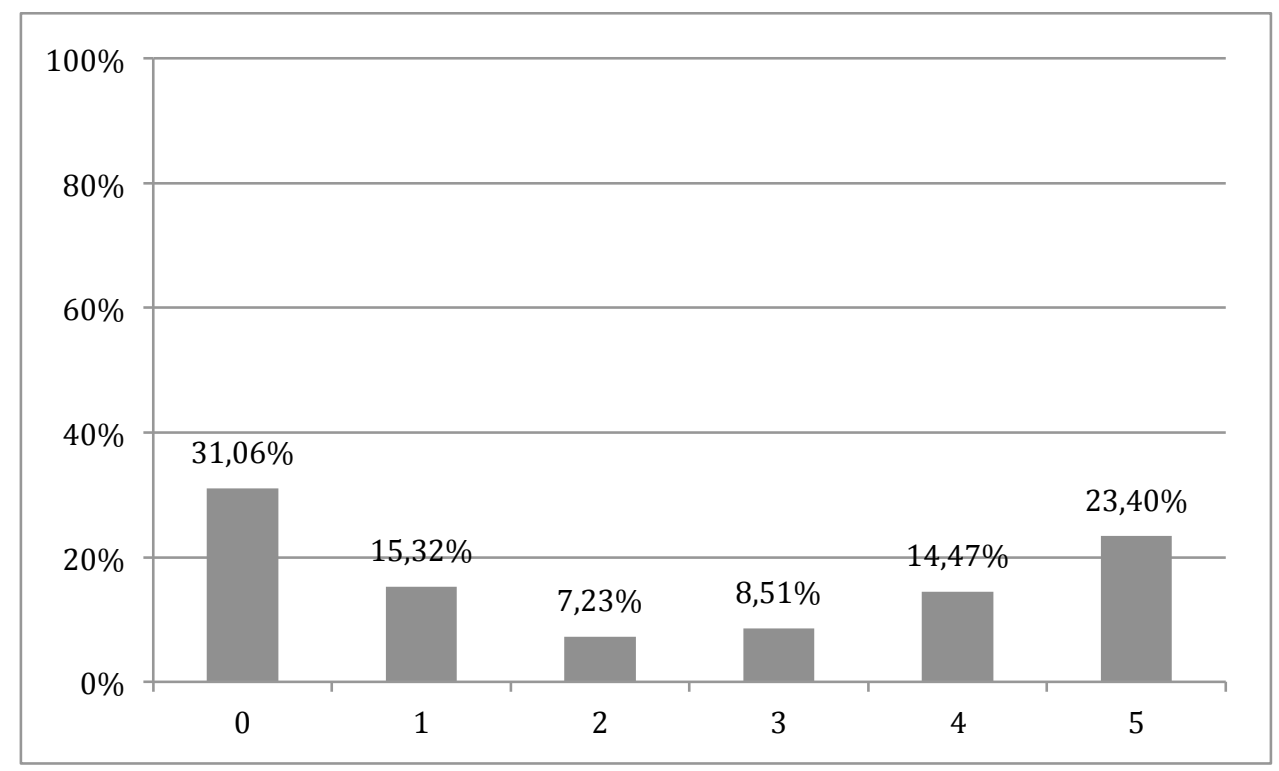

Este gráfico muestra que el $31,06 \%$ de la muestra en estudio no cumplía con ninguno de los criterios para considerar un sujeto reganador. Como contrapunto se 
observa que un $23,4 \%$ de los pacientes cumplen todos los criterios de reganancia, quedando el $45,54 \%$ restante con al menos un criterio, pero no cumpliéndolos todos.

Utilizando el criterio que establece como reganadores a aquellos pacientes que registren un incremento de peso superior al $15 \%$ respecto del peso mínimo alcanzado posoperatorio (nadir), se indaga sobre los motivos mediantes los cuales los pacientes que se encuentran en este grupo explican el por qué de esta situación.

Gráfico $N^{\circ}$ 17: Motivos por los que son reganadores. $(n=112)$

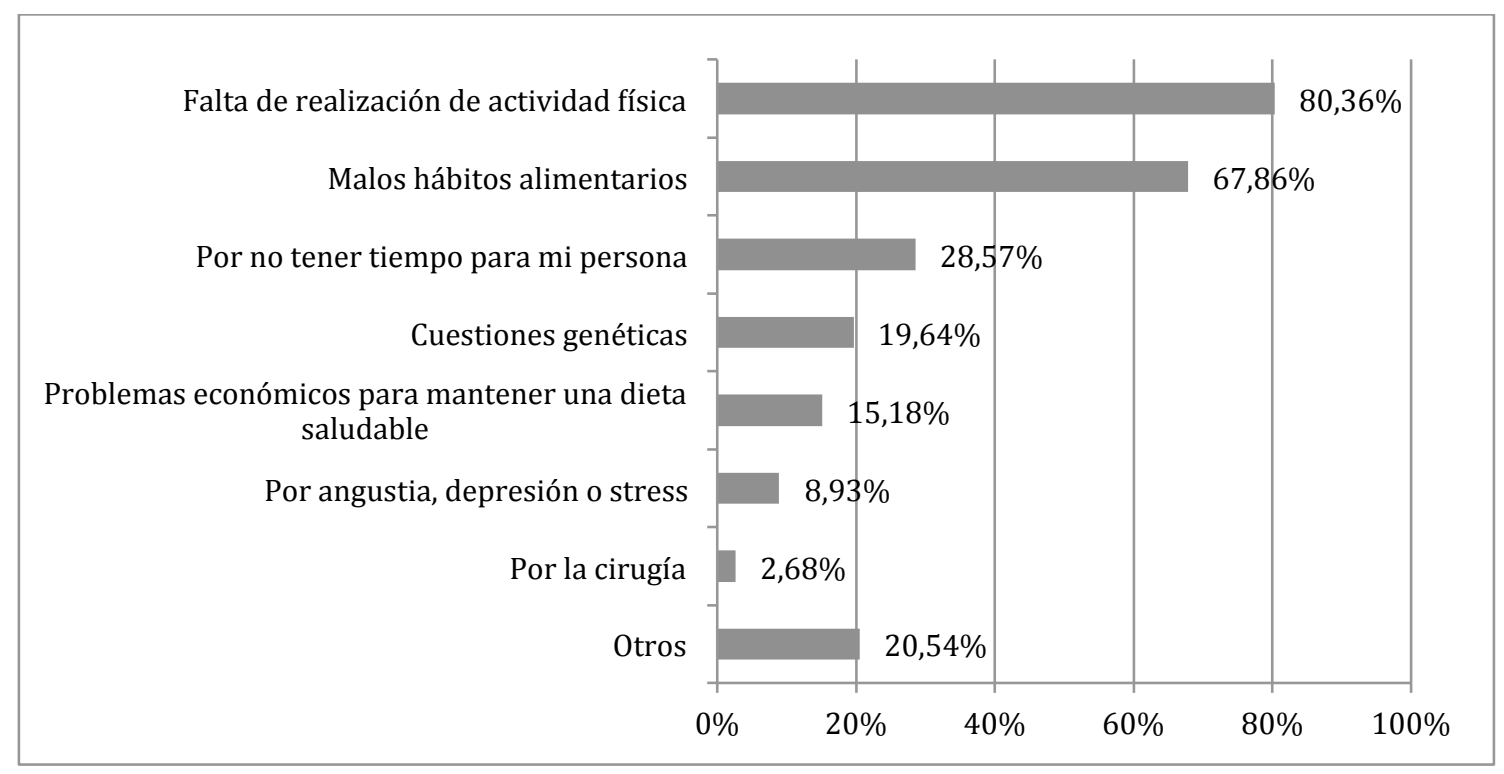

Los pacientes clasificados como reganadores, según el criterio que indica que son aquellos pacientes que registren un incremento de peso superior al $15 \%$ respecto del peso mínimo alcanzado posoperatorio (nadir), señalan como los principales motivos de esta situación la falta de realización de actividad física y los malos hábitos alimentarios. Estos motivos son referidos por la mayoría de los pacientes de este grupo. También entre las causas se refieren la falta de tiempo, cuestiones genéticas y problemas económicos con porcentajes superiores al $15 \%$ en todos los casos.

Por su parte, entre aquellos pacientes que no entran dentro del criterio para ser reganadores, también se indaga sobre los motivos por los cuales se produce esa situación. 
Gráfico $\mathbf{N}^{\circ}$ 18: Motivos por los cuales son mantenedores o no reganadores $(n=142)$

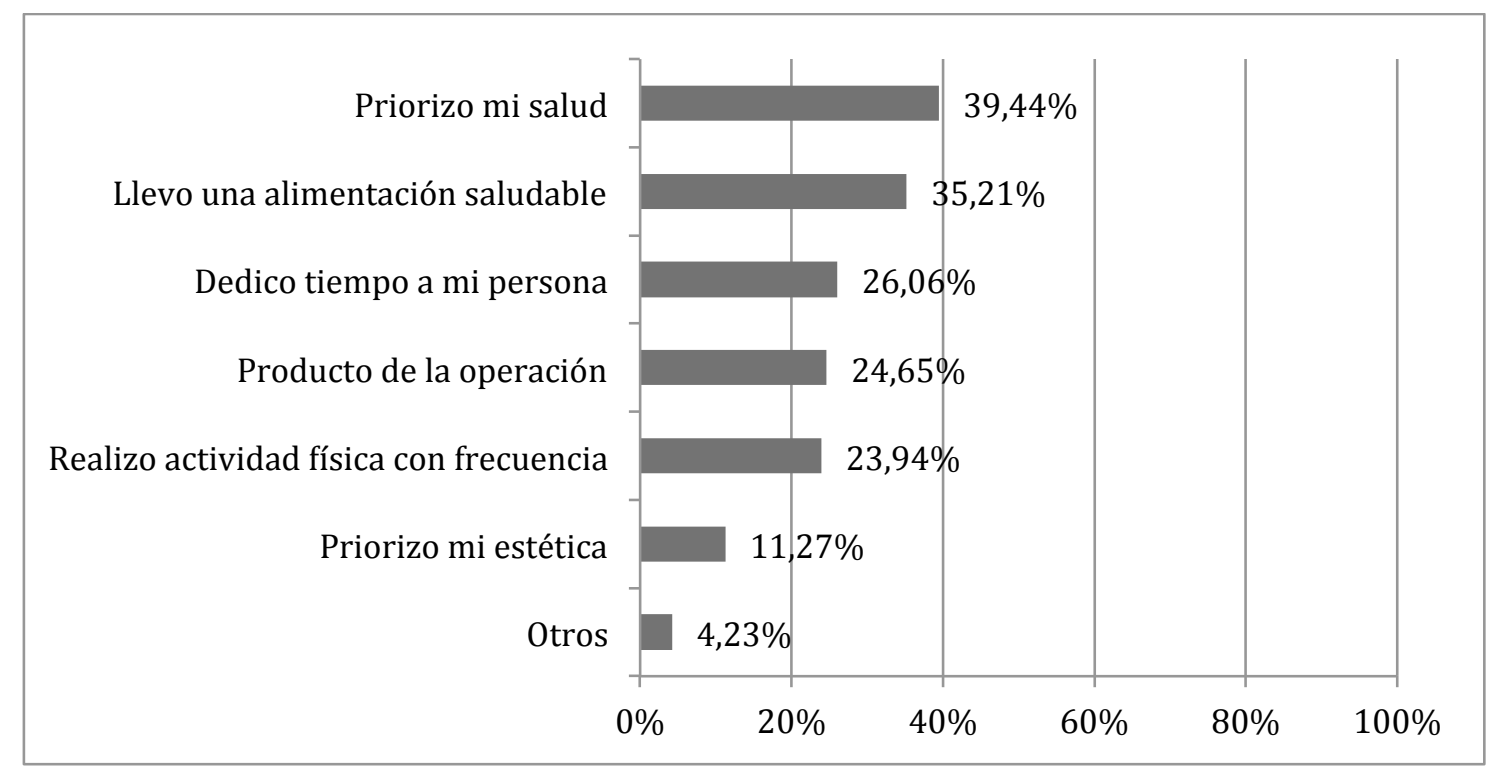

En función de los resultados presentados se observa que en ningún caso las respuestas son mayoritarias, pero la priorización de la salud, llevar una alimentación saludable y el hecho de dedicar tiempo a sí mismos son los motivos más mencionados con porcentajes que superan el $25 \%$.

Seguidamente se presenta un análisis comparativo entre las variables analizadas según grupo al que pertenecer los pacientes, es decir, Reganadores $(R) \circ$ No Reganadores (No R).

Respecto de la edad se observan los valores comparativos como se presentan a continuación. 
Gráfico $\mathbf{N}^{\circ}$ 19: Edad diferenciada por grupos $(n=254)$

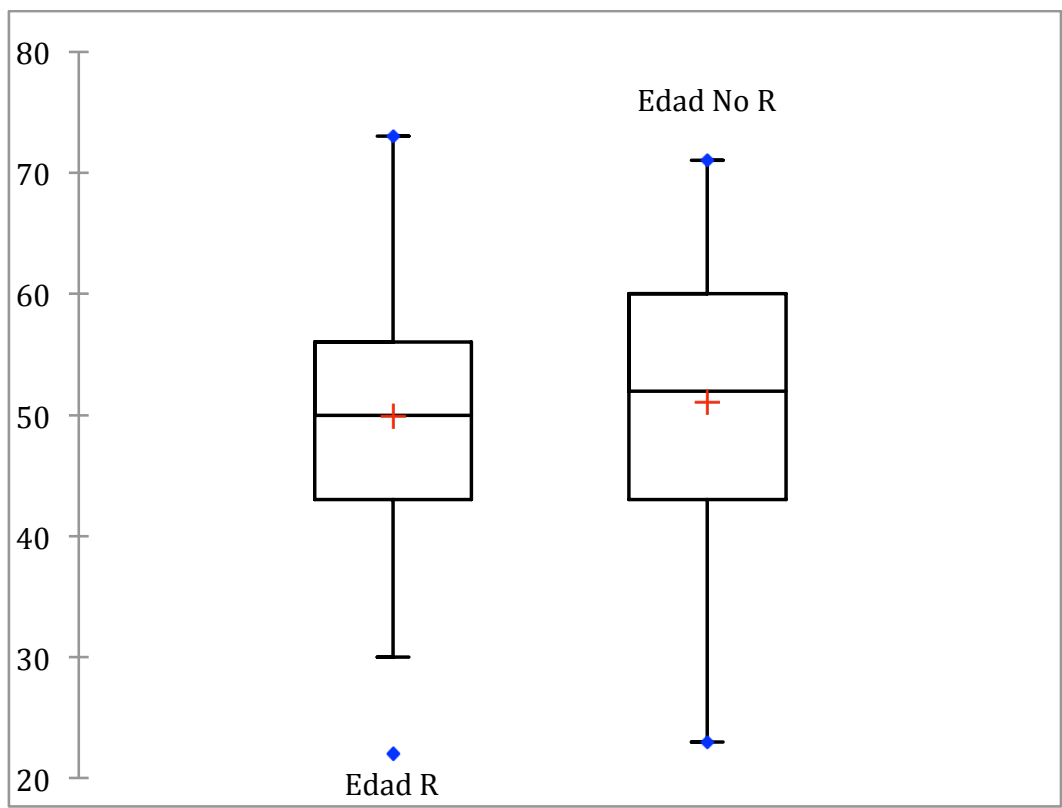

La muestra en estudio no refleja diferencias estadísticamente significativas entre la edad y la reganancia de peso ( $p$-valor bilateral 0,394).

Considerando la distribución por sexo se observan los valores comparativos como se presentan a continuación.

Gráfico $\mathbf{N}^{\circ}$ 20: Distribución por sexo diferenciada por grupos $(\mathrm{n}=254)$

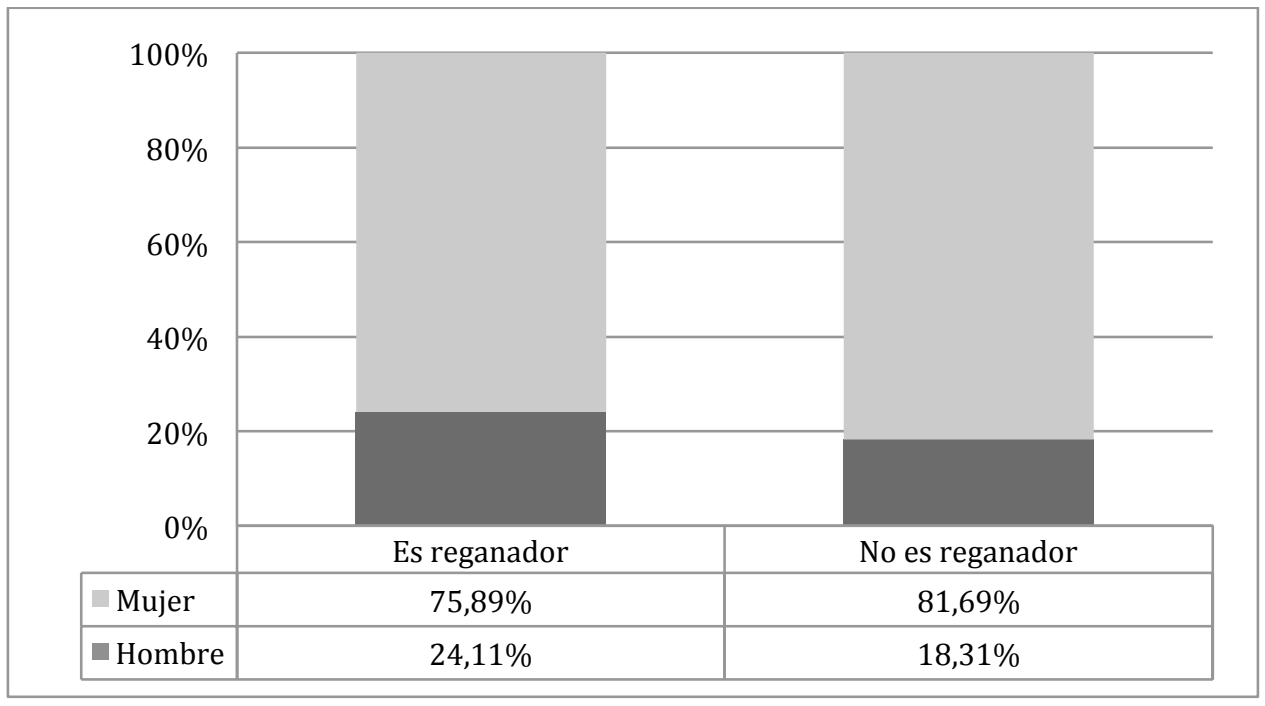

Al realizar una prueba prueba Chi cuadrada de comparación de distribuciones del sexo diferenciada por grupos se obtiene un p-valor de 0,259. Si bien en la distribución total de la muestra estudiada se observa una notoria prevalencia de personas de sexo femenino, el resultado de esta comparación ha sido llamativo pues 
se esperaba encontrar alguna relación significativa entre estas variables, situación que no se presenta.

Respecto de la técnica quirúrgica utilizada se obtienen los resultados que a continuación se presentan.

Gráfico $\mathbf{N}^{\circ} 21$ : Técnica quirúrgica diferenciada por grupos $(n=254)$

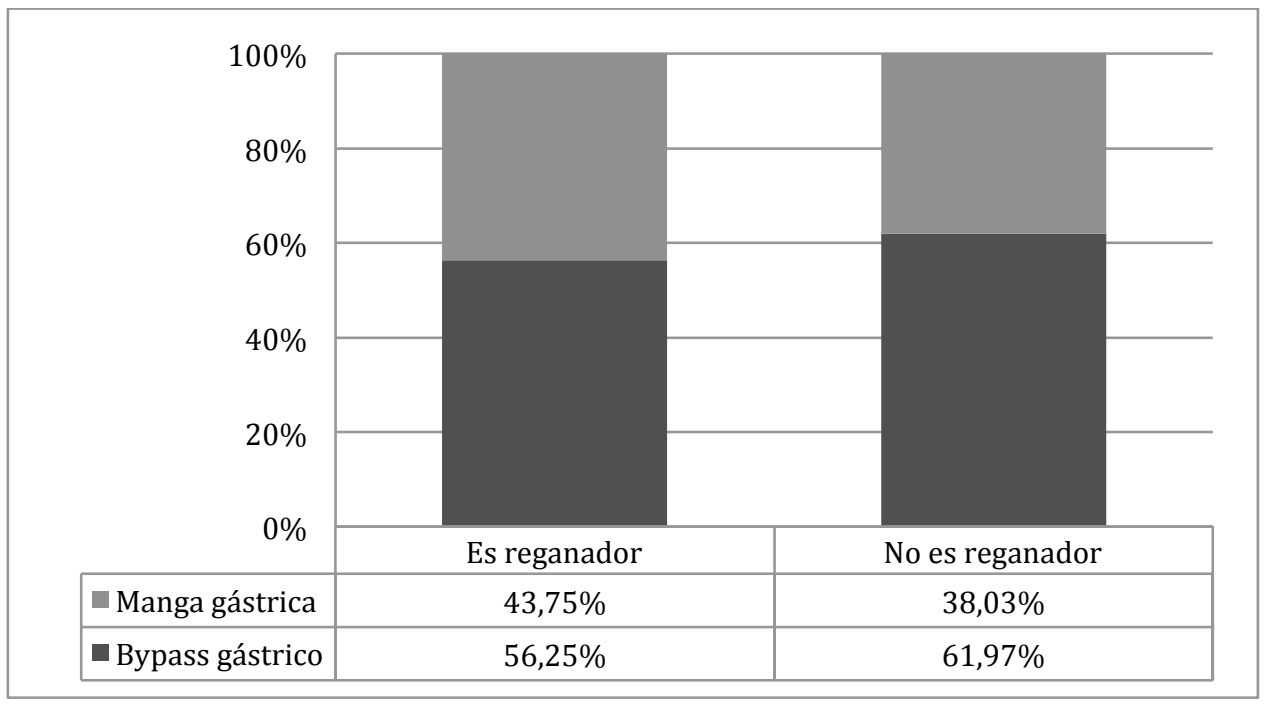

Al realizar una Prueba Chi cuadrado de comparación de distribuciones de las técnicas quirúrgicas diferenciada por grupos se obtiene un p-valor de 0,356. Es bien conocido y estudiado que los pacientes con cirugías malabsortivas o mixtas presentan menores tasas de reganancia de peso post cirugía, sin embargo en la muestra estudiada los pacientes con bypass gástrico o manga gástrica no muestran una diferencia estadísticamente significativa con reganar o no peso.

Al analizar comparativamente el nivel educativo entre ambos grupos se obtienen los resultados que a continuación se presentan. 
Gráfico $N^{\circ} 22$ : Nivel Educativo diferenciado por grupos $(n=254)$

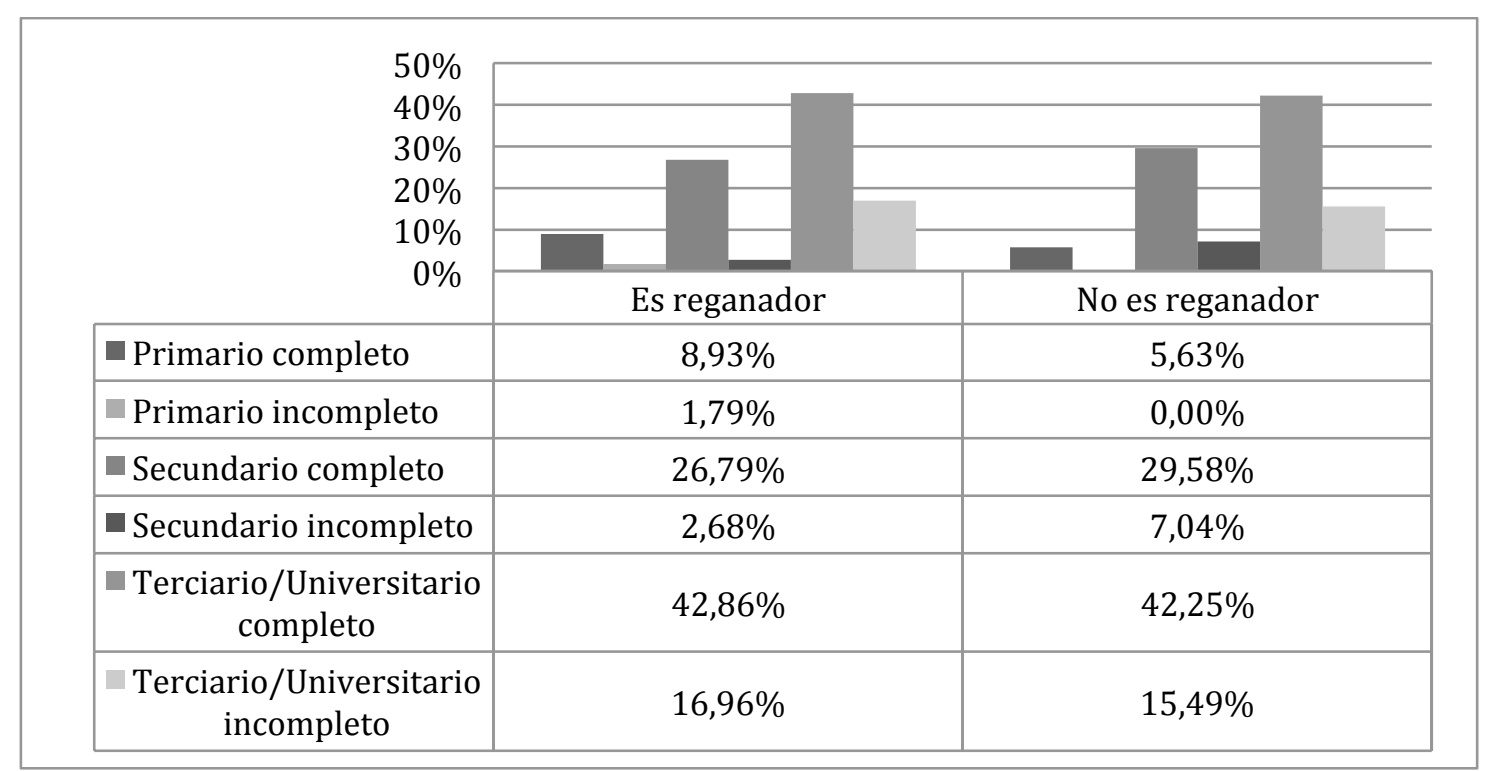

Al realizar una Prueba Chi cuadrado de comparación de distribuciones del nivel educativo diferenciado por grupos se obtiene un $p$-valor de 0,298. Tener un mayor nivel educativo presupondría tener mejor entendimiento de lo que es llevar una alimentación saludable y la importancia de mantener un peso normal para la salud, sin embargo el nivel educativo tampoco muestra diferencia significativa entre reganadores y no reganadores.

Considerando el momento de inicio del exceso de peso de los pacientes, se obtienen los siguientes resultados en el análisis comparativo por grupos 
Gráfico $\mathbf{N}^{\circ}$ 23: Inicio del exceso de peso diferenciado por grupos $(n=254)$

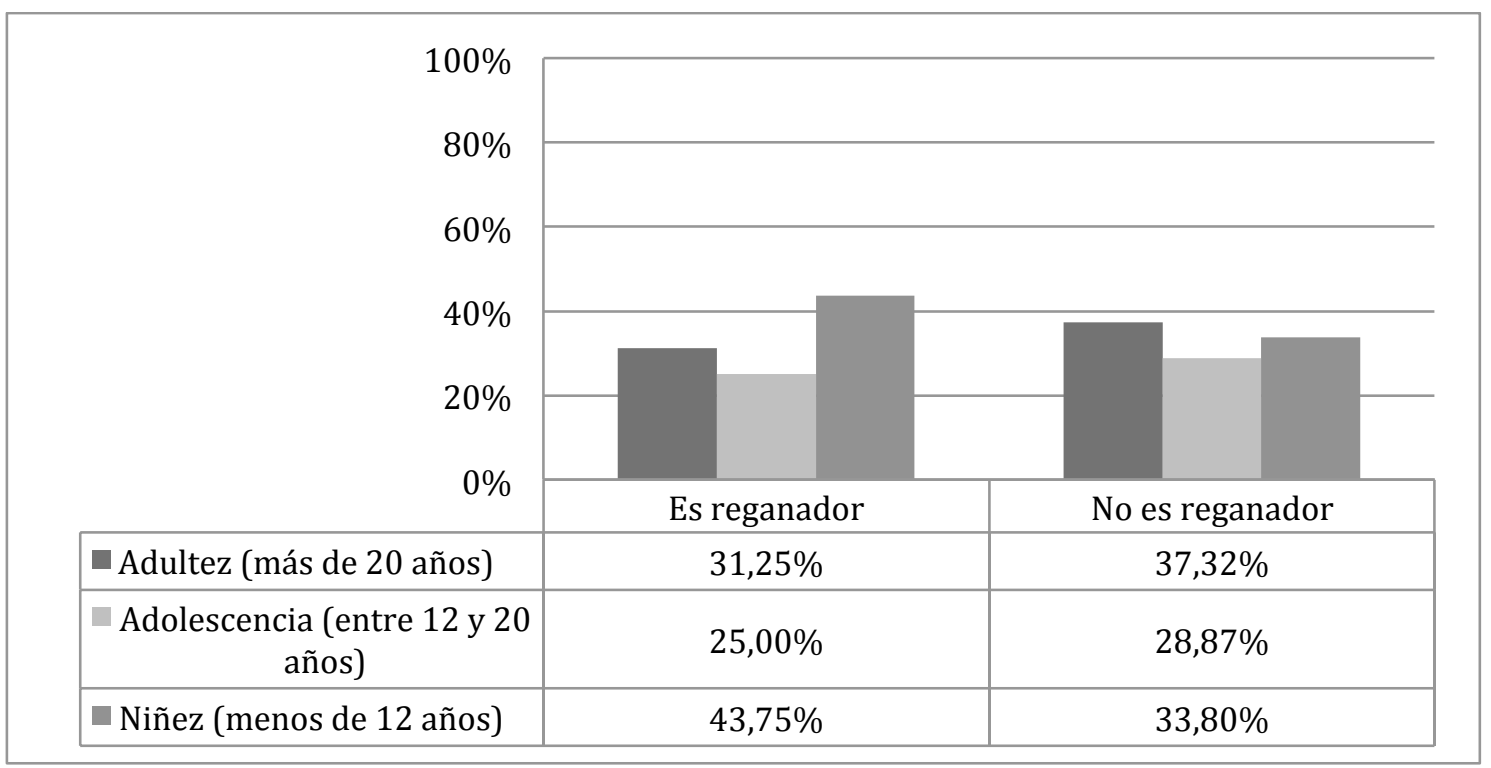

Al realizar una Prueba Chi cuadrado de comparación de distribuciones del momento del inicio del exceso de peso diferenciado por grupos se obtiene un p-valor de 0,268 . Convivir toda una vida con sobrepeso a presentarlo de edad adulta se creía que podía marcar una diferencia en la población estudiada, sin embargo el inicio del sobrepeso en la niñez, adolescencia y adultez no muestran diferencias significativas al momento de comparar entre grupos de reganadores y no reganadores de peso post cirugía bariátrica.

Al considerar la situación de convivencia de los pacientes con los que se realiza este trabajo, comparativamente entre grupos se obtienen los resultados que siguen.

Gráfico $N^{\circ}$ 24: Convivencia diferenciada por grupos $(n=254)$

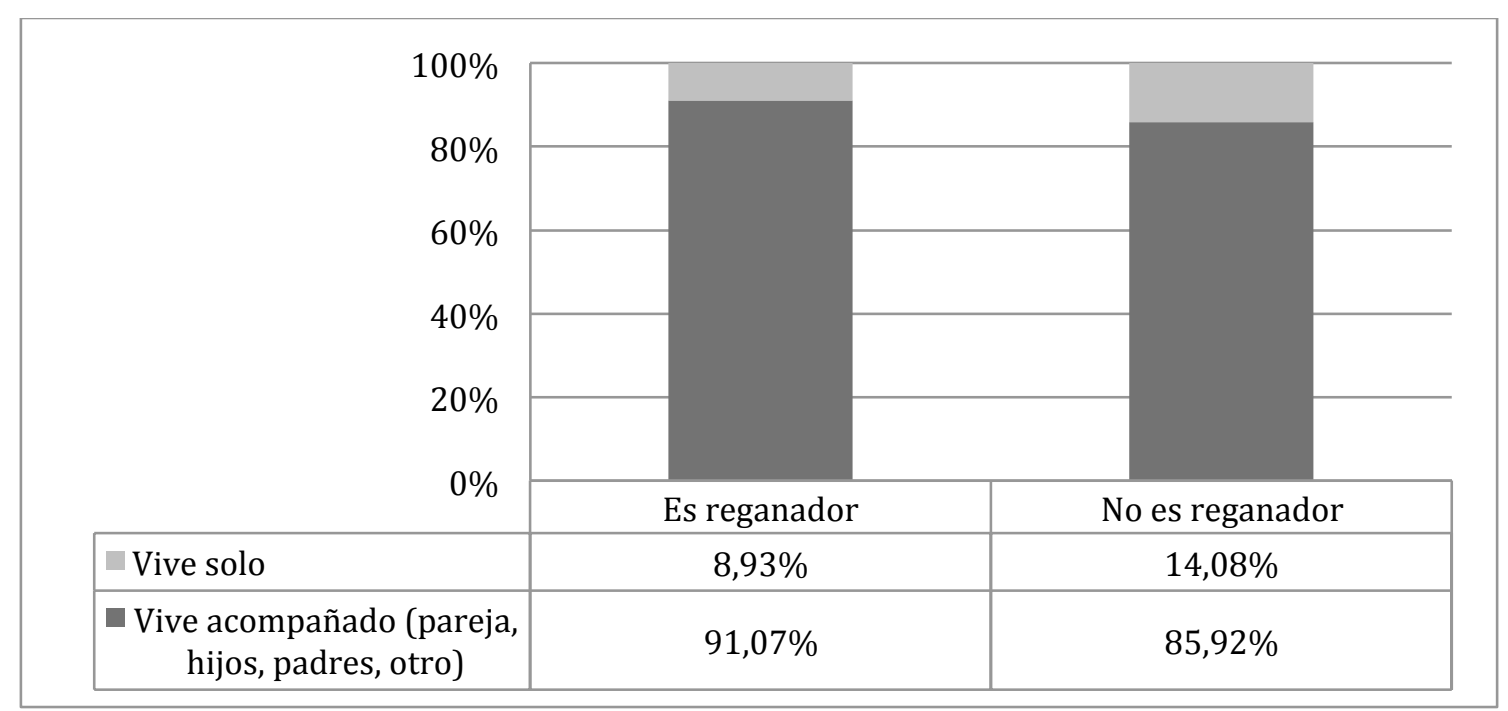


Al realizar una Prueba Chi cuadrada de comparación de distribuciones de la situación de convivencia diferenciado por grupos se obtiene un p-valor de 0,206. Aquellos sujetos que viven solos y los que lo hacen acompañados no muestran diferencia significativa para reganar o no peso según el criterio establecido para este trabajo.

Otra variable a considerar es el cumplimiento o no del objetivo de descenso de peso preoperatorio. Al realizar el análisis comparativo por grupos se obtienen los resultados que a continuación se presentan.

Gráfico $\mathbf{N}^{\circ}$ 25: Objetivo de descenso de peso preoperatorio diferenciado por grupos $(n=254)$

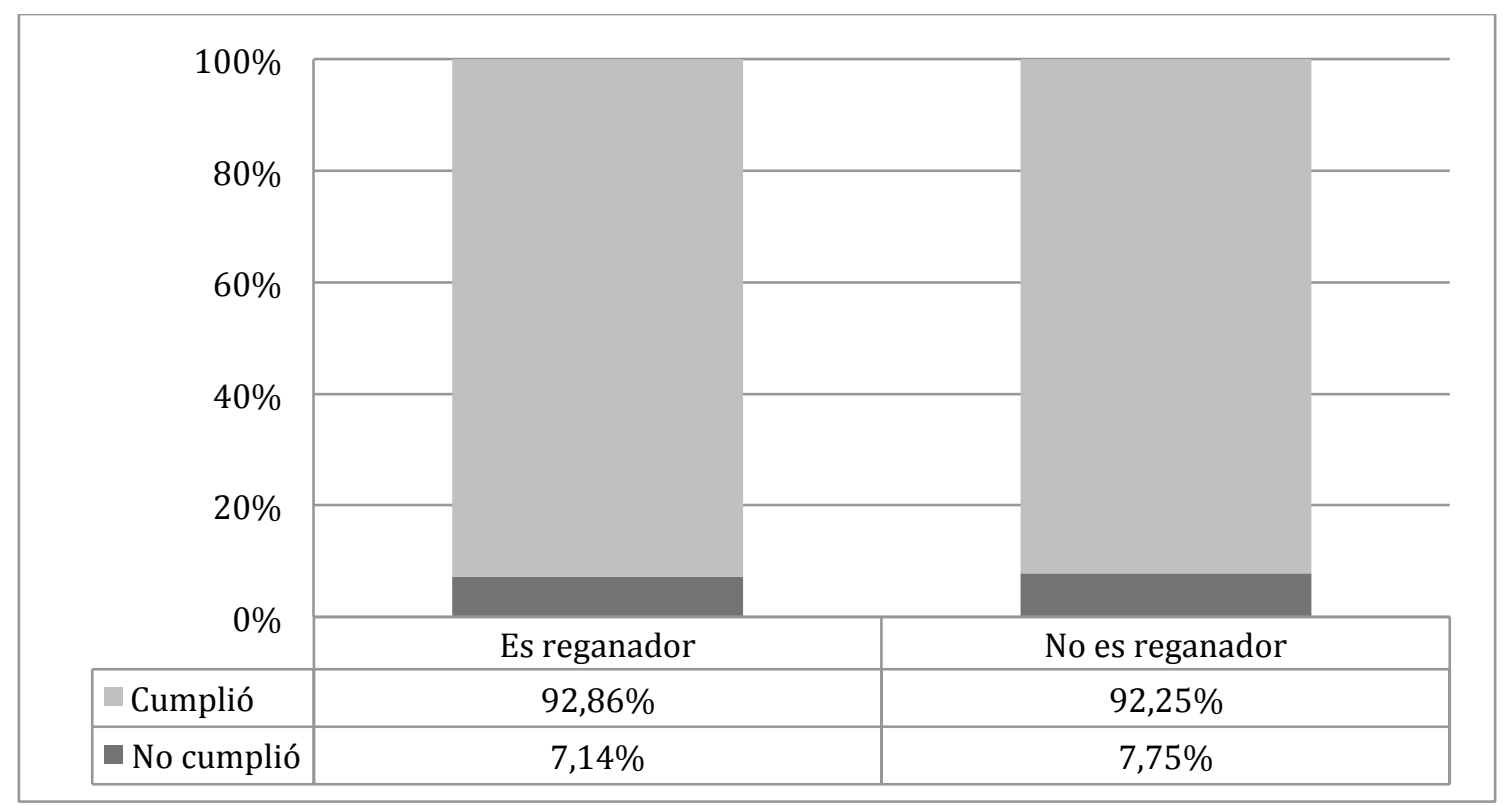

Al realizar una Prueba Chi cuadrada de comparación de distribuciones del cumplimiento del objetivo de descenso de peso preoperatorio diferenciado por grupos se obtiene un p-valor de 0,856. Bajar de peso previo a la cirugía es una recomendación que realizan la mayoría de los centros quirúrgicos y la amplia mayoría de los pacientes cumplimentaron con este requerimiento, sin embargo no existen diferencias significativas en la clasificación posterior respecto de la reganancia o no de peso posoperatorio.

Respecto de la frecuencia de las instancias de control de peso, al analizar comparativamente ente reganadores y no reganadores se obtienen los siguientes resultados. 
Gráfico $\mathbf{N}^{\circ}$ 26: Control de peso (frecuencia) diferenciado por grupos $(n=254)$

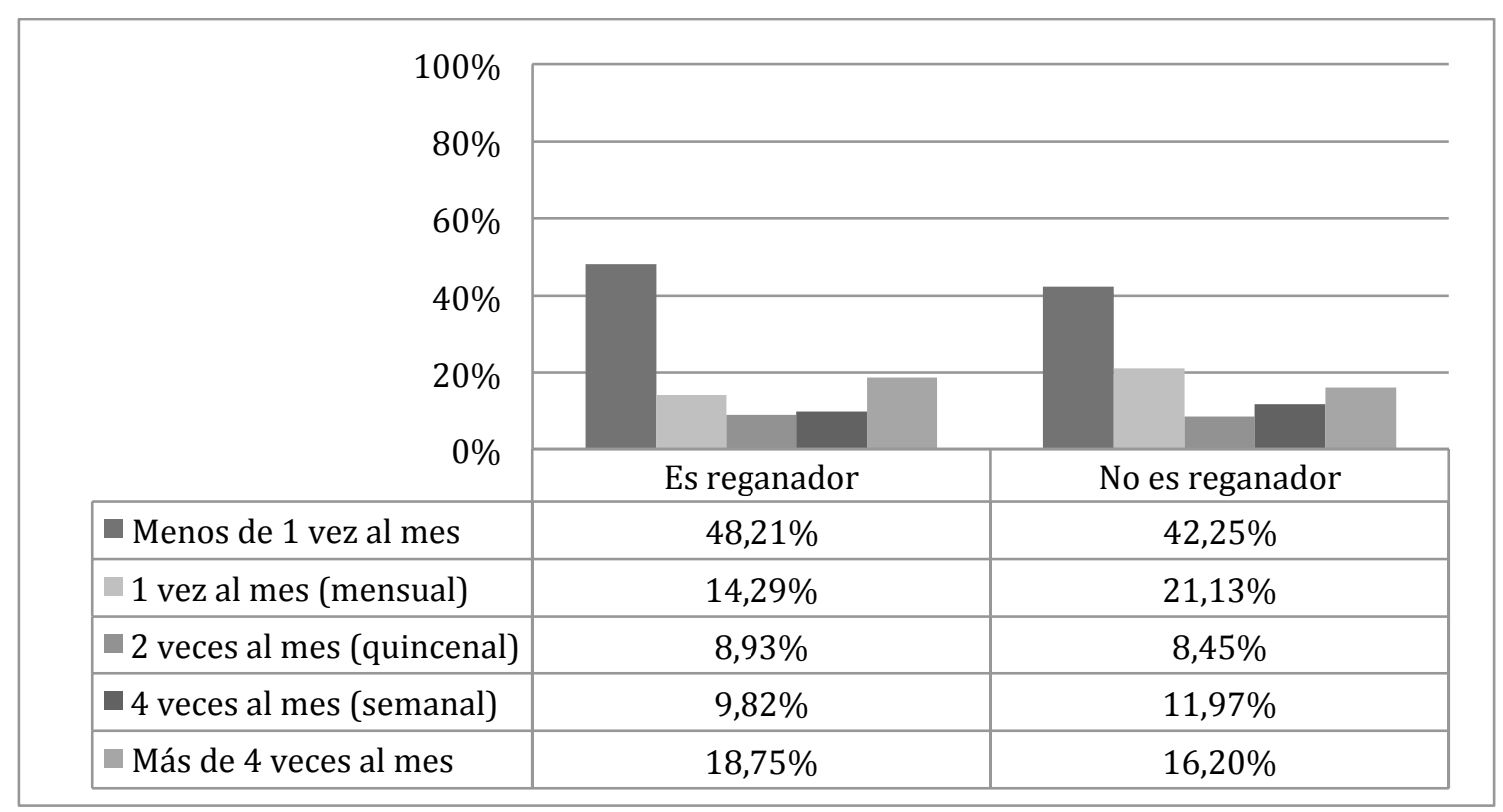

Al realizar una Prueba Chi cuadrada de comparación de distribuciones de las frecuencias de control de peso diferenciado por grupos se obtiene un p-valor de 0,622. Resulta razonable considerar que el paciente con mayores frecuencias de control de peso podría mantener mejor su peso post cirugía. Sin embargo, no se encuentran diferencias estadísticamente significativas entre aquellos pacientes clasificados como reganadores o no reganadores de peso, respecto de si se pesan más de una vez por semana, semanalmente, quincenalmente, mensualmente o menos de una vez por mes.

Al observar con mayor profundidad el proceso de control de peso, se analiza comparativamente quién se encarga de este proceso, considerando como opciones un profesional, el propio paciente o ambos. 
Gráfico $\mathbf{N}^{\circ}$ 27: Control de peso (controlador) comparativo por grupos $(\mathrm{n}=254)$

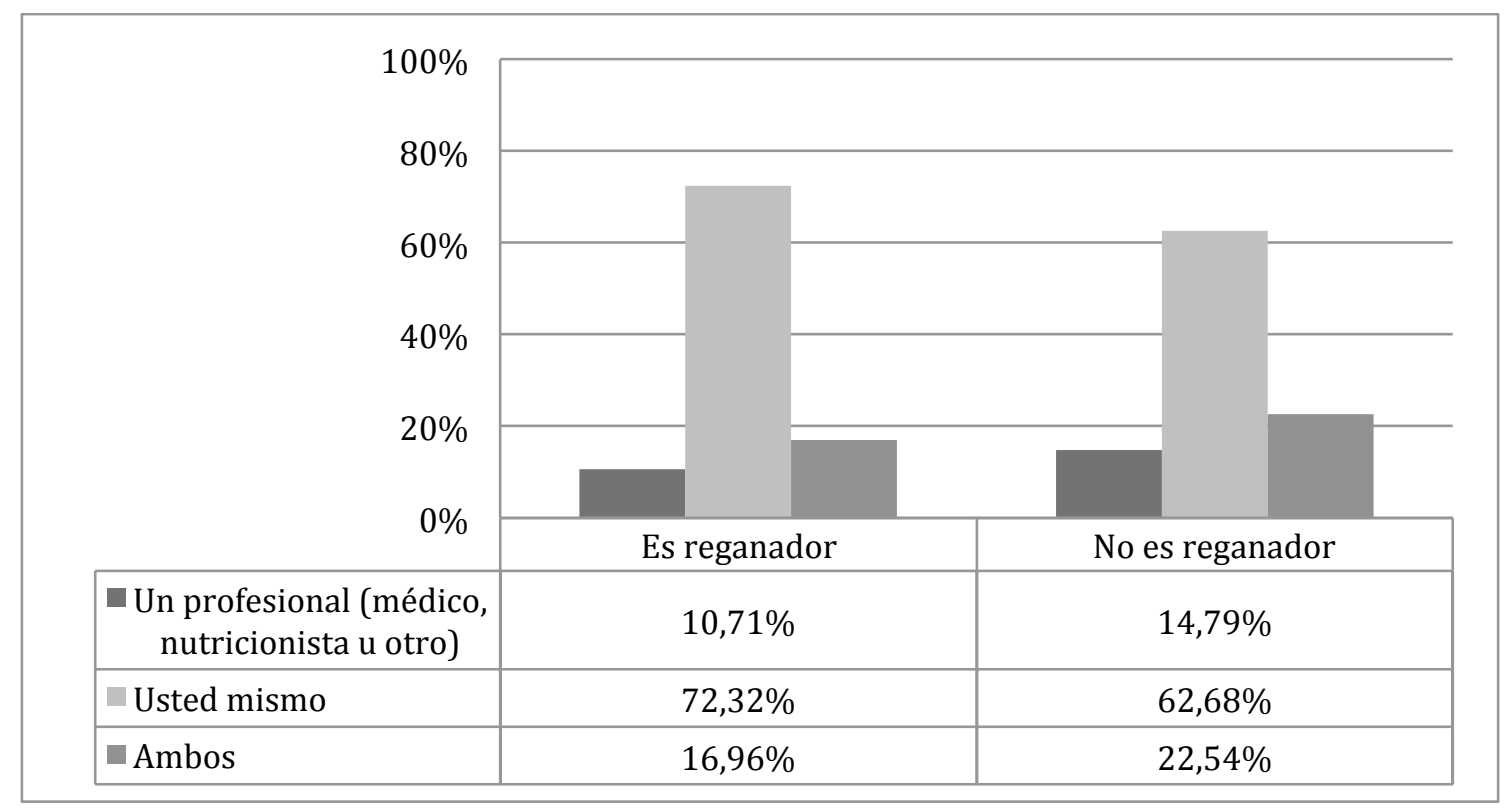

Al realizar una Prueba Chi cuadrada de comparación de distribuciones del responsable del control de peso diferenciado por grupos se obtiene un p-valor de 0,267 . Nuevamente se observan similares distribuciones en ambos grupos, y como resultado de la prueba de comparación obtenemos que no existen diferencias significativas en la distribución del o los responsables del proceso de control de peso, respecto de si son o no reganadores de peso.

Otro aspecto que resulta importante de analizar y comparar es la frecuencia de consulta con un profesional de la nutrición. Los resultados obtenidos se presentan a continuación. 
Gráfico $\mathbf{N}^{\circ}$ 28: Consulta al nutricionista (frecuencia) comparativo por grupos $(\mathrm{n}=254)$

\begin{tabular}{|c|c|c|}
\hline \multicolumn{3}{|l|}{$100 \%$} \\
\hline \multicolumn{3}{|l|}{$80 \%$} \\
\hline \multicolumn{3}{|l|}{$60 \%$} \\
\hline \multicolumn{3}{|l|}{$40 \%$} \\
\hline $20 \%$ & & \\
\hline & Es reganador & No es reganador \\
\hline Sin control & $74,11 \%$ & $52,82 \%$ \\
\hline Anual & $10,71 \%$ & $21,83 \%$ \\
\hline Semestral & $6,25 \%$ & $13,38 \%$ \\
\hline Trimestral & $6,25 \%$ & $4,93 \%$ \\
\hline Mensual & $2,68 \%$ & $7,04 \%$ \\
\hline
\end{tabular}

Al realizar una Prueba Chi cuadrada de comparación de distribuciones de la frecuencia de visita al nutricionista diferenciado por grupos se obtiene un p-valor de 0,005. Si bien la mayoría en ambos grupos se encuentra sin control nutricional, resulta muy grato conocer la importancia del rol del profesional nutricionista en el mantenimiento de peso de nuestros pacientes. Este estudio ha demostrado que existe diferencia significativa entre aquellos sujetos que son controlados por un nutricionista o médico nutricionista, ya sea una vez por año, dos veces por año, trimestralmente o mensualmente con respecto a aquellos sujetos que no tienen control de peso. Tener un seguimiento nutricional favorece la menor prevalencia de reganancia de peso post cirugía bariátrica.

Ahondando en los procesos vinculados con el control y apoyo de profesionales, se indaga sobre la concurrencia a grupos de apoyos con nutricionistas, médicos o psicólogos durante el primer año luego de la cirugía. El análisis comparativo entre los reganadores y no reganadores se presenta a continuación. 
Gráfico $\mathbf{N}^{\circ}$ 29: Concurrencia a grupos de apoyo con nutricionistas, médicos o psicólogos durante el primer año después de operado, comparativo por grupos $(n=254)$

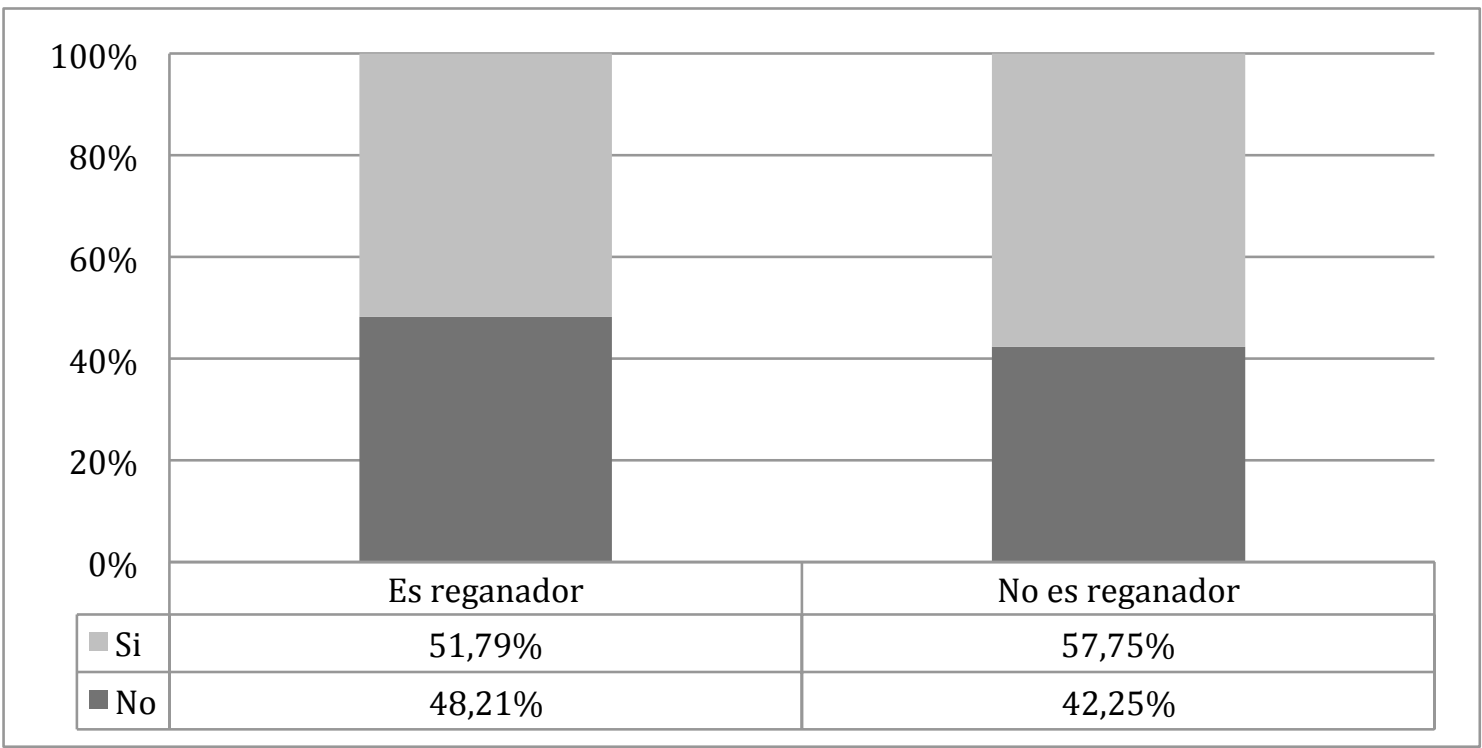

No existe diferencia significativa entre pacientes reganadores y no reganadores de peso por el hecho de concurrir o no a un grupo de apoyo durante el primer año post quirúrgico.

Al realizar una Prueba Chi cuadrada de comparación de distribuciones de la concurrencia a grupos de apoyo durante el primer año luego de la cirugía diferenciado por grupos se obtiene un p-valor de 0,310. No existe diferencia significativa entre pacientes reganadores y no reganadores de peso por el hecho de concurrir o no a un grupo de apoyo durante el primer año post quirúrgico. 
Gráfico No 30: Concurrencia actual a grupos de apoyo, comparativo por grupos $(n=254)$

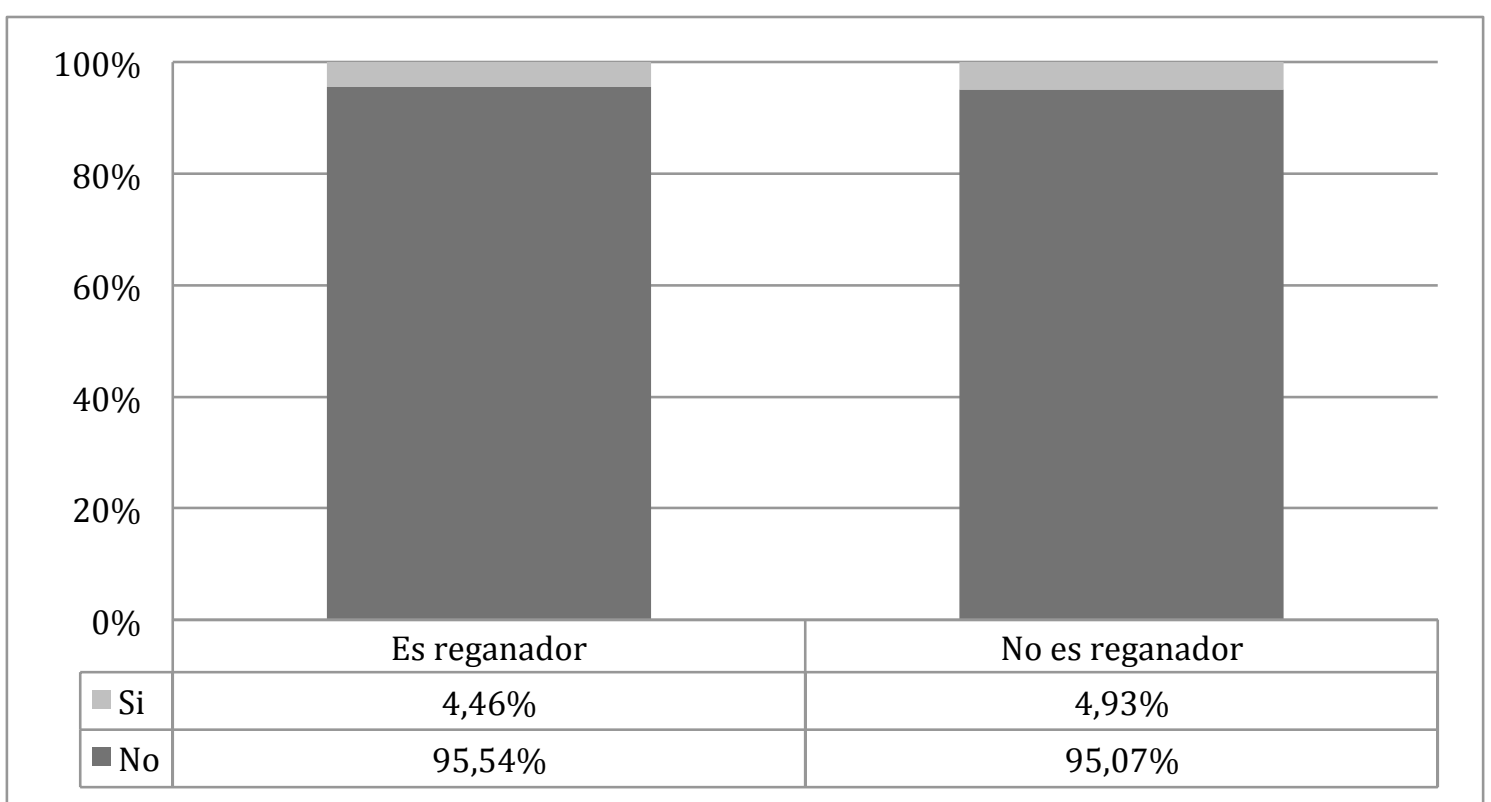

Al realizar una Prueba Chi cuadrada de comparación de distribuciones de la concurrencia actual a grupos de apoyo luego de la cirugía diferenciado por grupos se obtiene un p-valor de 0,862. Casi la totalidad de los encuestados no participa actualmente de grupos de apoyo. Consecuentemente con esto no existe diferencia significativa entre aquellos que concurren o no a estos grupos actualmente entre reganadores y no reganadores de peso.

En la siguiente sección se realizará el análisis comparativo entre grupos de reganadores y no reganadores de los hábitos alimentarios. Inicialmente se considerarán tanto las cuatro comidas principales como las colaciones.

Gráfico $\mathbf{N}^{\circ}$ 31: Desayuno diferenciado por grupos $(n=254)$

\begin{tabular}{|c|c|c|}
\hline \multicolumn{3}{|l|}{$100 \%$} \\
\hline \multicolumn{3}{|l|}{$80 \%$} \\
\hline \multicolumn{3}{|l|}{$60 \%$} \\
\hline $40 \%$ & & \\
\hline $20 \%$ & & \\
\hline $0 \%$ & Es reganador & No es reganador \\
\hline Menos de 1 vez por semana & $4,46 \%$ & $0,70 \%$ \\
\hline$\square 1$ o 2 veces por semana & $2,68 \%$ & $1,41 \%$ \\
\hline - 3 o 4 veces por semana & $4,46 \%$ & $3,52 \%$ \\
\hline$\square$ o 6 veces por semana & $1,79 \%$ & $1,41 \%$ \\
\hline$\square$ Todos los días & $86,61 \%$ & $92,96 \%$ \\
\hline
\end{tabular}


Al realizar una Prueba Chi cuadrada de comparación de distribuciones de la frecuencia de realización del desayuno diferenciada por grupos se obtiene un $p$-valor de 0,315. La amplia mayoría en ambos grupos manifiesta realizar el desayuno todos los días de la semana. Al analizar comparativamente estos grupos se encuentra que no existe diferencia significativa entre los mismos.

Gráfico $N^{\circ}$ 32: Almuerzo diferenciado por grupos $(n=254)$

\begin{tabular}{|c|c|c|}
\hline \multicolumn{3}{|l|}{$100 \%$} \\
\hline \multicolumn{3}{|l|}{$80 \%$} \\
\hline $60 \%$ & & \\
\hline $40 \%$ & & \\
\hline & & \\
\hline $0 \%$ & Es reganador & No es reganador \\
\hline Menos de 1 vez por semana & $7,14 \%$ & $0,00 \%$ \\
\hline 1 o 2 veces por semana & $1,79 \%$ & $0,70 \%$ \\
\hline 3 o 4 veces por semana & $5,36 \%$ & $4,93 \%$ \\
\hline 5 o 6 veces por semana & $9,82 \%$ & $4,23 \%$ \\
\hline Todos los días & $75,89 \%$ & $90,14 \%$ \\
\hline
\end{tabular}

Al realizar una Prueba Chi cuadrada de comparación de distribuciones de la frecuencia de realización del almuerzo diferenciada por grupos se obtiene un p-valor de 0,004 . A partir de los datos presentados se observa que más del $90 \%$ de los no reganadores tienen el hábito de realizar el almuerzo todos los días de la semana, mientras que entre los reganadores este hábito y frecuencia deseable solo se presenta en algo más del $75 \%$. Al analizar ambos grupos comparativamente se encuentra que existen diferencias significativas en las frecuencias entre ambos grupos. 
Gráfico $\mathbf{N}^{\circ}$ 33: Merienda diferenciada por grupos $(\mathrm{n}=254)$

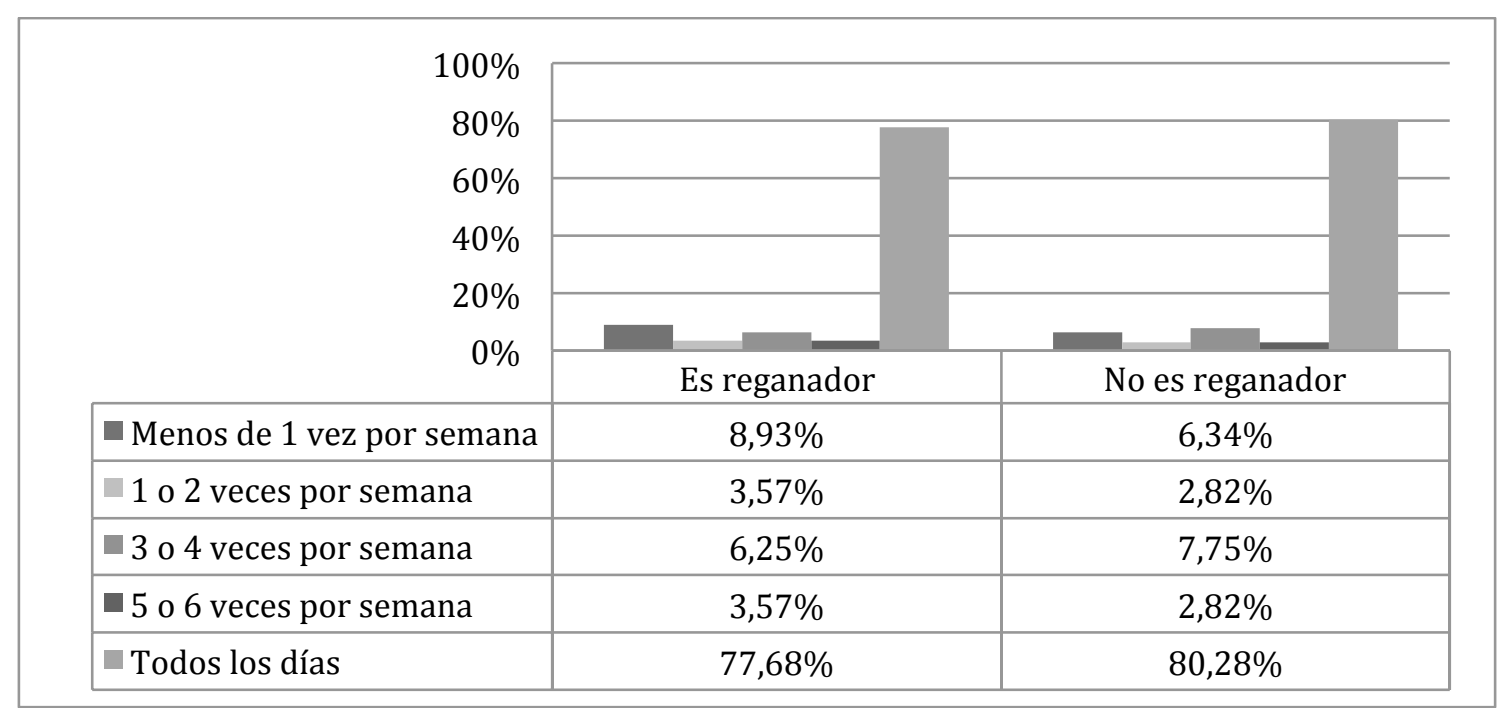

Al realizar una Prueba Chi cuadrada de comparación de distribuciones de la frecuencia de realización de la merienda diferenciada por grupos se obtiene un p-valor de 0,904 . Se observan similares distribuciones entre los reganadores y los no reganadores respecto de la frecuencia de realización de la merienda. No existe diferencia significativa entre estos grupos.

Gráfico $N^{\circ} 34$ : Cena diferenciada por grupos $(n=254)$

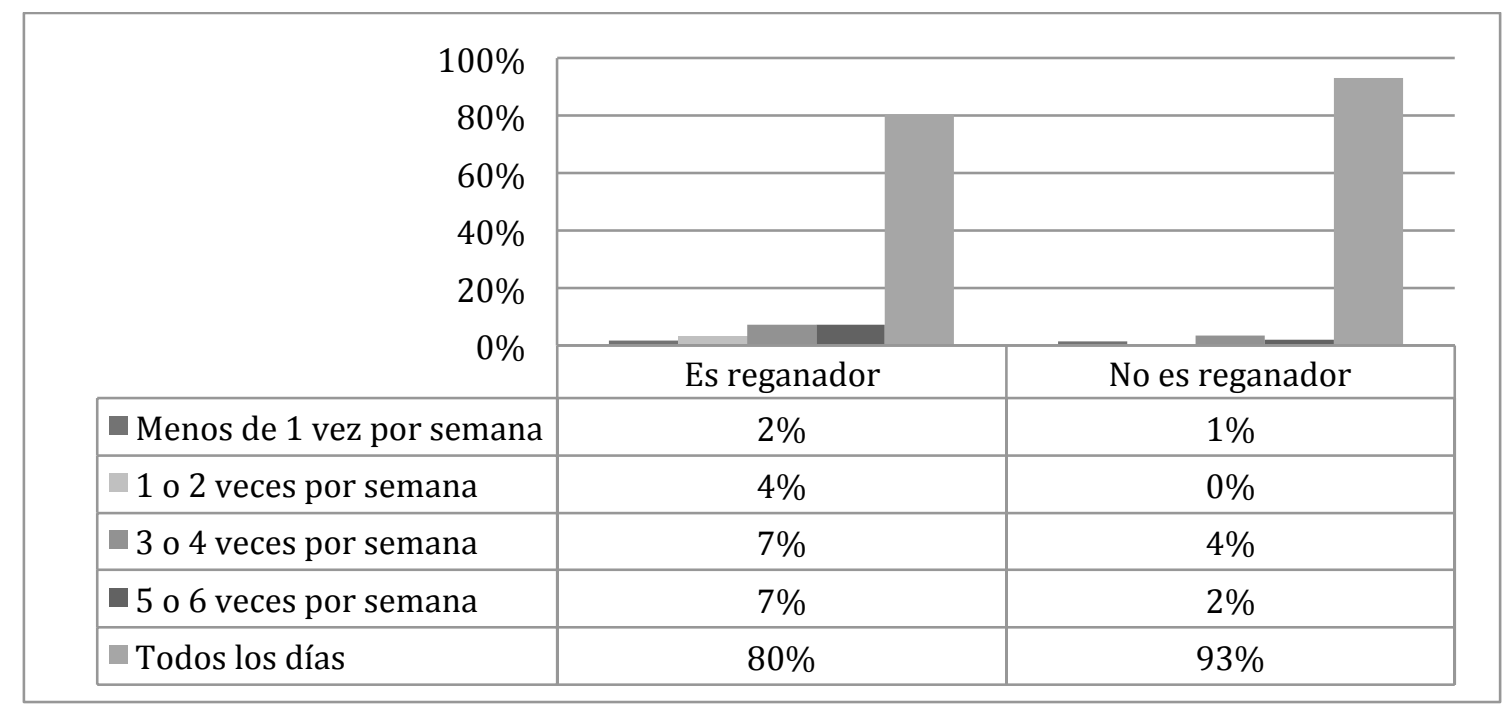

Al realizar una Prueba Chi cuadrada de comparación de distribuciones de la frecuencia de realización de la cena diferenciada por grupos se obtiene un p-valor de 0,021 . De los pacientes encuestados que no son reganadores de peso, el hábito de realizar la cena todos los días es referido por un $93 \%$, mientras que en los reganadores el porcentaje disminuye a un $80 \%$. Consecuentemente con esto existen diferencias significativas entre reganadores y no reganadores, respecto de la frecuencia de realización de la cena. 
Gráfico $N^{\circ}$ 35: Colación de media mañana diferenciado por grupos $(n=254)$

\begin{tabular}{|c|c|c|}
\hline \multicolumn{3}{|l|}{$100 \%$} \\
\hline \multicolumn{3}{|l|}{$80 \%$} \\
\hline \multicolumn{3}{|l|}{$60 \%$} \\
\hline \multirow{2}{*}{\multicolumn{3}{|c|}{$20 \%$}} \\
\hline & & \\
\hline $0 \%$ & Es reganador & No es reganador \\
\hline Menos de 1 vez por semana & $44,64 \%$ & $38,73 \%$ \\
\hline$\square 1$ o 2 veces por semana & $8,93 \%$ & $9,15 \%$ \\
\hline - 3 o 4 veces por semana & $8,93 \%$ & $10,56 \%$ \\
\hline 5 o 6 veces por semana & $5,36 \%$ & $6,34 \%$ \\
\hline Todos los días & $32,14 \%$ & $35,21 \%$ \\
\hline
\end{tabular}

Al realizar una Prueba Chi cuadrada de comparación de distribuciones de la frecuencia de realización de la colación de media mañana diferenciado por grupos se obtiene un p-valor de 0,913. Las distribuciones de realización de la colación de media mañana son muy similares entre los reganadores y los no reganadores. No existen diferencias significativas entre estas distribuciones en ambos grupos.

Gráfico $N^{\circ} 36$ : Colación de media tarde diferenciado por grupos $(n=254)$

\begin{tabular}{|c|c|c|}
\hline \multicolumn{3}{|l|}{$100 \%$} \\
\hline \multicolumn{3}{|l|}{$80 \%$} \\
\hline \multicolumn{3}{|l|}{$60 \%$} \\
\hline \multirow{2}{*}{\multicolumn{3}{|c|}{$20 \%$}} \\
\hline & & \\
\hline $0 \%$ & Es reganador & No es reganador \\
\hline Menos de 1 vez por semana & $51,79 \%$ & $44,37 \%$ \\
\hline$\square 1$ o 2 veces por semana & $6,25 \%$ & $5,63 \%$ \\
\hline - 3 o 4 veces por semana & $8,93 \%$ & $9,15 \%$ \\
\hline 5 o 6 veces por semana & $1,79 \%$ & $6,34 \%$ \\
\hline Todos los días & $31,25 \%$ & $34,51 \%$ \\
\hline
\end{tabular}

Al realizar una Prueba Chi cuadrada de comparación de distribuciones de la frecuencia de realización de la colación de media tarde diferenciado por grupos se obtiene un p-valor de 0,411. Nuevamente las distribuciones de frecuencias de consumo de las colaciones, en este caso de media tarde, son similares. No existen diferencias significativas entre los reganadores y los no reganadores respecto de la frecuencia de realización de las colaciones de media tarde. 
Gráfico $\mathbf{N}^{\circ}$ 37: Realización de ingestas a media noche diferenciado por grupos $(n=254)$

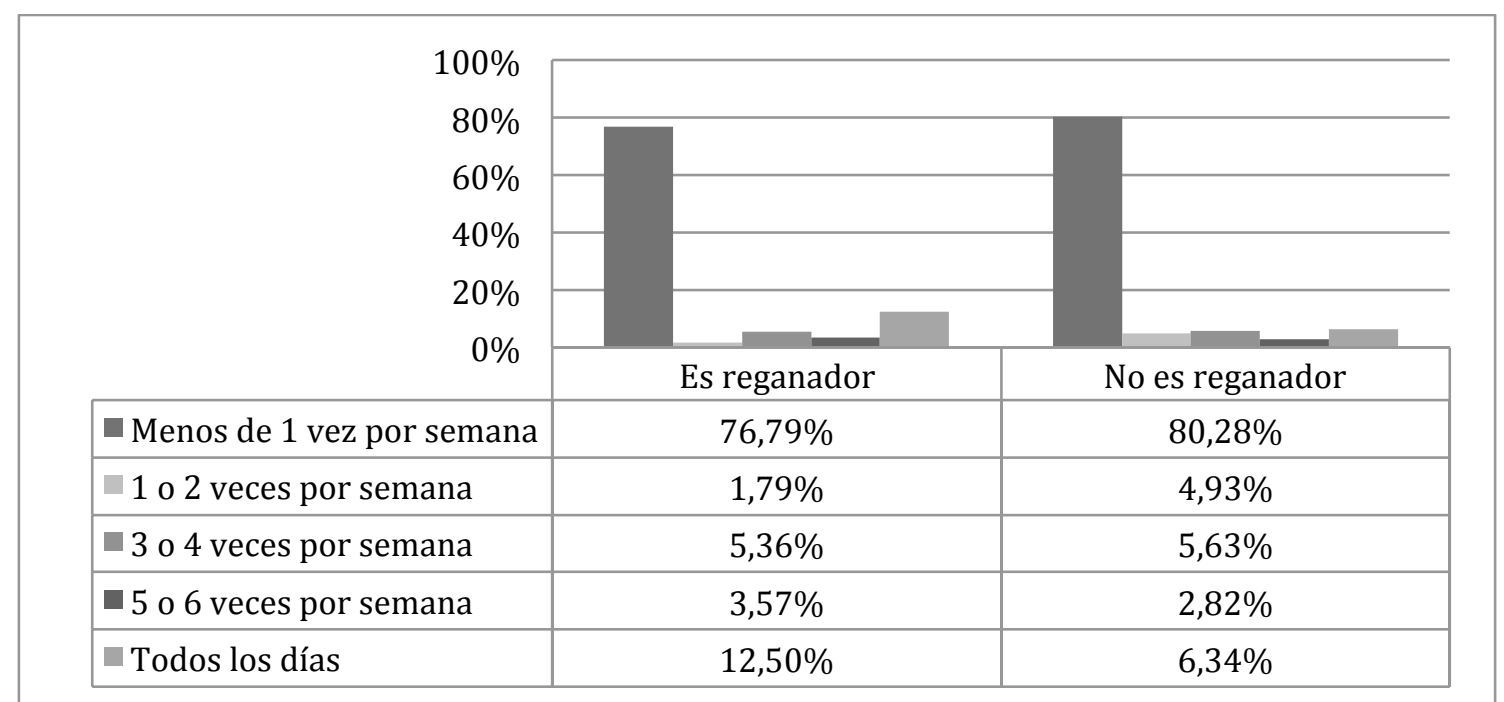

Al realizar una Prueba Chi cuadrada de comparación de distribuciones de la frecuencia de realización de ingestas a media noche diferenciado por grupos se obtiene un $p$-valor de 0,332 . No existe diferencia significativa entre reganadores y no reganadores de peso en cuanto a la frecuencia de ingestas a media noche.

Seguidamente se analizan otros hábitos, vinculados con la alimentación, pero no referidos a frecuencias de consumos sino a costumbres, características $u$ opiniones.

Gráfico $\mathbf{N}^{\circ}$ 38: ¿Su comida más importante o principal es antes de las $15 \mathrm{~h}$ ? $(n=254)$

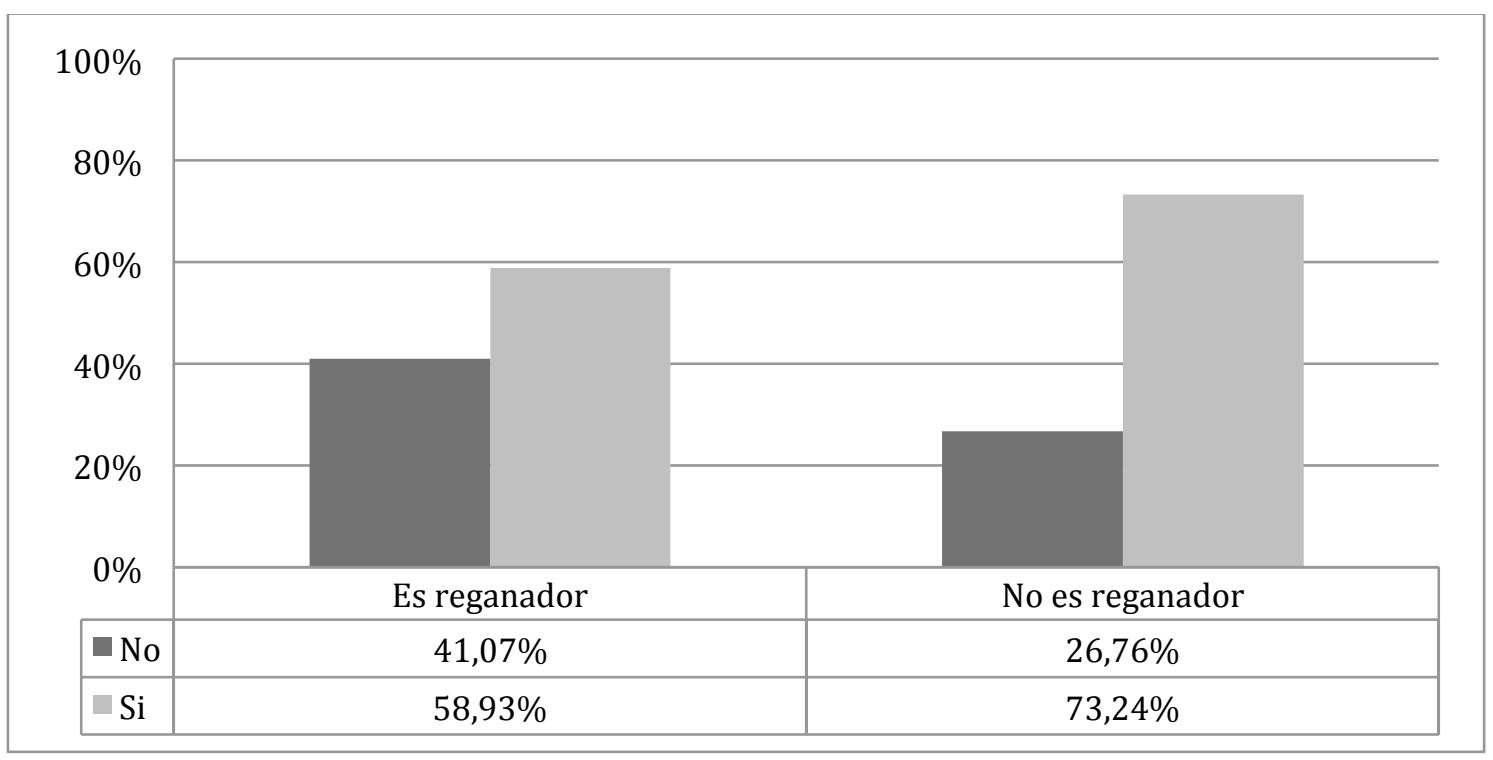

Al realizar una Prueba Chi cuadrada de comparación de distribuciones respecto de si la comida principal es antes de las $15 \mathrm{~h}$ diferenciado por grupos se obtiene un p-valor de 0,016. En función de los datos observamos que casi tres cuartas 
partes de los no reganadores realizan la comida principal antes de las $15 \mathrm{~h}$, mientras que entre los reganadores de peso esta característica la presenta menos de un $60 \%$. Existe evidencia de la importancia que tienen las primeras comidas del día en sujetos operados de cirugía bariátrica; estos sujetos pierden mayor peso que los comedores tardíos según un estudio de Hollanda et. al. (45)

A partir de estos resultados se indaga en la relación que tiene priorizar las primeras comidas del día. Los resultados muestran que existen diferencias significativas entre aquellos sujetos que su comida principal es antes de las $15 \mathrm{~h}$. con respecto a los que su comida principal es por la tarde o noche.

Gráfico N³9: ¿Cuál es su comida principal? $(n=254)$

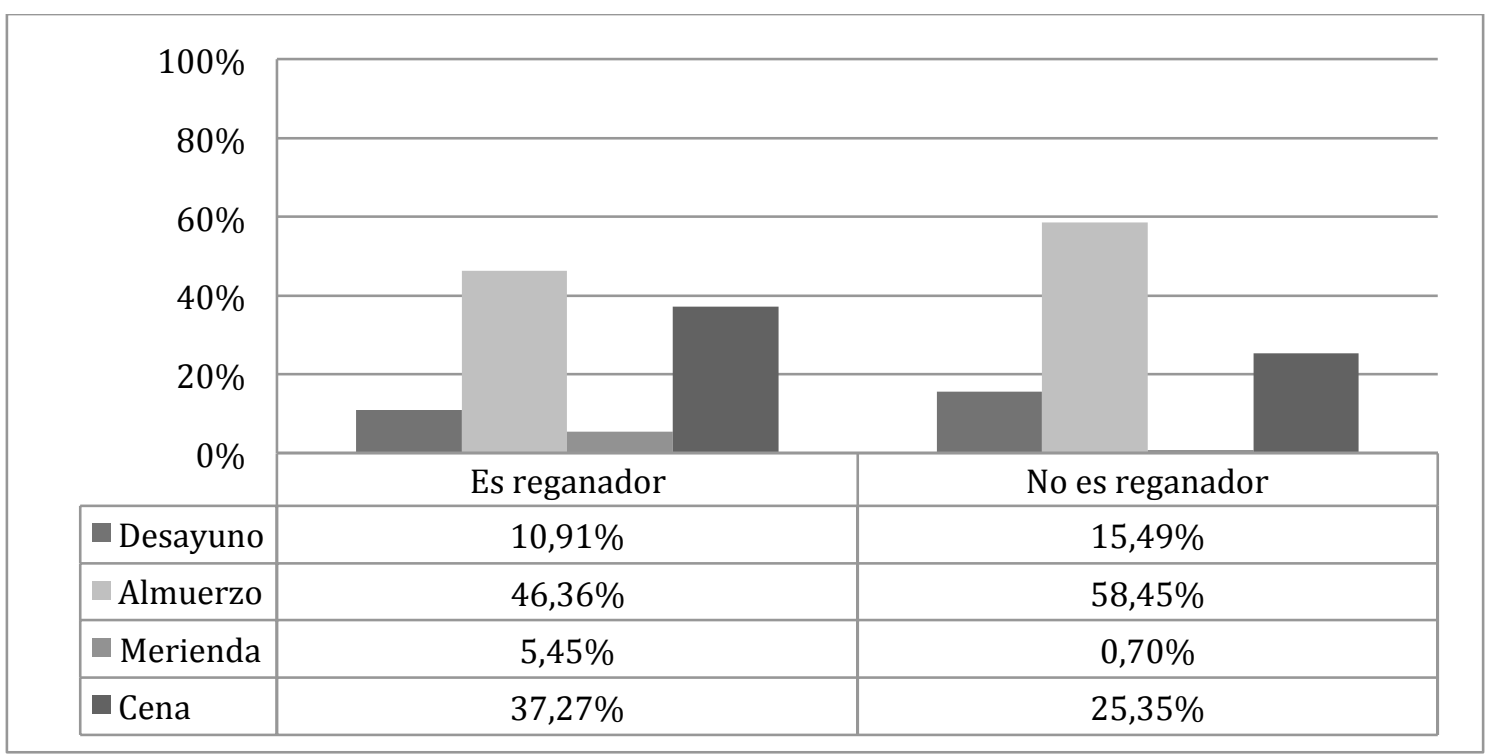

Al realizar una Prueba Chi cuadrada de comparación de distribuciones respecto de cuál es la comida principal diferenciado por grupos se obtiene un $p$-valor de 0,005 que indica la existencia de una diferencia estadísticamente significativa. Se observa que un $58,45 \%$ de los sujetos no reganadores tienen como comida principal el almuerzo, en cambio entre los reganadores este porcentaje disminuye a un 46,36\%.

En el mismo sentido se observan diferencias porcentuales respecto de quienes refieren al desayuno como principal comida, siendo también mayor el porcentaje entre los no reganadores. Tanto la merienda como la cena son referidas como comidas principales en mayor porcentaje entre los reganadores respecto de los no reganadores. 
Gráfico N 40: ¿Considera que lleva una alimentación saludable después de la cirugía? $(n=254)$

\begin{tabular}{|c|c|c|}
\hline \multicolumn{3}{|l|}{$100 \%$} \\
\hline \multicolumn{3}{|l|}{$80 \%$} \\
\hline \multicolumn{3}{|l|}{$60 \%$} \\
\hline \multicolumn{3}{|l|}{$40 \%$} \\
\hline \multicolumn{3}{|l|}{$20 \%$} \\
\hline $0 \%$ & Es reganador & No es reganador \\
\hline Nada saludable & $9,82 \%$ & $2,11 \%$ \\
\hline Poco saludable & $22,32 \%$ & $8,45 \%$ \\
\hline Algo saludable & $32,14 \%$ & $21,83 \%$ \\
\hline - Saludable & $29,46 \%$ & $52,11 \%$ \\
\hline Muy saludable & $6,25 \%$ & $15,49 \%$ \\
\hline
\end{tabular}

Al realizar una Prueba Chi cuadrada de comparación de distribuciones respecto de la opinión acerca de la propia dieta diferenciado por grupos se obtiene un $p$-valor de $<0,0001$. Las personas no reganadoras de peso post cirugía consideran que su alimentación es saludable o muy saludable en su mayoría, marcando una clara diferencia con respecto a los reganadores.

Gráfico $\mathbf{N}^{\circ}$ 41: ¿Picotea o realiza ingestas continuamente acompañadas de la sensación de pérdida de control con frecuencia? $(n=254)$

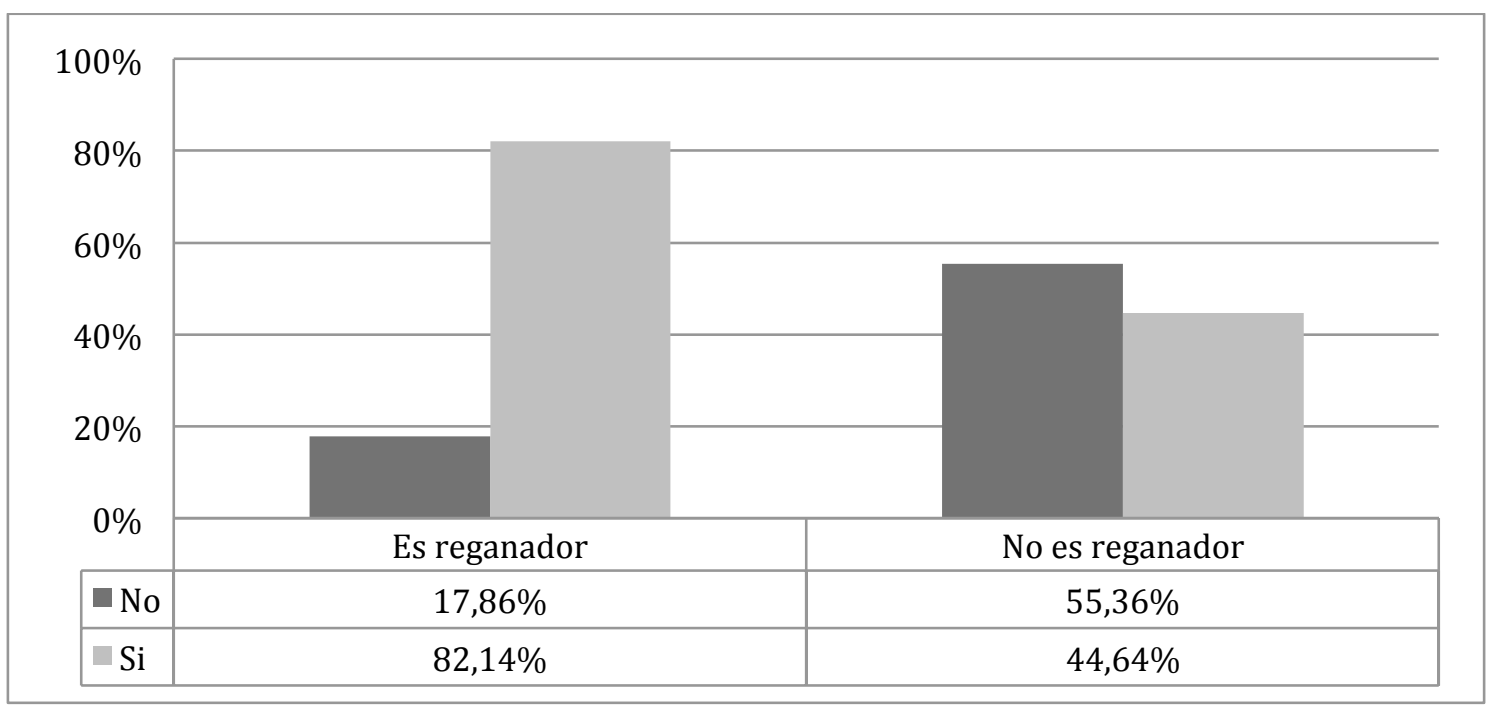

Al realizar una Prueba Chi cuadrada de comparación de distribuciones respecto del hábito de picotear entre comidas diferenciado por grupos se obtiene un $\mathrm{p}$ valor de $<0,0001$. Se encontró en este estudio una relación entre el picoteo y la reganancia de peso. Las personas no reganadoras de peso post cirugía tienen menor 
prevalencia de picoteo que los reganadores siendo esta diferencia estadísticamente significativa.

Para complementar este análisis se indaga sobre la frecuencia de realización de este hábito negativo.

Gráfico $\mathbf{N}^{\circ}$ 42: De quienes reconocieron hacer picoteo, ¿con qué frecuencia la realizan? $(n=172)$

\begin{tabular}{|c|c|c|}
\hline \multirow{2}{*}{$\begin{array}{c}100 \% \\
80 \%\end{array}$} & & \\
\hline & & \\
\hline \multicolumn{2}{|l|}{$60 \%$} & \\
\hline \multicolumn{3}{|l|}{$40 \%$} \\
\hline \multicolumn{3}{|l|}{$20 \%$} \\
\hline $0 \%$ & Es reganador & No es reganador \\
\hline Menos de 1 vez por semana & $3,26 \%$ & $6,25 \%$ \\
\hline 1 o 2 veces por semana & $4,35 \%$ & $20,00 \%$ \\
\hline - 3 o 4 veces por semana & $20,65 \%$ & $32,50 \%$ \\
\hline 5 o 6 veces por semana & $5,43 \%$ & $10,00 \%$ \\
\hline Todos los días & $66,30 \%$ & $31,25 \%$ \\
\hline
\end{tabular}

Se observa que, entre los reganadores de peso, la frecuencia de realización de picoteo entre comidas que presenta la mayoría de respuestas corresponde a todos los días, demostrando el impacto negativo que tiene este hábito.

Gráfico $N^{\circ}$ 43: ¿Hace atracones o considera que come más de lo que debería comer en un tiempo menor al debido con sensación de pérdida de control? $(n=254)$

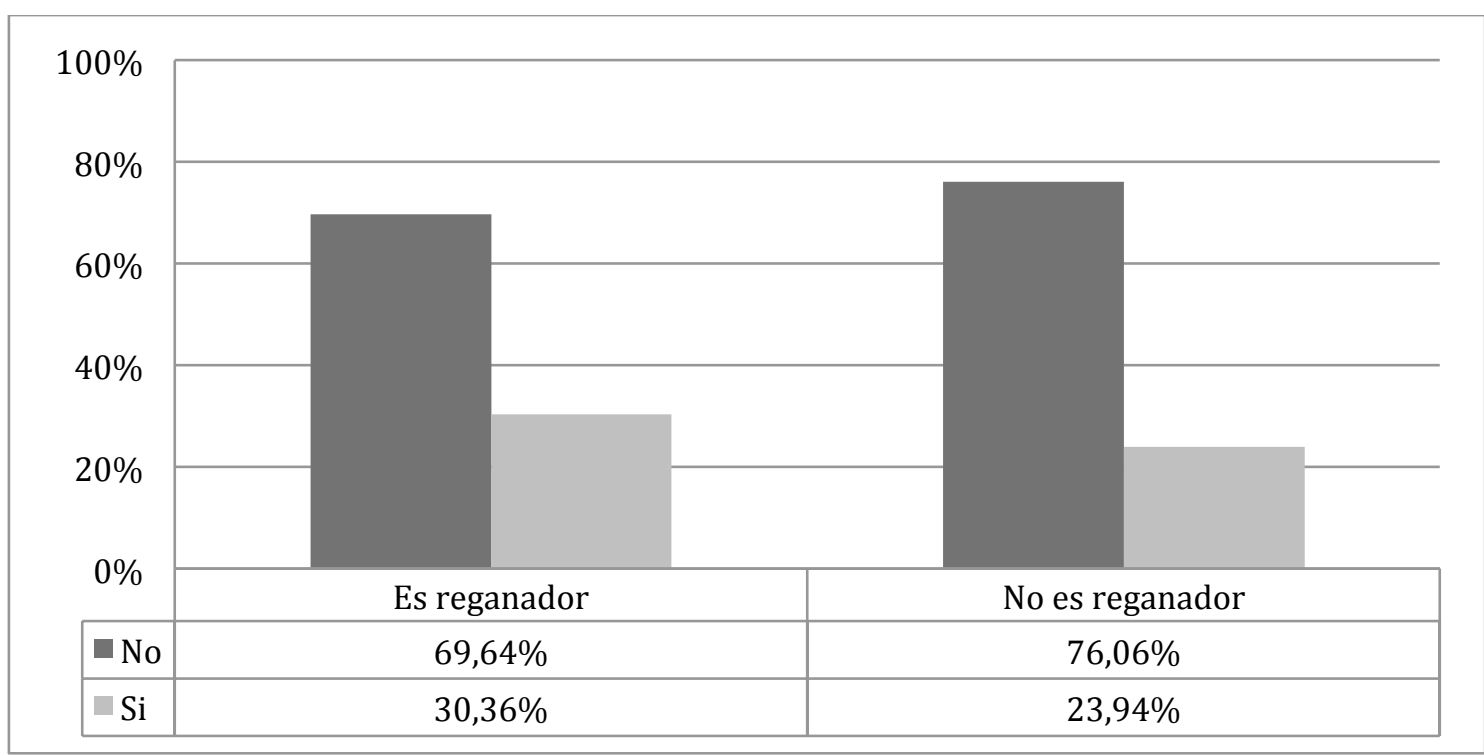


Al realizar una Prueba Chi cuadrada de comparación de distribuciones respecto de la realización de atracones o excesos en las comidas diferenciado por grupos se obtiene un $p$-valor de 0,252. Tal como era esperable la frecuencia de atracones post cirugía es mucho menor que el hábito de picoteo. No se encontró una diferencia estadísticamente significativa entre hacer o no atracones post cirugía bariátrica, y reganar o no peso.

Para complementar este análisis se indaga sobre la frecuencia de ocurrencia de atracones o excesos y la antigüedad que presenta esta situación.

Gráfico $\mathbf{N}^{\circ}$ 44: De quienes reconocieron hacen atracones, ¿con qué frecuencia la realizan? $(n=66)$

\begin{tabular}{|c|c|c|}
\hline \multicolumn{3}{|l|}{$100 \%$} \\
\hline \multicolumn{3}{|l|}{$80 \%$} \\
\hline \multicolumn{3}{|l|}{$60 \%$} \\
\hline \multirow{2}{*}{\multicolumn{3}{|c|}{$20 \%$}} \\
\hline & & \\
\hline $0 \%$ & Es reganador & No es reganador \\
\hline Menos de 1 vez por semana & $24,24 \%$ & $33,33 \%$ \\
\hline$\square 1$ o 2 veces por semana & $27,27 \%$ & $33,33 \%$ \\
\hline - 3 o 4 veces por semana & $21,21 \%$ & $21,21 \%$ \\
\hline - 5 o 6 veces por semana & $6,06 \%$ & $3,03 \%$ \\
\hline Todos los días & $21,21 \%$ & $9,09 \%$ \\
\hline
\end{tabular}

Gráfico $N^{\circ}$ 45: Si tiene atracones, ¿son desde hace más de 3 meses? $(n=66)$

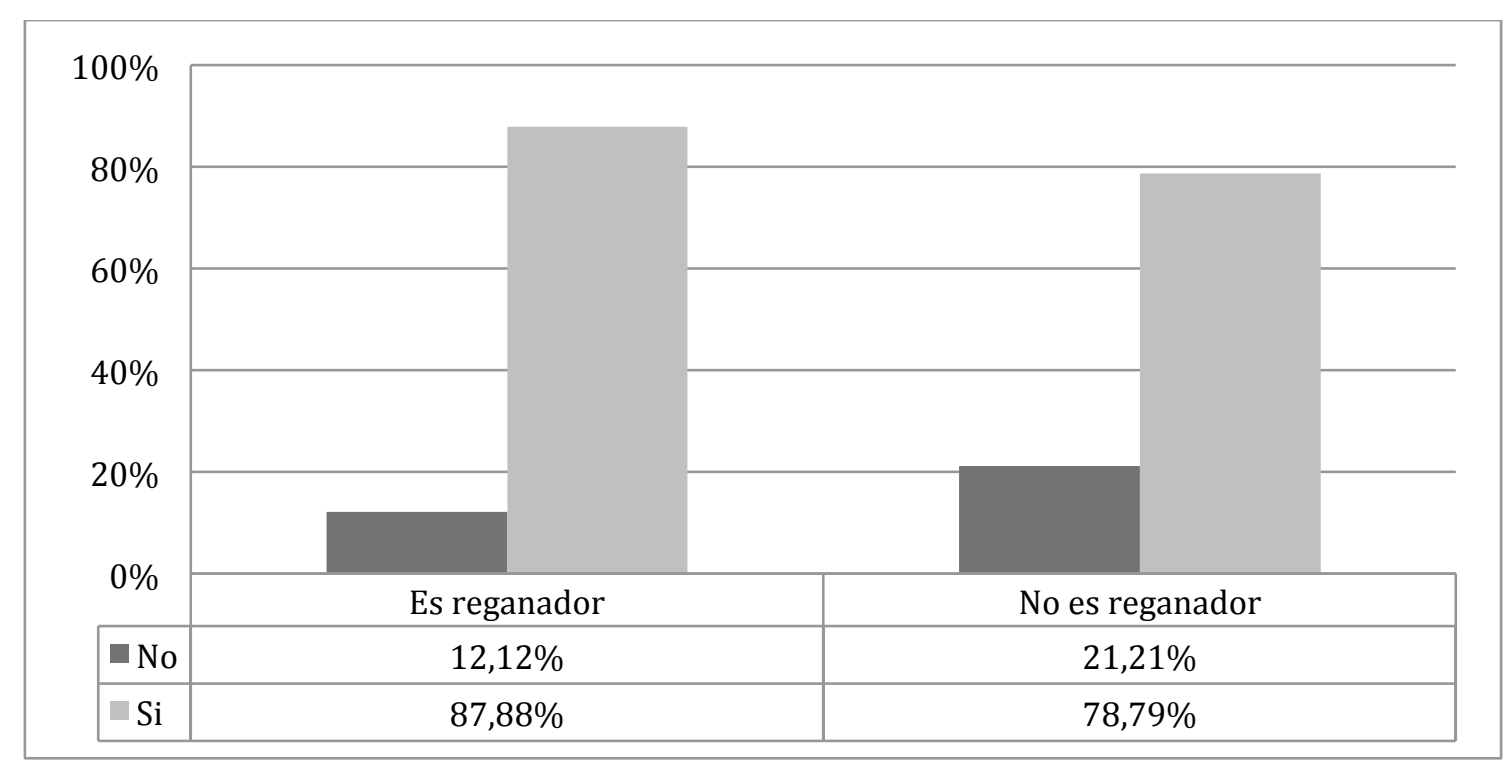


No se observan resultados notoriamente diferentes respecto de la frecuencia y antigüedad de realización de atracones entre ambos grupos.

Gráfico $\mathbf{N}^{\circ}$ 46: Siente que come en respuesta a... $(n=254)$

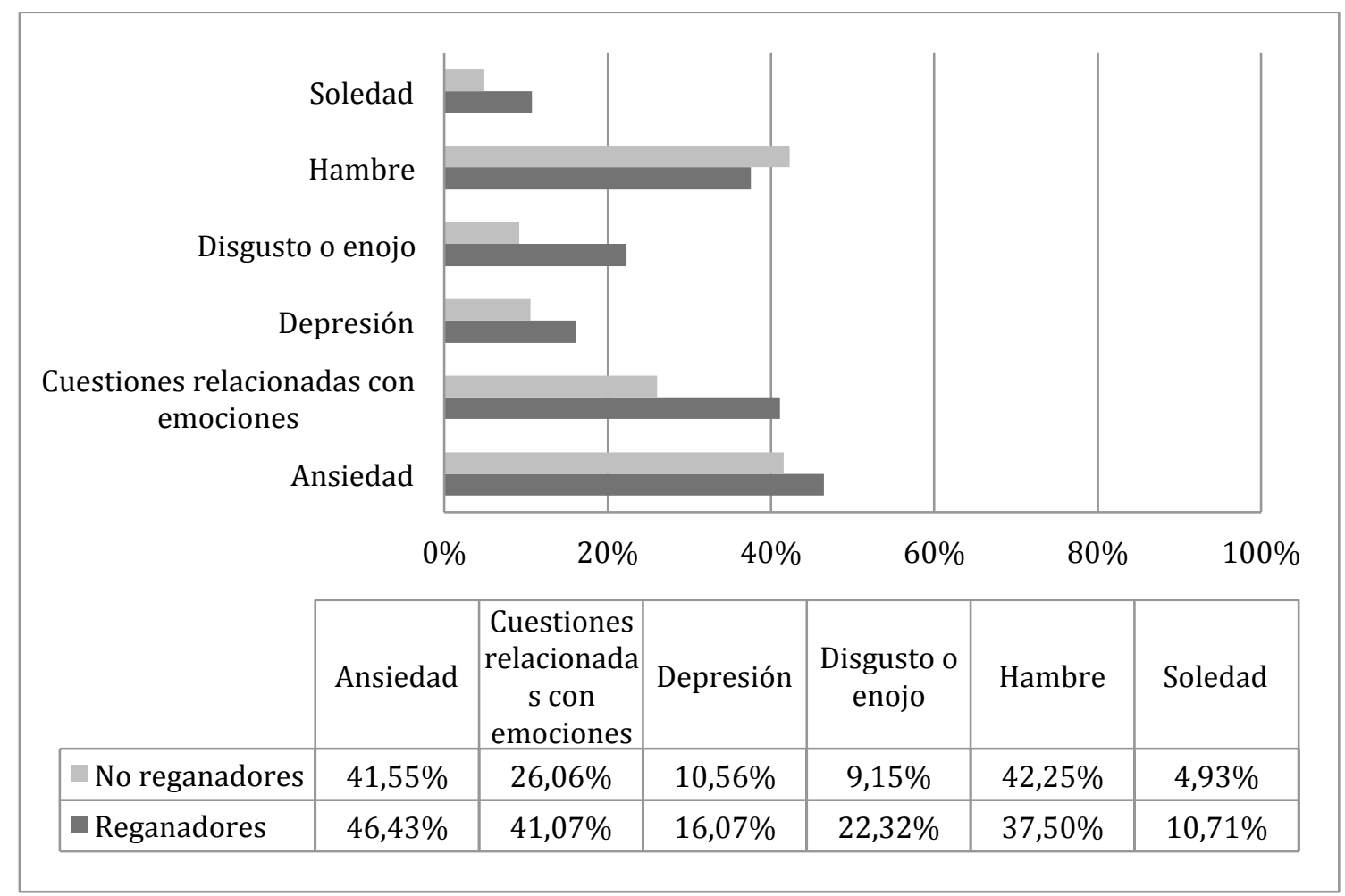

Para ambos grupos las respuestas que presentan mayores porcentajes corresponden a la referencia de que comen en respuesta a ansiedad, cuestiones relacionadas con emociones y hambre. 
Gráfico N 47: ¿Cuántas veces por día consume alimentos ricos en azúcar como golosinas, facturas, helados, tortas, galletitas dulces, etc.? $(n=254)$

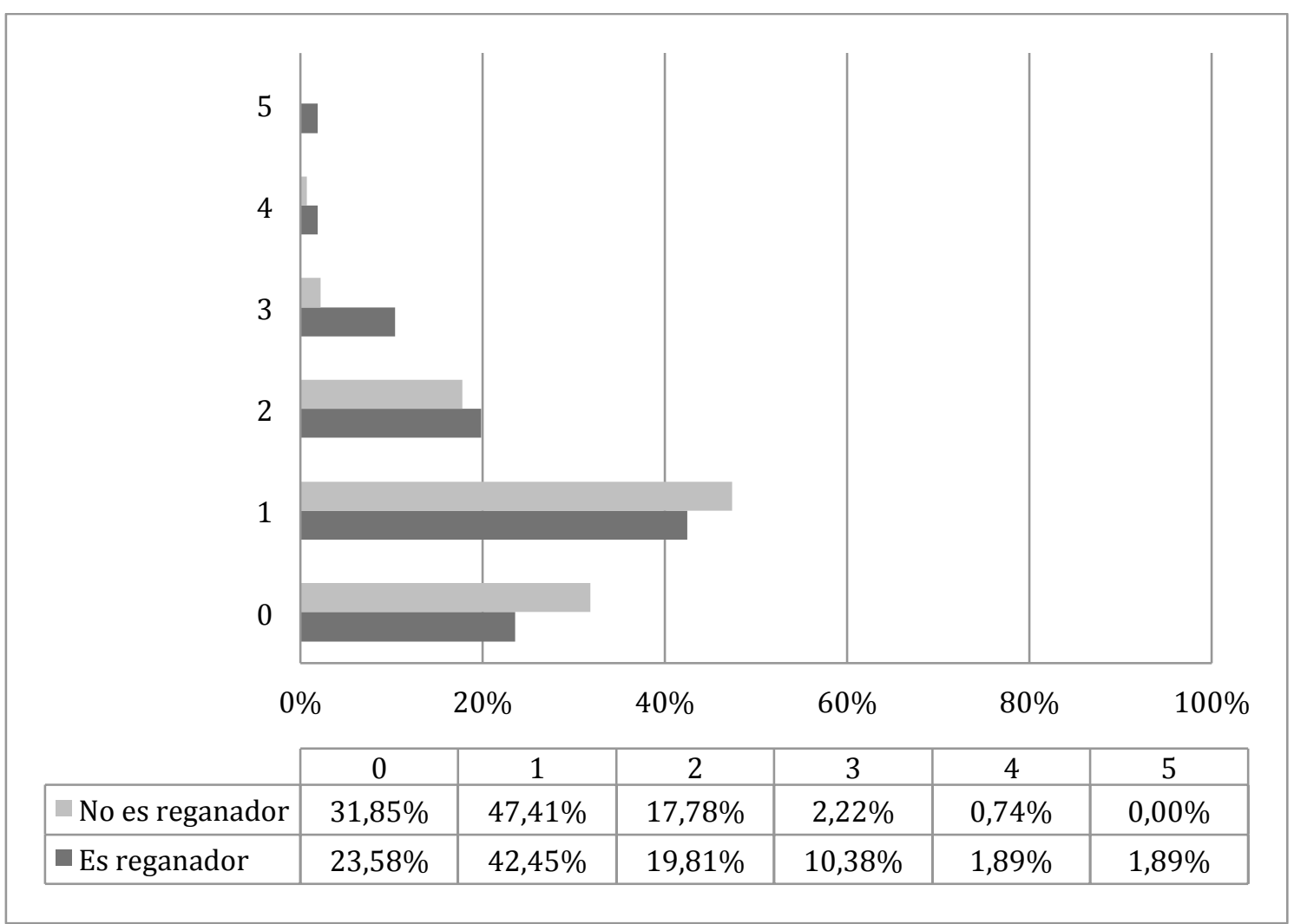

Al realizar una Prueba Chi cuadrada de comparación de distribuciones respecto de la frecuencia diaria de consumo de alimentos ricos en azúcar diferenciado por grupos se obtiene un p-valor de 0,037.

Las frecuencias que indican una ausencia de consumo de azúcares o un consumo de una vez por día presentan mayores porcentajes entre los no reganadores respecto de los reganadores. En las frecuencias mayores a una vez por día se presentan mayores porcentajes entre los reganadores. Esto confirma que los sujetos reganadores consumen con frecuencia mayor a diaria, alimentos dulces que los no reganadores, siendo esta diferencia estadísticamente significativa. 
Gráfico N 48: ¿Siente mucho apetito por las noches, dificultad para dormir y se despierta para comer por las noches? $(n=254)$

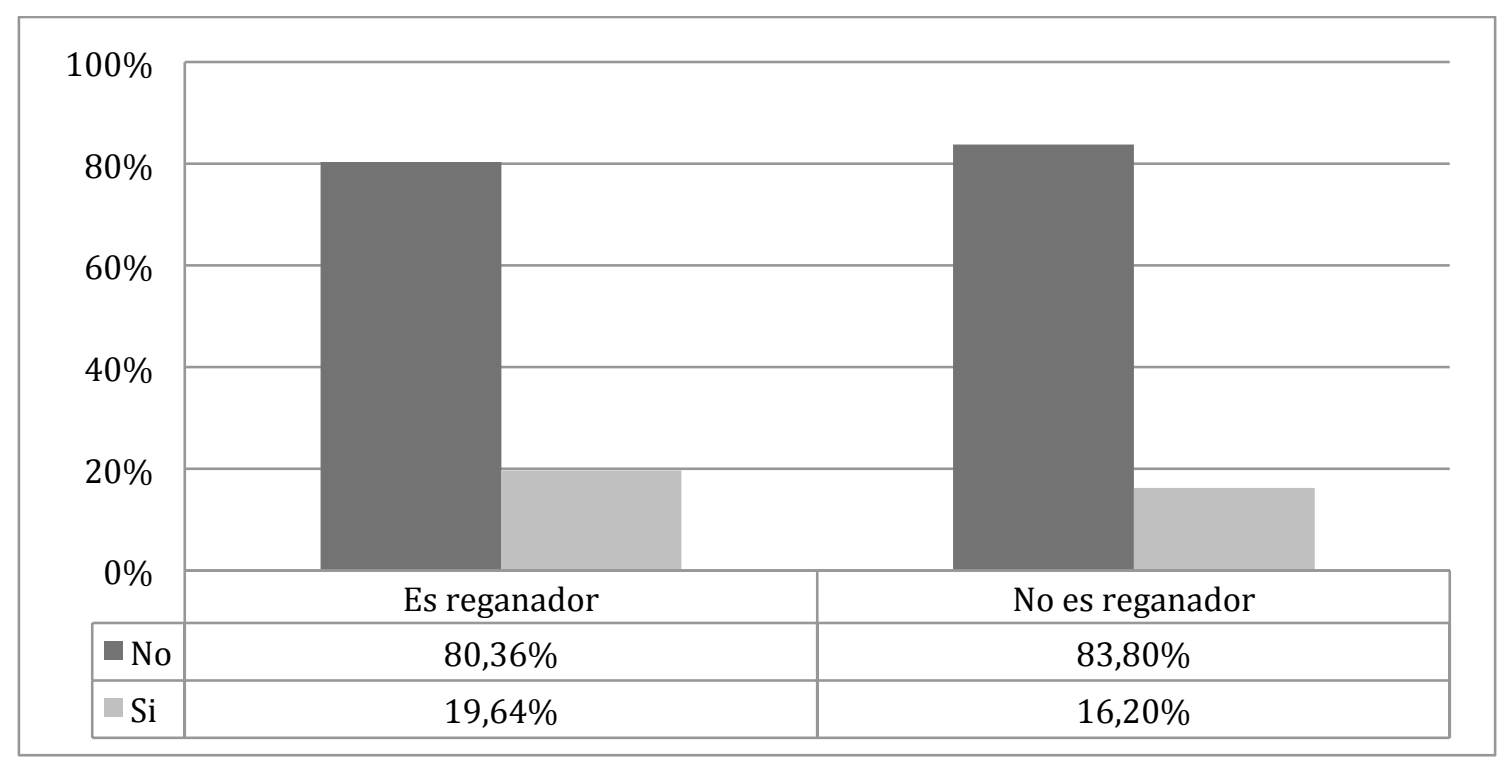

Al realizar una Prueba Chi cuadrada de comparación de distribuciones respecto de ser un comedor nocturno diferenciado por grupos se obtiene un p-valor de 0,475. Al analizar el hábito de ingesta nocturna, la dificultad para dormir y el hecho de levantarse a comer, comparativamente entre reganadores y no reganadores, se observan similares distribuciones entre ambos grupos y consecuentemente no se encuentran diferencias estadísticamente significativas entre ellos.

A continuación se analizan las cuestiones vinculadas con la realización de Actividad Física por parte de los pacientes luego de la cirugía bariátrica. Se busca analizar comparativamente cómo podría influir la misma sobre la condición de ser o no reganador de peso. 
Gráfico N49: ¿Realiza actividad o ejercicio físico? $(n=254)$

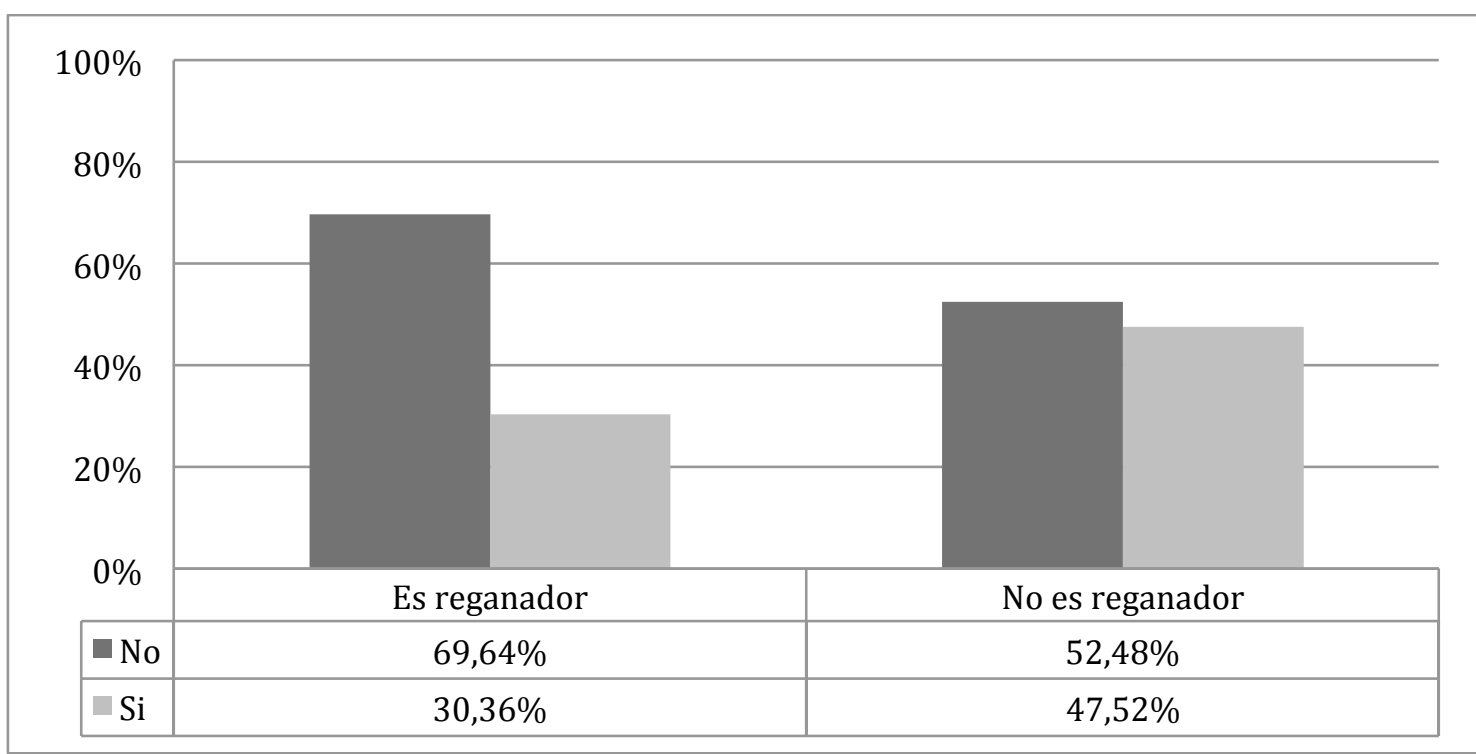

Al realizar una Prueba Chi cuadrada de comparación de distribuciones respecto de realización de actividad física diferenciada por grupos se observa un $p$ valor de 0,006 .

Son bien conocidos los beneficios de la actividad física para la salud. Tanto para el descenso de peso como para su mantenimiento, con o sin cirugía bariátrica, ocupa un rol fundamental. Se observan mayores porcentajes de realización de ejercicio físico entre los no reganadores, aunque ni siquiera dentro de este grupo la realización de actividad física llega a ser mayoritaria. El p-valor de 0,006 muestra que existe una diferencia estadísticamente significativa en la realización de actividad física respecto de ser o no reganador de peso.

Gráfico $N^{\circ}$ 50: Si realiza actividad o ejercicio, ¿cuántas veces por semana? $(n=100)$

\begin{tabular}{|c|c|c|}
\hline \multicolumn{3}{|l|}{$100 \%$} \\
\hline \multicolumn{3}{|l|}{$80 \%$} \\
\hline \multicolumn{3}{|l|}{$60 \%$} \\
\hline \multicolumn{3}{|l|}{$40 \%$} \\
\hline \multicolumn{3}{|l|}{$20 \%$} \\
\hline $0 \%$ & Es reganador & No es reganador \\
\hline$\square 1$ o 2 veces por semana & $27,27 \%$ & $28,36 \%$ \\
\hline$\square 3$ o 4 veces por semana & $57,58 \%$ & $53,73 \%$ \\
\hline 5 veces por semana o más & $15,15 \%$ & $17,91 \%$ \\
\hline
\end{tabular}


Gráfico $N^{\circ}$ 51: ¿Cuántos minutos dura la actividad o ejercicio? $(n=100)$

\begin{tabular}{|c|c|c|}
\hline \multicolumn{3}{|l|}{$100 \%$} \\
\hline \multicolumn{3}{|l|}{$80 \%$} \\
\hline \multicolumn{3}{|l|}{$60 \%$} \\
\hline \multicolumn{3}{|l|}{$40 \%$} \\
\hline \multicolumn{3}{|l|}{$20 \%$} \\
\hline $0 \%$ & Es reganador & No es reganador \\
\hline Menos de 30 minutos & $15,15 \%$ & $11,94 \%$ \\
\hline De 30 a 60 minutos & $12,12 \%$ & $13,43 \%$ \\
\hline De 60 a 90 minutos & $66,67 \%$ & $61,19 \%$ \\
\hline 90 minutos o más & $6,06 \%$ & $13,43 \%$ \\
\hline
\end{tabular}

Tanto la frecuencia como el tiempo dedicado a la actividad física son muy similares en ambos grupos. Por lo que se analiza el tipo de actividad física que realizan sin comparar ambos grupos.

Gráfico $\mathbf{N}^{\circ}$ 52: Tipo de actividad física $(n=100)$

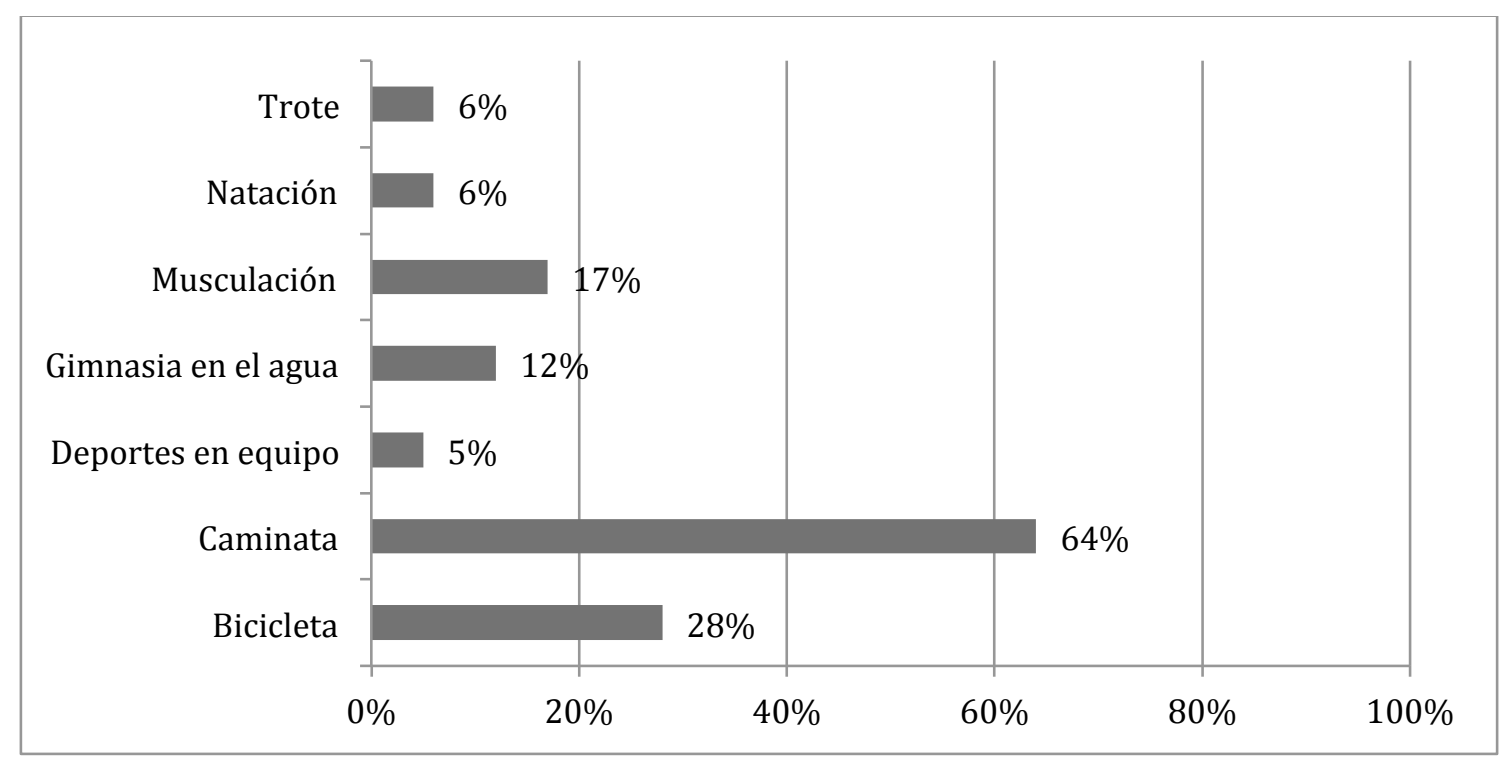


Gráfico $\mathbf{N}^{\circ}$ 53: Intensidad de la Actividad que realiza $(n=100)$

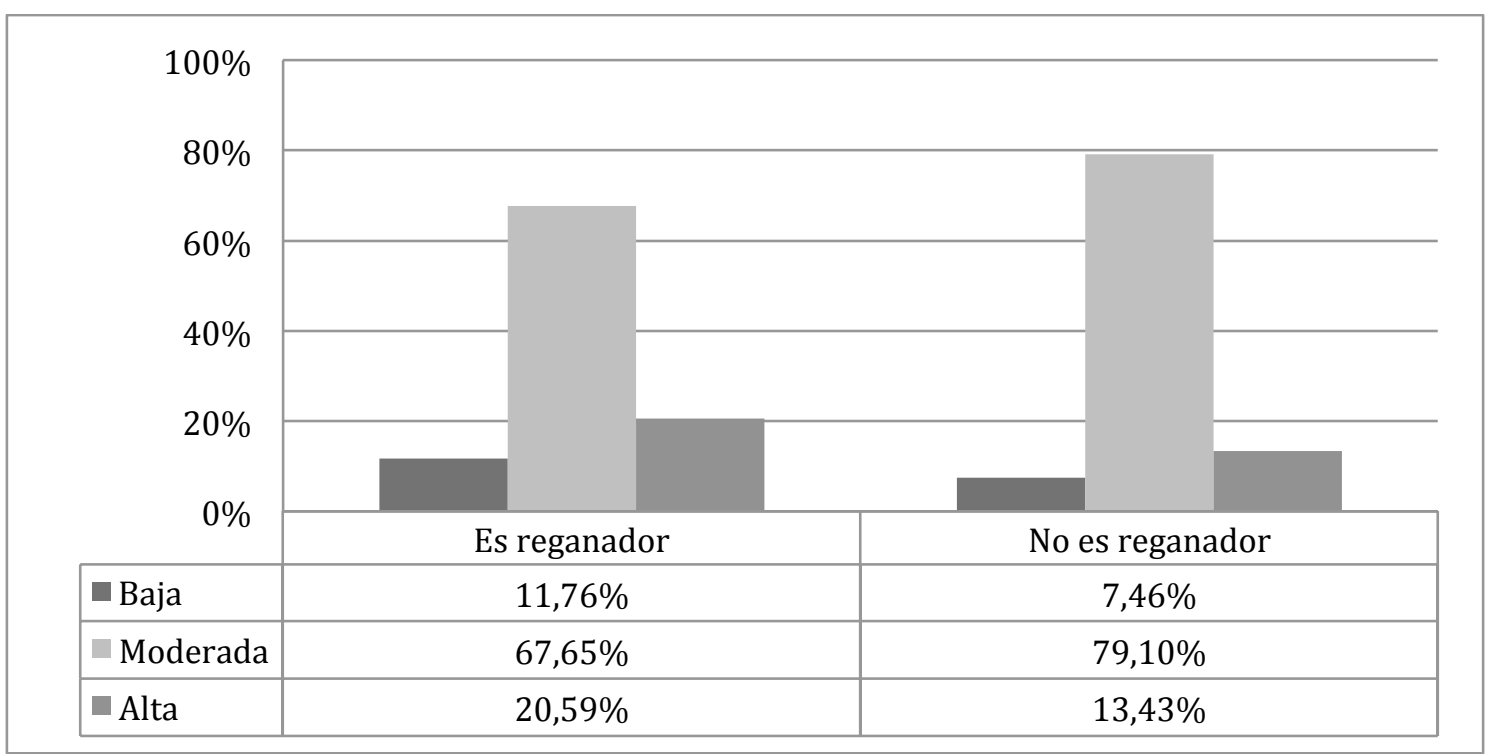

Al realizar una Prueba Chi cuadrada de comparación de distribuciones respecto de la intensidad en la realización de actividad física diferenciada por grupos se obtiene un p-valor de 0,451. Si bien la presencia de este hábito es importante, la intensidad con que se realiza actividad física no muestra un valor estadísticamente significativo.

Seguidamente se analizan otros aspectos que podría tener influencia en la situación de ser o no reganador de peso luego de una cirugía bariátrica.

Gráfico $\mathbf{N}^{\circ}$ 54: ¿Duerme al menos 7 horas promedio por noche? $(\mathrm{n}=254)$

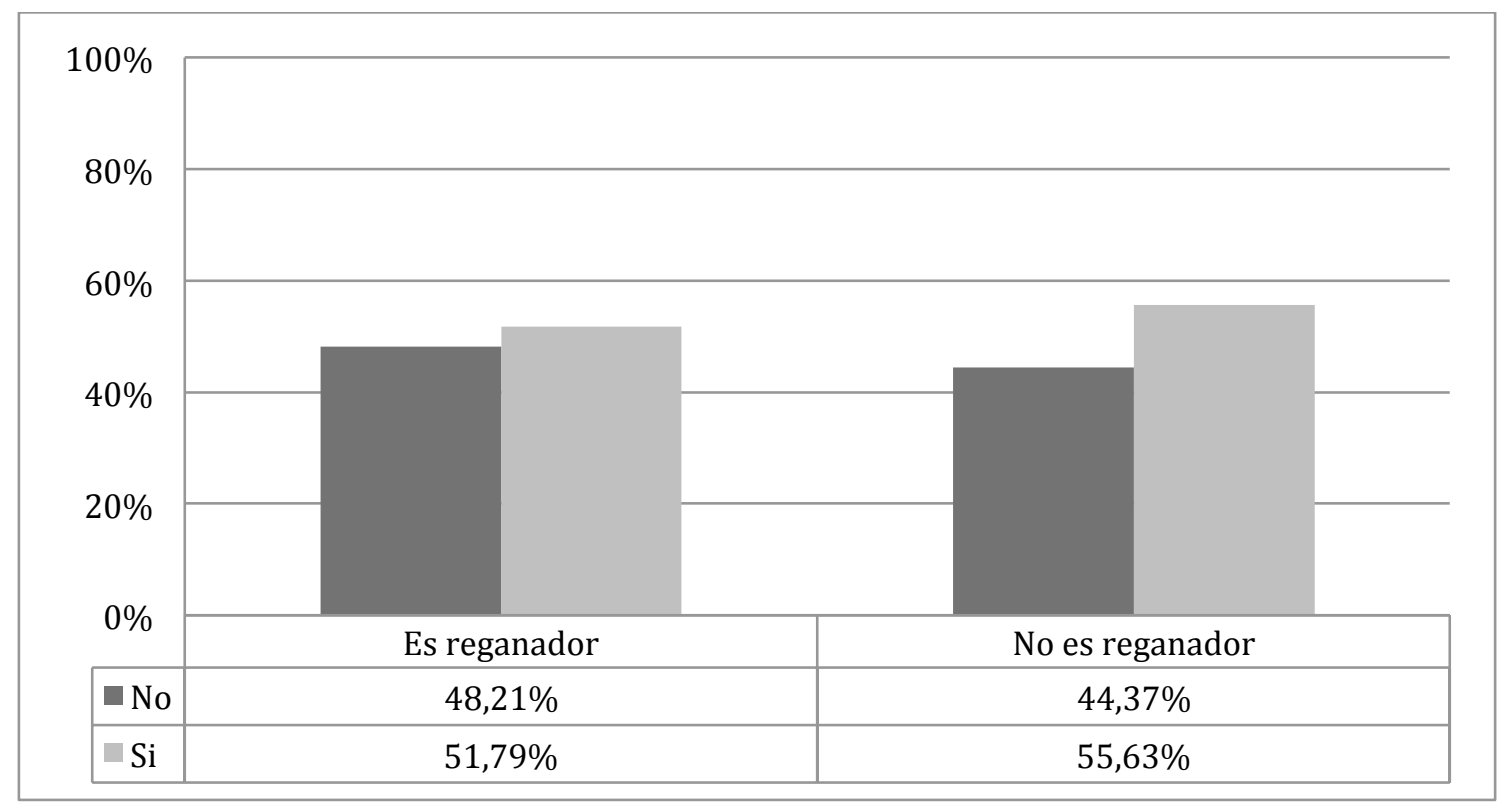


Al realizar una Prueba Chi cuadrada de comparación de distribuciones respecto del promedio de horas de sueño diferenciada por grupos se obtiene un $\mathrm{p}$ valor de 0,541 .

Pocos estudios hechos con pacientes que fueron sometidos a cirugías bariátricas hablan del beneficio de descansar para mantener un peso saludable. En este estudio se encuentran similares porcentajes entre pacientes reganadores y no reganadores de peso respecto del promedio de horas que duermen, y como era de esperar no se encuentran diferencias estadísticamente significativas.

Gráfico $\mathbf{N}^{\circ}$ 55: ¿Trabaja en relación con alimentos? (kiosco, gastronomía, panadería, rotisería, etc. $)(n=254)$

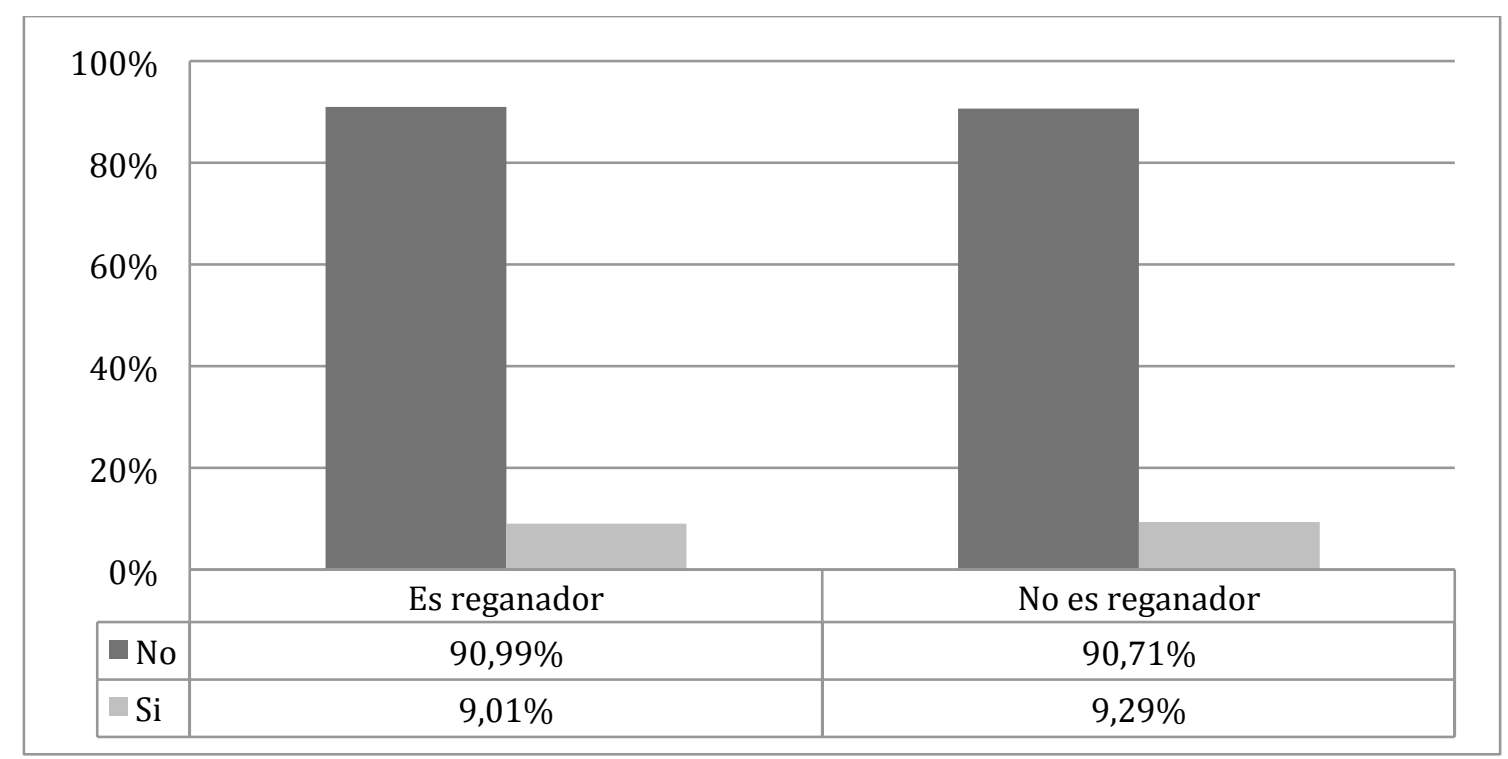

En este estudio no muestra relación alguna entre trabajar en relación con alimentos y reganancia de peso, ya que se observan porcentajes prácticamente idénticos en ambos grupos. 
Gráfico $\mathbf{N}^{\circ}$ 56: ¿Toma diariamente la suplementación de vitaminas y minerales sugerida por el equipo quirúrgico? $(n=254)$

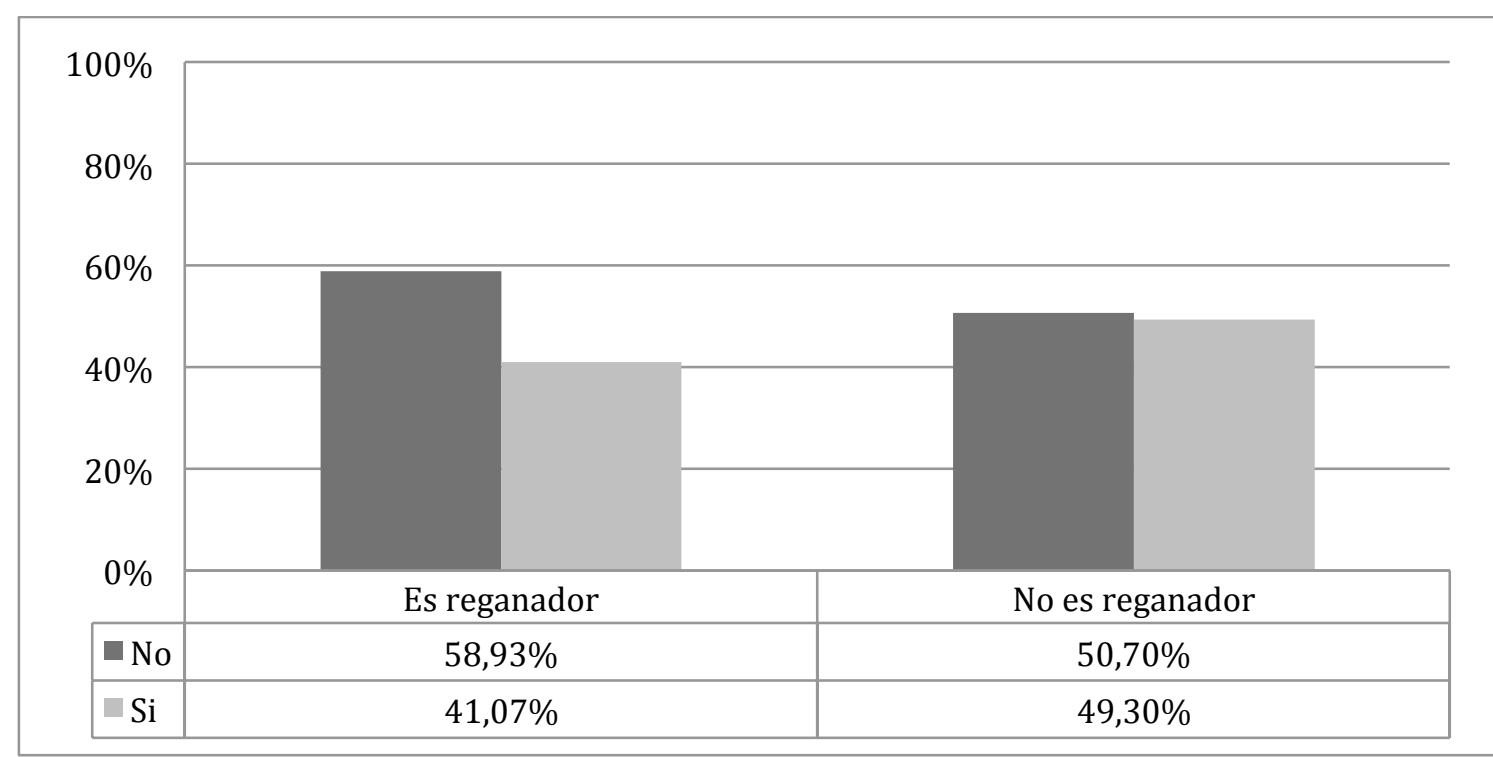

Al realizar una Prueba Chi cuadrada de comparación de distribuciones respecto del consumo de suplementos dietarios diferenciado por grupos se obtiene un p-valor de 0,191. A partir de los resultados se observa que los pacientes no reganadores consumen en mayor porcentaje suplementos multivitamínicos, pero esta diferencia no resulta estadísticamente significativa.

Gráfico N 57: ¿Consume alcohol? $(n=254)$

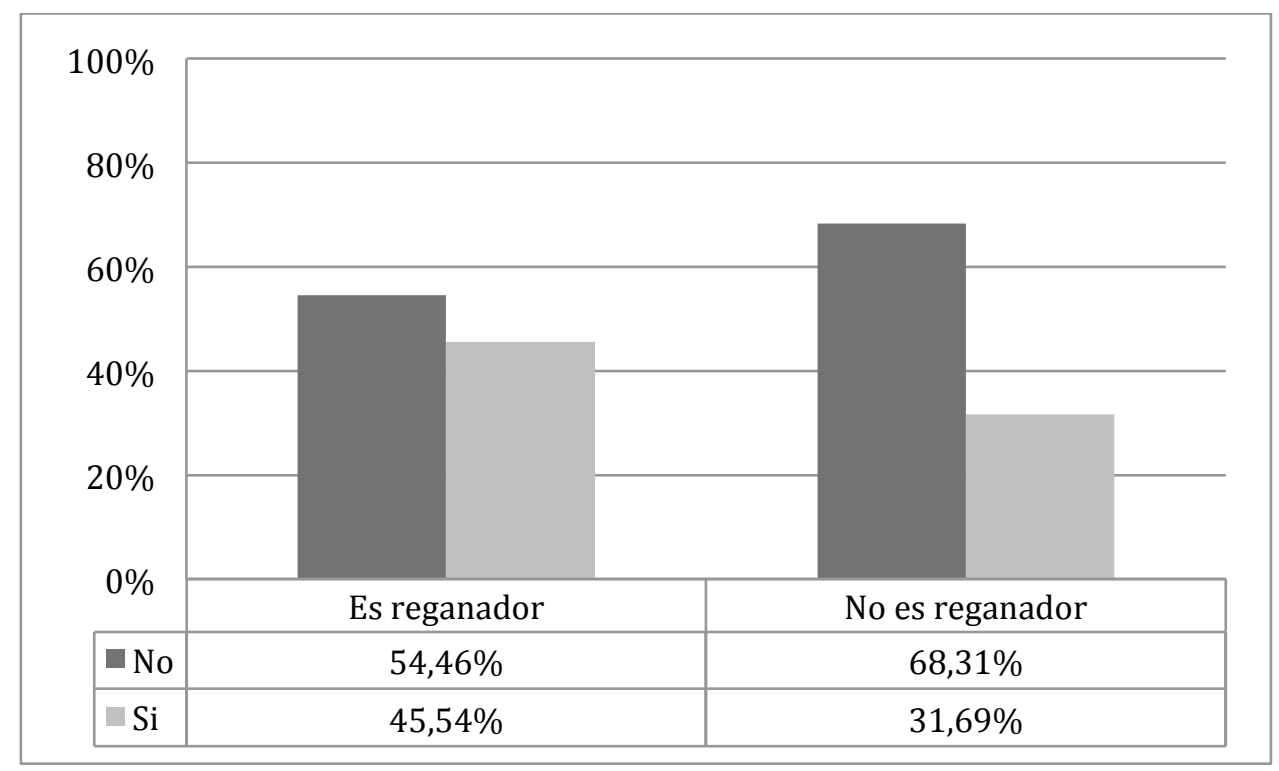

Al realizar una Prueba Chi cuadrada de comparación de distribuciones respecto del consumo de alcohol diferenciado por grupos se obtiene un p-valor de 0,024. El hábito de consumir alcohol es bien conocido por no ser favorecedor para el mantenimiento y descenso de peso. Los resultados muestran que entre los 
reganadores de peso el porcentaje de consumo es más alto, respecto del otro grupo. Al realizar el test de hipótesis se obtiene un p-valor de 0,024 indicando que existe evidencia estadísticamente significativa para relacionar este hábito y el hecho de reganar o no peso post cirugía bariátrica.

Gráfico $\mathbf{N}^{\circ}$ 58: Si consume alcohol, ¿con qué frecuencia lo hace? $(n=96)$

\begin{tabular}{|c|c|c|}
\hline \multirow{2}{*}{$\begin{array}{r}100 \% \\
80 \%\end{array}$} & & \\
\hline & & \\
\hline \multicolumn{3}{|l|}{$60 \%$} \\
\hline \multicolumn{3}{|l|}{$40 \%$} \\
\hline \multicolumn{2}{|l|}{$20 \%$} & \\
\hline $0 \%$ & Es reganador & No es reganador \\
\hline Menos de 1 vez por semana & $35,42 \%$ & $55,56 \%$ \\
\hline$\square 1$ o 2 veces por semana & $27,08 \%$ & $22,22 \%$ \\
\hline - 3 o 4 veces por semana & $16,67 \%$ & $15,56 \%$ \\
\hline 5 o 6 veces por semana & $4,17 \%$ & $4,44 \%$ \\
\hline Todos los días & $16,67 \%$ & $2,22 \%$ \\
\hline
\end{tabular}

Al realizar una Prueba Chi cuadrada de comparación de distribuciones respecto de la frecuencia de consumo de alcohol diferenciado por grupos se obtiene un p-valor de 0,119. Si bien entre los reganadores de peso la frecuencia de consumo sería levemente superior al otro grupo, la misma no muestra una diferencia estadísticamente significativa.

A continuación se analiza el resultado de una serie de preguntas vinculadas con la Salud Mental de los pacientes que participaron de este trabajo. Se busca encontrar, si existe, alguna vinculación entre la misma y la clasificación como reganadores o no reganadores de peso utilizada. 
Gráfico $\mathbf{N}^{\circ}$ 59: ¿Realizó después de operado psicoterapia durante 6 meses o más? $(n=254)$

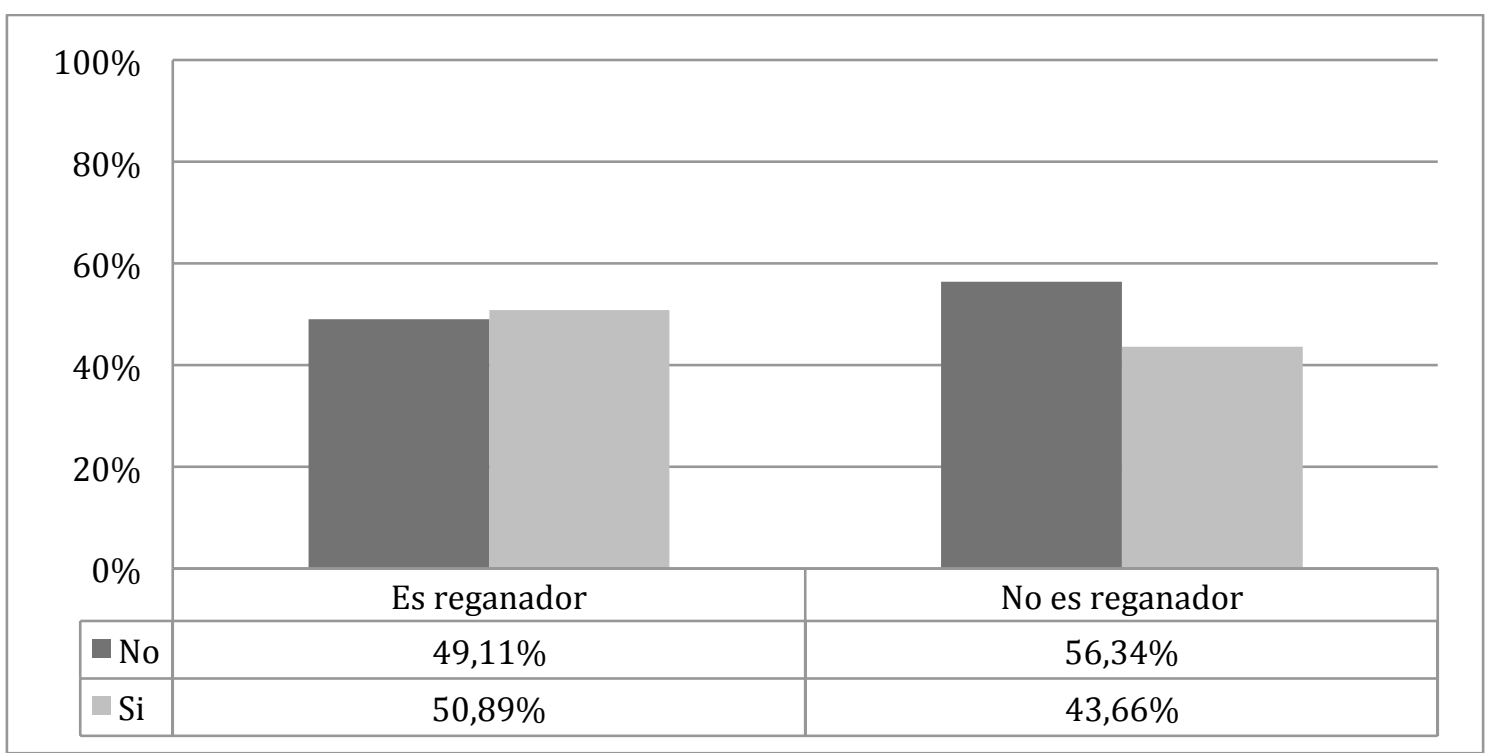

Al realizar una Prueba Chi cuadrada de comparación de distribuciones respecto de la realización de psicoterapia diferenciado por grupos se obtiene un pvalor de 0,252 . Sorprendentemente se observa una mayor concurrencia a psicoterapia entre los reganadores de peso, sin embargo, tener un apoyo terapéutico después de la cirugía bariátrica no ha mostrado evidencia significativa de diferenciarse dentro de la clasificación como reganadores o no reganadores de peso.

Gráfico N 60: ¿Recibió medicación psiquiátrica durante 6 meses o más? $(n=254)$

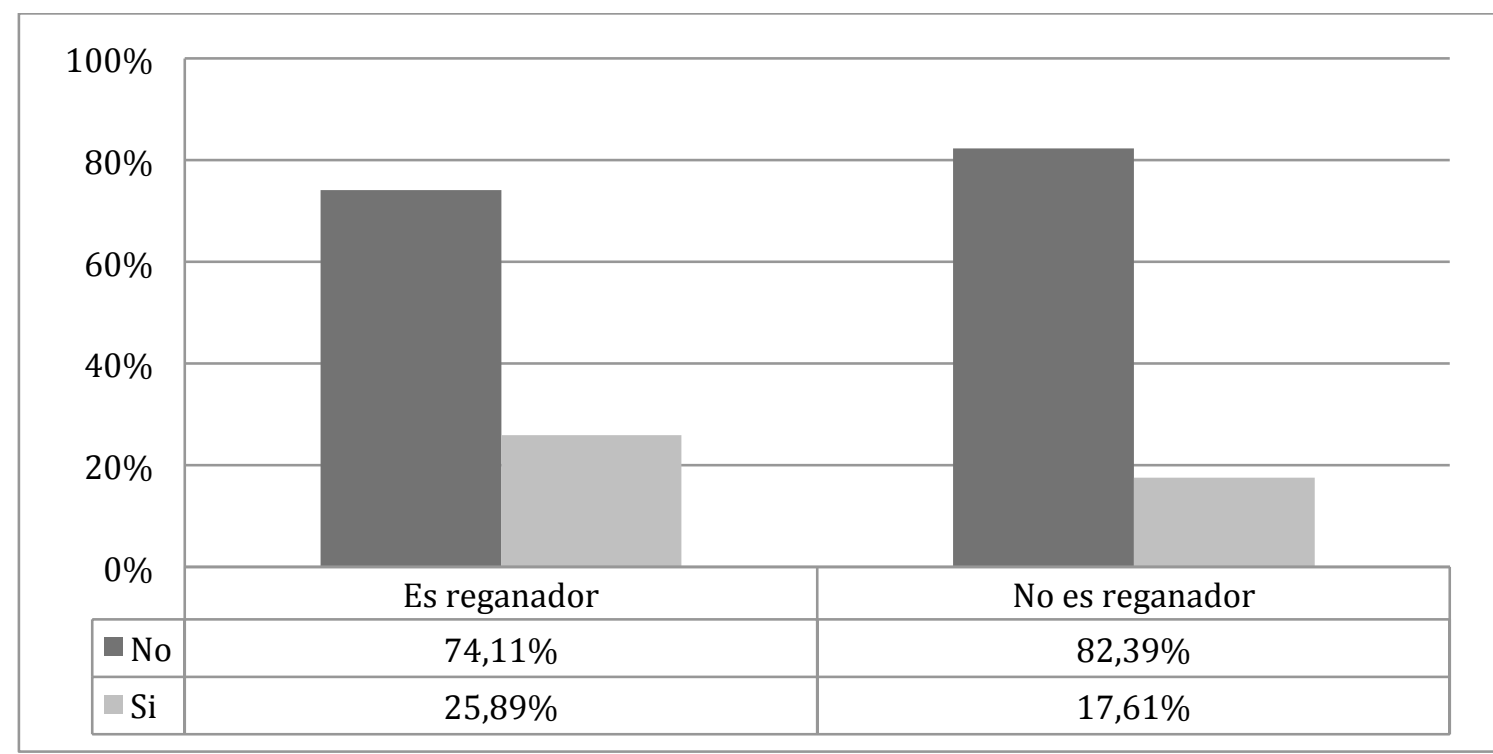

Al realizar una Prueba Chi cuadrada de comparación de distribuciones respecto de la utilización de medicación psiquiátrica diferenciado por grupos se obtiene un $p$-valor de 0,109 . A pesar de que el consumo de medicación psiquiátrica es 
mayor entre los reganadores de peso, esta variable no presenta una diferencia significativa entre los dos grupos.

Gráfico $\mathbf{N}^{\circ}$ 61: ¿Le habían diagnosticado antes de la cirugía algún trastorno mental? $(n=254)$

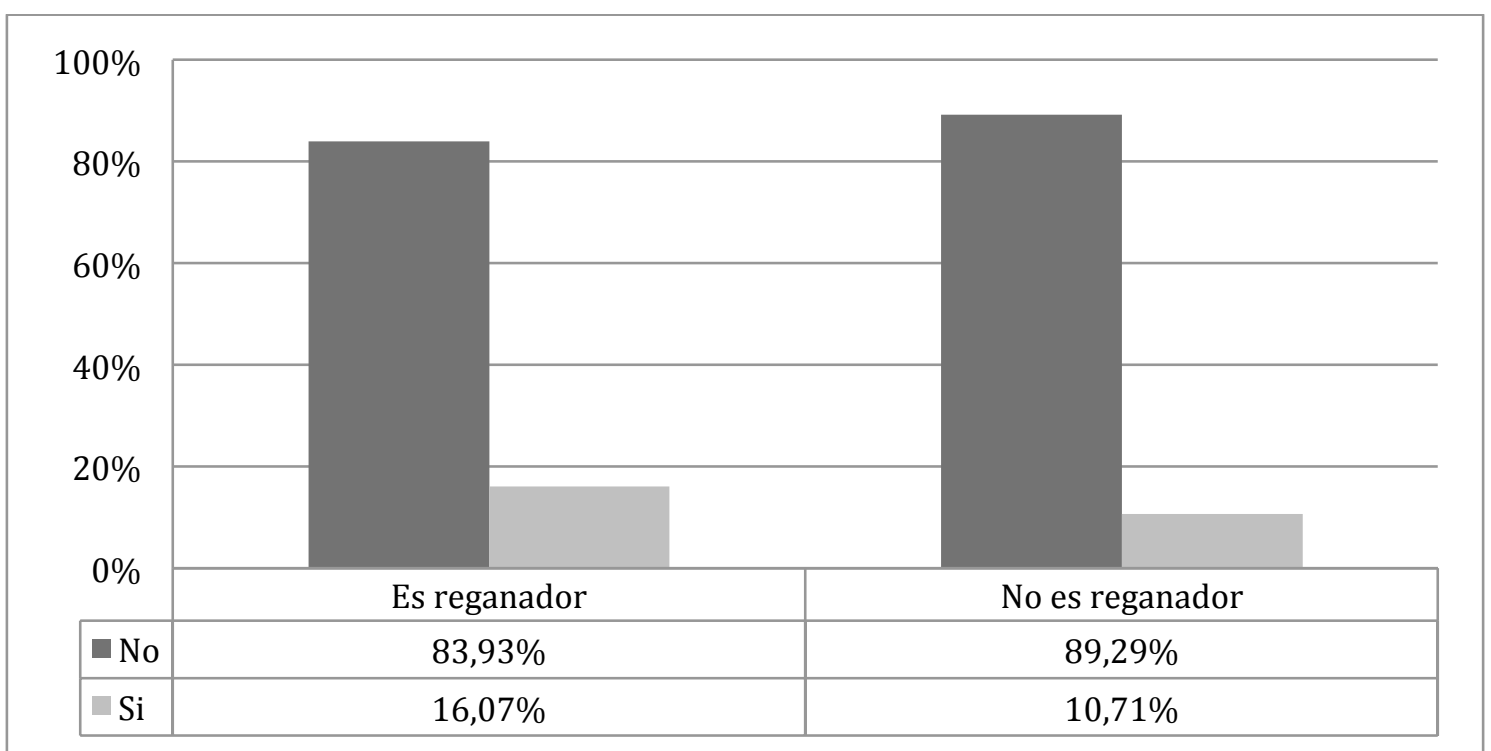

Al realizar una Prueba Chi cuadrada de comparación de distribuciones respecto del diagnóstico previo a la cirugía de algún trastorno mental diferenciado por grupos se obtiene un p-valor de 0,210. Se observan similares porcentajes de diagnóstico prequirúrgico de trastornos mentales en ambos grupos. Consecuentemente con esto no se observan diferencias significativas entre los reganadores y no reganadores respecto de este tipo de enfermedad. 
Gráfico $\mathbf{N}^{\circ}$ 62: ¿Le diagnosticaron algún trastorno mental después de la cirugía? $(n=254)$

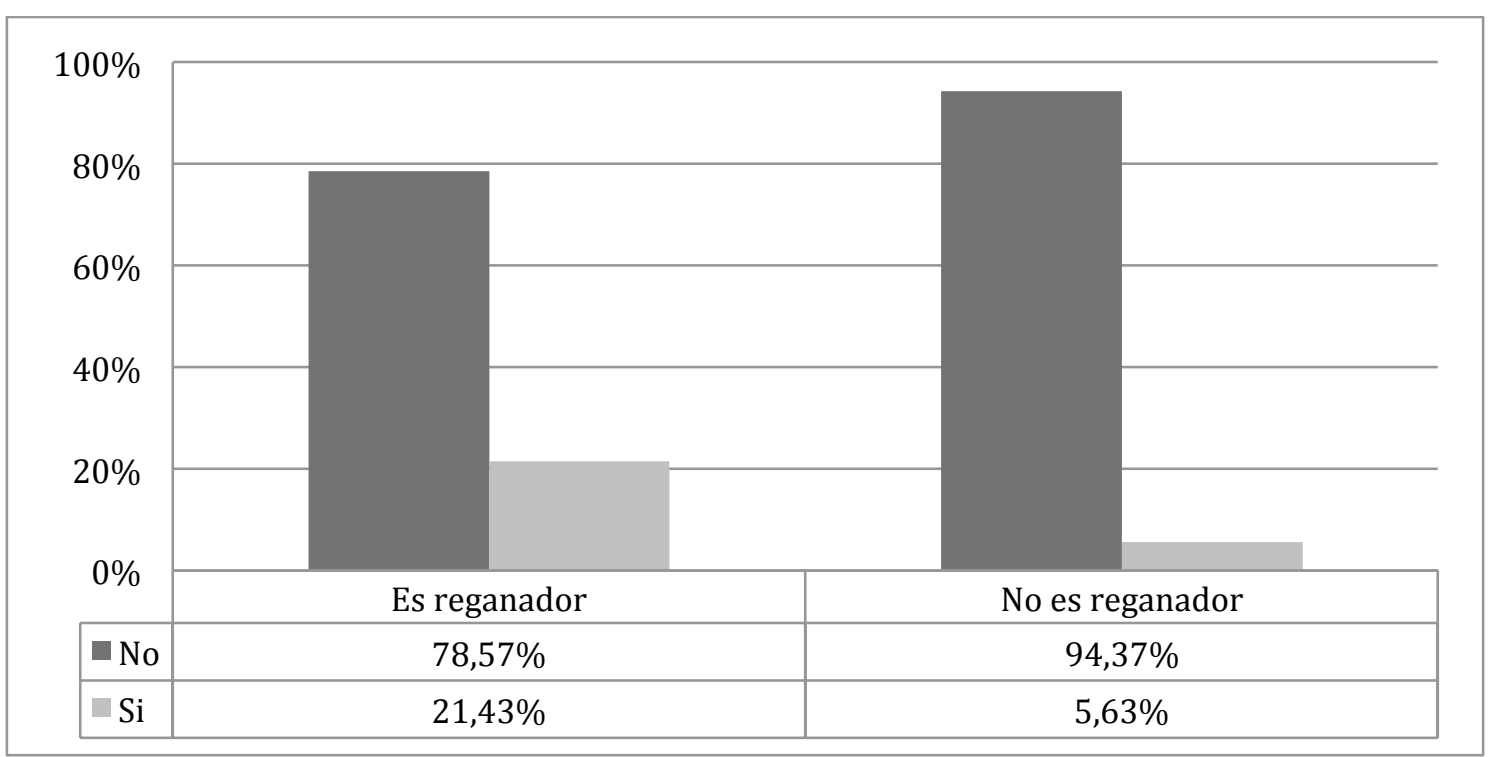

Al realizar una Prueba Chi cuadrada de comparación de distribuciones respecto del diagnóstico posterior a la cirugía de algún trastorno mental diferenciado por grupos se obtiene un p-valor de 0,0002. A partir de los datos anteriormente presentados se observa un mayor porcentaje de pacientes diagnosticados con algún tipo de trastorno mental luego de la cirugía entre los reganadores, respecto de los no reganadores. $\mathrm{Al}$ analizar ambos grupos comparativamente se encuentra que existen diferencias significativas en los mencionados porcentajes. 
Gráfico $\mathbf{N}^{\circ}$ 63: ¿Hubo algún evento que considera que pudo haber influido en su peso después de la cirugía, como una mudanza, separación, muerte de un familiar, robo, hacerse cargo de un familiar $u$ otro? $(n=254)$

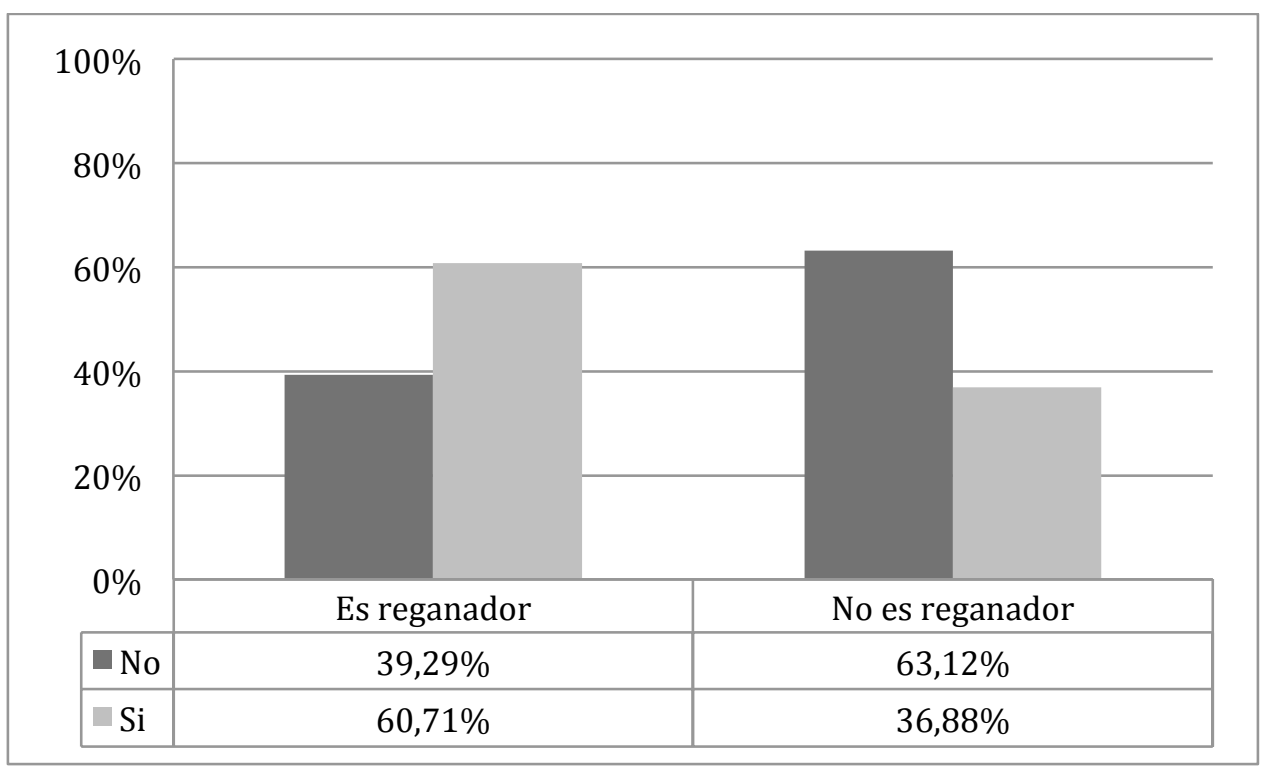

Al realizar una Prueba Chi cuadrada de comparación de distribuciones respecto del padecimiento de hechos traumáticos posteriores a la cirugía diferenciado por grupos se obtiene un p-valor de 0,0002. En función de los resultados presentados se observan tendencias opuestas entre los grupos de reganadores y no reganadores respecto del padecimiento de algún hecho traumático luego de la cirugía, siendo el primero de estos grupos el que presenta resultados afirmativos mayoritarios. Hechos traumáticos después de la cirugía muestran que tienen una influencia en la reganancia de peso. Esto se evidencia en el hecho de obtener un p-valor que indica que las diferencias halladas entre ambos grupos resultan significativas.

A continuación se aplica el Cuestionario BAROS (Bariatric Analysis and Reporting Outcome System) que es un sistema validado de evaluación y análisis de aspectos relacionados con la cirugía bariátrica. Este cuestionario consta de una serie de afirmaciones incompletas sobre las cuales los pacientes deben elegir la opción que consideren más adecuada para completarla en función de su situación personal.

Seguidamente se presentan los resultados obtenidos para cada una de estas afirmaciones diferenciadas por grupos, con el correspondiente test de independencia de variables. 
Gráfico $\mathbf{N}^{\circ}$ 64: Después de la operación me siento... $(n=254)$

\begin{tabular}{|c|c|c|}
\hline \multicolumn{3}{|l|}{$100 \%$} \\
\hline \multicolumn{3}{|l|}{$80 \%$} \\
\hline \multicolumn{3}{|l|}{$60 \%$} \\
\hline \multicolumn{3}{|l|}{$40 \%$} \\
\hline \multicolumn{3}{|l|}{$20 \%$} \\
\hline $0 \%$ & Es reganador & No es reganador \\
\hline Mucho mejor & $56,25 \%$ & $78,17 \%$ \\
\hline Mejor & $30,36 \%$ & $19,72 \%$ \\
\hline Igual & $6,25 \%$ & $1,41 \%$ \\
\hline Peor & $4,46 \%$ & $0,70 \%$ \\
\hline Mucho peor & $2,68 \%$ & $0,00 \%$ \\
\hline
\end{tabular}

Al realizar una Prueba Chi cuadrada de comparación de distribuciones respecto de la afirmación "Después de la operación me siento... " diferenciado por grupos se obtiene un p-valor de 0,001. Según la primera afirmación del cuestionario sobre calidad de vida BAROS hay evidencia de que existen diferencias estadísticamente significativas en la forma de sentirse luego de la operación entre reganadores y no reganadores de peso. Los no reganadores de peso que manifiestan sentirse "Mucho mejor" o "Mejor" suman casi un 98\%, mientras que entre los reganadores este porcentaje es solo de un $86 \%$ aproximadamente.

Gráfico $\mathbf{N}^{\circ}$ 65: Participo en actividades físicas... $(n=254)$

\begin{tabular}{|c|c|c|}
\hline \multicolumn{3}{|l|}{$100 \%$} \\
\hline \multicolumn{3}{|l|}{$80 \%$} \\
\hline \multicolumn{3}{|l|}{$60 \%$} \\
\hline \multicolumn{2}{|l|}{$40 \%$} & \\
\hline \multicolumn{2}{|l|}{$20 \%$} & \\
\hline $0 \%$ & Es reganador & No es reganador \\
\hline Mucho mejor & $32,14 \%$ & $40,85 \%$ \\
\hline Mejor & $25,00 \%$ & $28,87 \%$ \\
\hline Igual & $24,11 \%$ & $21,13 \%$ \\
\hline Peor & $12,50 \%$ & $4,93 \%$ \\
\hline Mucho peor & $6,25 \%$ & $4,23 \%$ \\
\hline
\end{tabular}

Al realizar una Prueba Chi cuadrada de comparación de distribuciones respecto de la afirmación "Participo en actividades físicas..." diferenciado por grupos se obtiene un p-valor de 0,152. Respecto de la segunda afirmación del cuestionario referida a la realización de actividades físicas, las diferencias que se pueden apreciar 
entre las distribuciones de reganadores y no reganadores de peso no resultan estadísticamente significativas.

Gráfico $N^{\circ}$ 66: Participo en actividades sociales... $(n=254)$

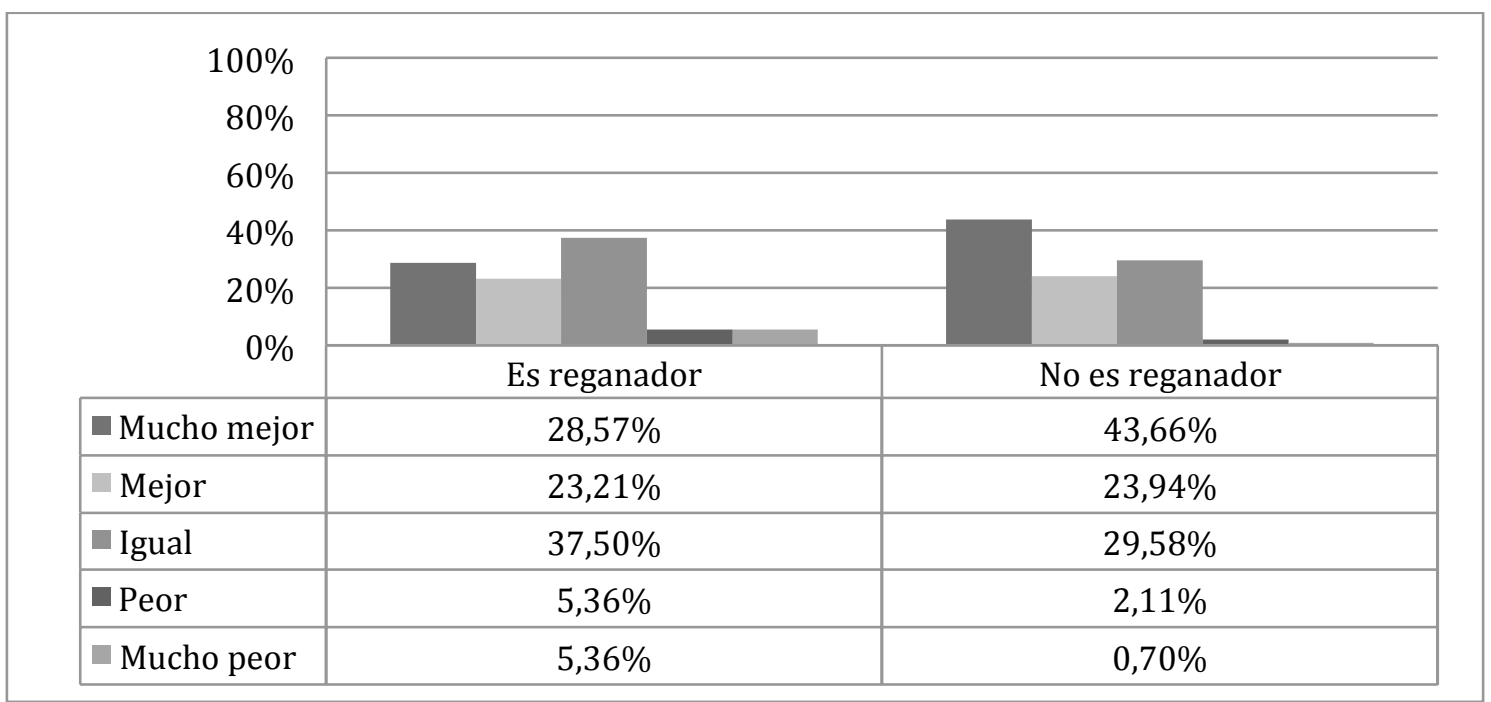

Al realizar una Prueba Chi cuadrada de comparación de distribuciones respecto de la afirmación "Participo en actividades sociales..." diferenciado por grupos se obtiene un p-valor 0,019. En función de la afirmación vinculada a la participación en actividades sociales se observan distribuciones diferentes entre ambos grupos. Al analizar la significatividad de las diferencias entre estas distribuciones se obtiene un $p$ valor que indica que hay una relación entre el grupo de pertenencia en cuanto a la reganancia y la participación en actividades sociales. 
Gráfico $N^{\circ}$ 67: Puedo trabajar... $(n=254)$

\begin{tabular}{|c|c|c|}
\hline \multicolumn{3}{|l|}{$100 \%$} \\
\hline \multicolumn{3}{|l|}{$80 \%$} \\
\hline \multicolumn{3}{|l|}{$60 \%$} \\
\hline \multicolumn{3}{|l|}{$40 \%$} \\
\hline \multicolumn{3}{|l|}{$20 \%$} \\
\hline $0 \%$ & Es reganador & No es reganador \\
\hline Mucho mejor & $36,61 \%$ & $50,00 \%$ \\
\hline Mejor & $25,89 \%$ & $22,54 \%$ \\
\hline Igual & $33,04 \%$ & $26,06 \%$ \\
\hline Peor & $4,46 \%$ & $0,00 \%$ \\
\hline Mucho peor & $0,00 \%$ & $1,41 \%$ \\
\hline
\end{tabular}

Al realizar una Prueba Chi cuadrada de comparación de distribuciones respecto de la afirmación "Puedo trabajar..." diferenciado por grupos se obtiene un pvalor de 0,019. En referencia a la afirmación vinculada con el trabajo se encuentran distribuciones algo diferentes entre ambos grupos. Al analizar la significatividad de estas diferencias encontramos evidencia que indica que hay relación entre la opinión respecto al trabajo y la pertenencia al grupo de reganadores o no reganadores. Entre los reganadores las opiniones que indican que trabajan "Mucho mejor" y "Mejor" alcanzan en conjunto un $52 \%$ aproximadamente, mientras que entre los no reganadores estas opciones son seleccionadas por algo más del $72 \%$.

Gráfico $N^{\circ}$ 68: Mi actividad sexual es... $(n=254)$

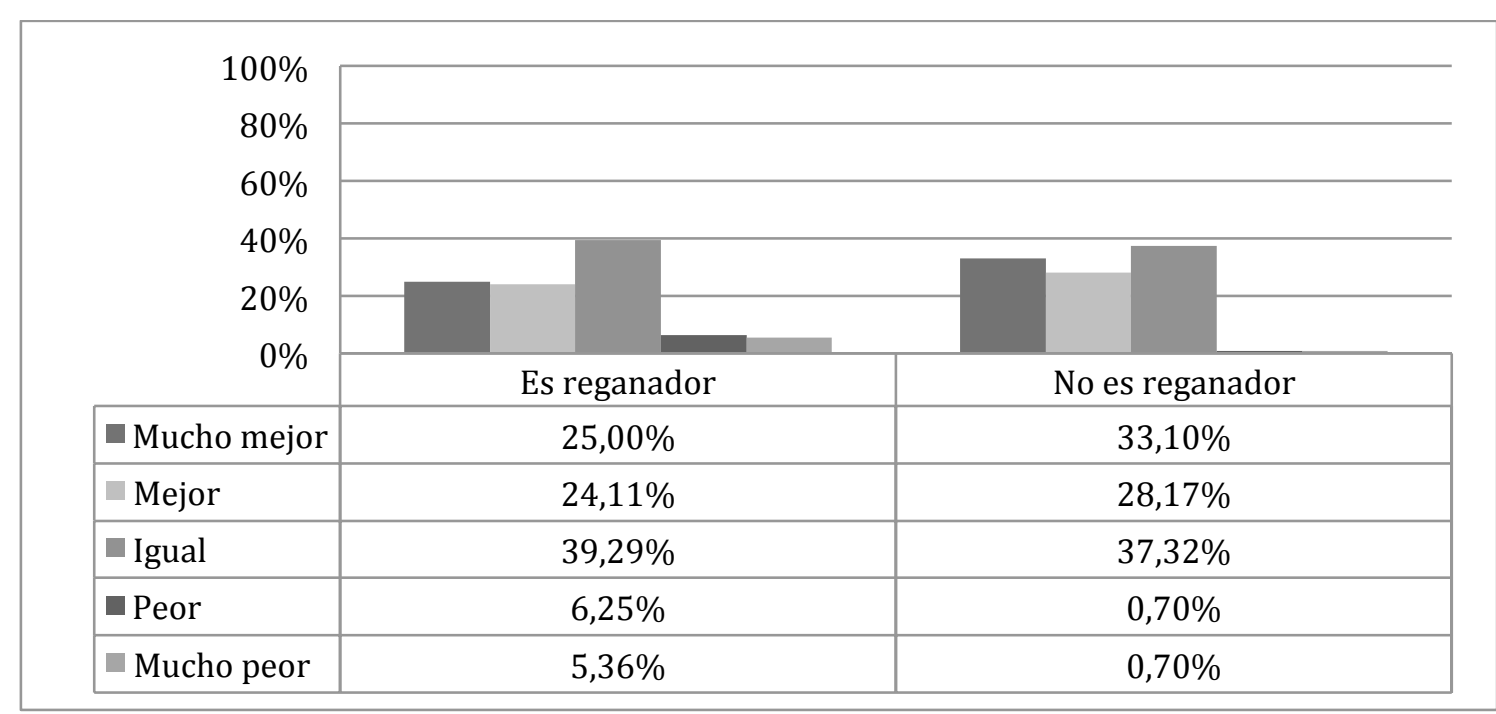


Al realizar una Prueba Chi cuadrada de comparación de distribuciones respecto de la afirmación "Mi actividad sexual es..." diferenciado por grupos se obtiene un p-valor de 0,012. En función de la afirmación vinculada a la actividad sexual se observan distribuciones diferentes entre ambos grupos. Al analizar la significatividad de las diferencias entre estas distribuciones se obtiene un p-valor que indica que hay una relación entre el grupo de pertenencia en cuanto a la reganancia y la actividad sexual. Los no reganadores tiene una actividad sexual "Mucho mejor" y "Mejor" en un $61 \%$ en conjunto, mientras que entre los reganadores estas opciones de respuestas fueron seleccionadas por solo un $49 \%$.

\section{Cálculo de los ODDS RATIO}

Odds Ratio (OR) es una medida de efecto comúnmente utilizada para comunicar los resultados de una investigación en salud. Matemáticamente un OR corresponde a un cociente entre dos odds, siendo un odds una forma alternativa de expresar la posibilidad de ocurrencia de un evento de interés o de presencia de una exposición. Desde un punto de vista metodológico, los OR pueden ser calculados en diseños prospectivos, retrospectivos y transversales.

A continuación se listan los posibles OR que se pueden calcular. Solo tiene sentido realizar estos cálculos sobre las variables que en el comparativo resultaron significativas. Es importante señalar que el cálculo de los OR debe realizarse en función de tablas de $2 \times 2$, donde se ubican por un lado los grupos de diferenciación ( $N$ y NR), y por el otro lado la presencia o ausencia respecto de un factor de riesgo:

1. Consulta al Nutricionista (su ausencia es un factor de riesgo):

\begin{tabular}{|l|l|l|}
\hline & \multicolumn{2}{|l|}{ Estimación } \\
\hline Proporción de casos expuestos & 0,741071 \\
\hline Proporción de controles expuestos & 0,528169 \\
\hline Odds ratio & 2,556782 \\
\hline Intervalo de Confianza (95\%) & 1,495924 & 4,369962 \\
\hline
\end{tabular}

Interpretación OR: "la razón entre Reganancia versus No Reganancia es 2,55. Es decir, la posibilidad de transformarse en Reganador es 2,55 veces mayor en pacientes sin control nutricional en comparación con pacientes con control nutricional. Esta asociación es estadísticamente significativa". 
2. Hábitos alimentarios (Almuerzo) (frecuencia menor a todos los días es un riesgo):

\begin{tabular}{|l|l|l|}
\hline & \multicolumn{2}{|l|}{ Estimación } \\
\hline Proporción de casos expuestos & 0,241071 \\
\hline Proporción de controles expuestos & 0,098592 \\
\hline Odds ratio & 2,904202 & 5,856159 \\
\hline Intervalo de Confianza (95\%) & 1,440259 & \multicolumn{2}{|l}{} \\
\hline
\end{tabular}

Interpretación OR: "la razón entre Reganancia versus No Reganancia es 2,9. Es decir, la posibilidad de transformarse en Reganador es 2,9 veces mayor en pacientes que no almuerzan todos los días en comparación con pacientes que si lo hacen. Esta asociación es estadísticamente significativa".

3. Hábitos alimentarios (Cena) (frecuencia menor a "todos los días" es un riesgo):

\begin{tabular}{|c|c|c|}
\hline & \multicolumn{2}{|l|}{ Estimación } \\
\hline Proporción de casos expuestos & \multicolumn{2}{|l|}{0,196429} \\
\hline Proporción de controles expuestos & \multicolumn{2}{|l|}{0,070423} \\
\hline Odds ratio & \multicolumn{2}{|l|}{3,226667} \\
\hline Intervalo de Confianza (95\%) & 1,458462 & 7,1386 \\
\hline
\end{tabular}

Interpretación OR: "la razón entre Reganancia versus No Reganancia es 3,23. Es decir, la posibilidad de transformarse en Reganador es 3,23 veces mayor en pacientes que no cenan todos los días en comparación con pacientes que si lo hacen. Esta asociación es estadísticamente significativa". 
4. Principal comida antes de las 15h. (su ausencia es un potencial factor de riesgo):

\begin{tabular}{|l|l|l|}
\hline & Estimación \\
\hline Proporción de casos expuestos & 0,410714 \\
\hline Proporción de controles expuestos & 0,267606 \\
\hline Odds ratio & 1,907496 \\
\hline Intervalo de Confianza (95\%) & 1,12399 & 3,237165 \\
\hline
\end{tabular}

Interpretación OR: "la razón entre Reganancia versus No Reganancia es 1,9. Es decir, la posibilidad de transformarse en Reganador es 1,9 veces mayor en pacientes cuya comida principal es después de las $15 \mathrm{~h}$ en comparación con pacientes cuya comida principal es antes de las 15h. Esta asociación es estadísticamente significativa".

5. Comida principal (se considera un factor de riesgo que la comida principal sea merienda o cena):

\begin{tabular}{|l|l|l|}
\hline & Estimación \\
\hline Proporción de casos expuestos & 0,419643 \\
\hline Proporción de controles expuestos & 0,260563 \\
\hline Odds ratio & 2,051975 \\
\hline Intervalo de Confianza (95\%) & 1,207414 & 3,487288 \\
\hline
\end{tabular}

Interpretación OR: "la razón entre Reganancia versus No Reganancia es 2,05. Es decir, la posibilidad de transformarse en Reganador es 2,05 veces mayor en pacientes cuya comida principal es la merienda o cena en comparación con pacientes cuya comida principal es el desayuno o almuerzo. Esta asociación es estadísticamente significativa".

6. Picotea o realiza ingestas continuamente acompañadas de la sensación de pérdida de control (su presencia es un potencial factor de riesgo):

\begin{tabular}{|l|l|l|}
\hline & Estimación \\
\hline Proporción de casos expuestos & 0,821429 \\
\hline Proporción de controles expuestos & 0,56338 \\
\hline Odds ratio & 3,565 \\
\hline Intervalo de Confianza (95\%) & 1,983405 & 6,407781 \\
\hline
\end{tabular}


Interpretación OR: "la razón entre Reganancia versus No Reganancia es 3,56. Es decir, la posibilidad de transformarse en Reganador es 3,56 veces mayor en pacientes con el hábito de picoteo en comparación con pacientes sin este hábito. Esta asociación es estadísticamente significativa".

7. Veces por día que consume dulces (consumir dulces más de una vez al día es un factor de riesgo)

\begin{tabular}{|l|l|l|}
\hline & Estimación \\
\hline Proporción de casos expuestos & 0,321429 \\
\hline Proporción de controles expuestos & 0,197183 \\
\hline Odds ratio & 1,928571 \\
\hline Intervalo de Confianza (95\%) & 1,087564 & 3,419925 \\
\hline
\end{tabular}

Interpretación OR: "la razón entre Reganancia versus No Reganancia es 1,93. Es decir, la posibilidad de transformarse en Reganador es 1,93 veces mayor en pacientes que consumen dulces más de una vez por día en comparación con pacientes que consumen dulces una vez o menos por día. Esta asociación es estadísticamente significativa".

8. Realización de actividad física (su ausencia es un potencial factor de riesgo):

\begin{tabular}{|l|l|l|}
\hline & Estimación \\
\hline Proporción de casos expuestos & 0,696429 \\
\hline Proporción de controles expuestos & 0,524823 \\
\hline Odds ratio & 2,077107 \\
\hline Intervalo de Confianza (95\%) & 1,2333602 & 3,497378 \\
\hline
\end{tabular}

Interpretación OR: "la razón entre Reganancia versus No Reganancia es 2,07. Es decir, la posibilidad de transformarse en Reganador es 2,07 veces mayor en pacientes que no realizan actividad física en comparación con pacientes que si realizan actividad física. Esta asociación es estadísticamente significativa". 
9. Consumo de alcohol (su presencia es un potencial factor de riesgo):

\begin{tabular}{|c|c|c|}
\hline & \multicolumn{2}{|c|}{ Estimación } \\
\hline Proporción de casos expuestos & \multicolumn{2}{|l|}{0,455357} \\
\hline Proporción de controles expuestos & \multicolumn{2}{|l|}{0,316901} \\
\hline Odds ratio & \multicolumn{2}{|l|}{1,802186} \\
\hline Intervalo de Confianza (95\%) & 1,078861 & 3,010465 \\
\hline
\end{tabular}

Interpretación OR: "la razón entre Reganancia versus No Reganancia es 1,8. Es decir, la posibilidad de transformarse en Reganador es 1,8 veces mayor en pacientes que consumen alcohol en comparación con pacientes que no consumen alcohol. Esta asociación es estadísticamente significativa".

10. Presencia de enfermedades mentales, detectadas en la etapa posoperatoria (su presencia es un potencial factor de riesgo):

\begin{tabular}{|l|l|l|}
\hline & Estimación \\
\hline Proporción de casos expuestos & 0,214286 \\
\hline Proporción de controles expuestos & 0,056338 \\
\hline Odds ratio & 4,568182 \\
\hline Intervalo de Confianza (95\%) & 1,963994 & 10,62543 \\
\hline
\end{tabular}

Interpretación OR: "la razón entre Reganancia versus No Reganancia es 4,56. Es decir, la posibilidad de transformarse en Reganador es 4,56 veces mayor en pacientes que presentan enfermedades mentales en comparación con pacientes que no presentan las mismas. Esta asociación es estadísticamente significativa".

11. Evento negativo posoperatorio (su presencia es un potencial factor de riesgo):

\begin{tabular}{|l|l|l|}
\hline & Estimación \\
\hline Proporción de casos expuestos & 0,607143 \\
\hline Proporción de controles expuestos & 0,368794 \\
\hline Odds ratio & 2,645105 \\
\hline Intervalo de Confianza (95\%) & 1,587231 & 4,408041 \\
\hline
\end{tabular}

Interpretación OR: "la razón entre Reganancia versus No Reganancia es 2,64. Es decir, la posibilidad de transformarse en Reganador es 2,64 veces mayor en pacientes que padecieron un evento negativo en la etapa posoperatoria en comparación con pacientes que no padecieron este tipo de evento. Esta asociación es estadísticamente significativa". 


\section{Discusión}

Según el Consenso Argentino de Cirugía Bariátrica, existe una posición favorable hacia que la cirugía bariátrica constituye la alternativa terapéutica más eficaz en pacientes con obesidad mórbida, ante el fracaso del tratamiento convencional. (51) Es recomendada por todas las guías de práctica clínica de diagnóstico y tratamiento de la obesidad como opción terapéutica en pacientes con obesidad mórbida y por el impacto en la remisión y reducción de las comorbilidades asociadas a la obesidad.

Un resultado quirúrgico adecuado en el seguimiento inicial no garantiza el pronóstico favorable a largo plazo. El tratamiento quirúrgico debe ofrecer una pérdida ponderal adecuada y mantenida en el tiempo.

Se considera que el éxito de del tratamiento de la obesidad está definido por la reducción del peso y su mantenimiento en el tiempo, la remisión o mejoría de las comorbilidades, y la mejoría en la calidad de vida. Sin embargo, se sabe también que no todos los pacientes sometidos a este procedimiento logran mantener la pérdida de peso luego de varios años. Aunque la cirugía bariátrica es el tratamiento más efectivo contra la obesidad, en varios grupos se ha reportado reganancia de peso al largo plazo, que varía entre 20 a $87 \%$ según la técnica empleada. (53)

En este estudio se ha verificado la notoria disminución de los valores de IMC entre la evaluación inicial y la instancia donde se registra el peso mínimo postoperatorio. De la misma forma, respecto de la valoración actual se observa un incremento en los valores de IMC. Las medias en las tres instancias cambian su clasificación de obesidad mórbida a sobrepeso y posteriormente a obesidad grado 1. Con esto podemos mostrar la eficacia de la cirugía valorada por la pérdida del exceso de peso de nuestros pacientes y considerando también que un porcentaje importante de estos se mantiene en categoría de sobrepeso. Se debe destacar que más de la mitad de los pacientes después de 5 años de operados aumentan hasta un 15\% respecto del peso mínimo posoperatorio. Es este estudio un $44 \%$ de la población reganó peso logrando una buena calidad de vida valorada por el cuestionario BAROS.(70) Este resultado es difícil de comparar con la bibliografía consultada dado que no existe consenso sobre cómo definir reganancia de peso post cirugía bariátrica, en consecuencia los resultados de prevalencia son muy diversos porque se utilizan métodos diferentes de valoración. Pero sí coinciden como principales motivos, dentro de las posibles causas no quirúrgicas, la falta de realización de actividad física y los malos hábitos alimentarios. 
Según las guías de las sociedades AACE/TOS/ASMBS es de fundamental importancia contar con un equipo interdisciplinario entrenado en el manejo bariátrico pre y post quirúrgico. (3) (51) La preparación y el seguimiento médico-nutricional del paciente son decisivos para el éxito de la cirugía. Es sumamente importante que los pacientes continúen en contacto regularmente y como mínimo cada 6 meses con el equipo de cirugía bariátrica durante los primeros dos años y posteriormente anualmente como estrategia para el mantenimiento de peso. Según el estudio Weight Loss Maintenance Trial (64) aquellos sujetos que tenían contacto personalmente con los profesionales perdían más peso que aquellos sujetos que tienen contacto telefónicamente o por medio de internet. En este estudio no se encuentran diferencias estadísticamente significativas entre aquellos pacientes clasificados como reganadores o no reganadores de peso, respecto a la frecuencia de pesaje ni a los responsables del proceso de control de peso. Por el contrario, la concurrencia a la consulta con un profesional de la nutrición muestra una diferencia significativa entre reganadores y no reganadores de peso. Es por ello que podemos destacar la importancia de tener un seguimiento nutricional dado que favorece a menor prevalencia de reganancia de peso post cirugía bariátrica.

La adherencia a los controles por parte del equipo de cirugía durante el postoperatorio es con frecuencia subóptimo y puede afectar negativamente a la pérdida de peso. En informes recientes, sólo el $40 \%$ de los pacientes concurrió a las 4 visitas anuales previstas durante el primer año de seguimiento con el cirujano. Los que regresaron para todas sus visitas anuales de seguimiento perdieron significativamente más peso que aquellos pacientes que no regresaron. Un estudio más reciente sugiere que las personas que participaron regularmente en un grupo de apoyo mensual experimentaron una mayor pérdida de peso que aquellos que no asistieron el grupo de apoyo. (48) (51) (52) En cambio en este estudio se encontró que la concurrencia a grupos de apoyo es muy baja y no se encontró relación con ser o no reganador de peso.

Según un estudio a cargo de Colleen Cook et al. (54) sobre hábitos exitosos en pacientes con bypass gástrico se identificó que presentaban seis hábitos comunes relacionado con la alimentación, consumo de bebidas, consumo de suplementos de vitaminas y minerales, sueño, ejercicio físico y autocuidado. En cuento a la alimentación los pacientes exitosos consumen 3 comidas y dos colaciones cada día, consumiendo todos los grupos de alimentos: proteínas, vegetales, fruta, pan y pocos dulces. Consumen agua preferentemente y evitan las bebidas carbonatadas, bebidas azucaradas y el alcohol en su gran mayoría. También consumen diariamente el multivitamínico y toda aquella suplementación sugerida, descansan 7 horas promedio, 
el $77 \%$ de la población en estudio se ejercita cuatro veces a la semana 40 minutos. Y por último se hacen responsables del cuidado que merece la cirugía pesándose semanalmente. La mala calidad de la dieta, la elección de alimentos inapropiados y la falta de orientación nutricional han sido considerados como predictores claves de recuperación de peso después de la cirugía.

Respecto a lo referido a Collen Cook y col. (54) este estudio concuerda la relación entre comer de forma saludable, no ser un comedor de dulces o sweet eater, no consumir alcohol y realizar actividad física con respecto al mantenimiento de peso. En cambio no se encontró relación con descansar por lo menos $7 \mathrm{~h}$, número de ingestas diarias, ni la adherencia a consumir el suplemento multivitamínico mineral recomendado por el equipo multidisciplinario.

Muchos estudios sugieren que la adherencia a las recomendaciones nutricionales post cirugía es muy baja, que el valor calórico de la dieta aumenta notablemente con el correr de los años durante el postoperatorio. Oliveira Magro y col. (65) describieron que la causa de la reganancia de peso se atribuye a no incorporar hábitos saludables en el estilo de vida para mantener el peso perdido. En este estudio se encontró que existe relación entre no ser reganador de peso post cirugía y comer de manera saludable o muy saludable.

En un estudio realizado por Bastos et al. (60), ni la actividad física, el consumo de alcohol, la suplementación, el apetito ni el monitoreo nutricional influyeron en el aumento de peso postoperatorio. Pero sí mostró influencia trabajar en relación con alimentos $(p>0.003)$, es decir que las personas que trabajan habitualmente con alimentos podrían tener más probabilidades de reganar peso. Sin embargo este estudio no ha demostrado relación alguna, ya que se observan porcentajes prácticamente idénticos en ambos grupos.

Según Sarwer y col. (66) existen problemas alimentarios y desórdenes alimentarios post cirugía bariátrica: atracón o binge eating, comedor nocturno o night eating, comedor emocional o emotional eating, comedor de dulces o sweet eating, y picoteador o grazing. Estos pueden influir o revertir el éxito de la cirugía e impactar o afectar en la calidad de vida. Mientras la popularidad de la cirugía de pérdida de peso sigue aumentando, es necesaria una mayor comprensión de los factores de riesgo que pueden desvirtuar los resultados óptimos de peso. Picotear después de la cirugía bariátrica puede afectar el descenso de peso post cirugía o contribuir a la reganancia. Mientras que algunos patrones alimentarios pueden mejorar después de la cirugía, especialmente a corto plazo, algunos estudios muestran que las alteraciones de la conducta alimentaria tienden a persistir después de la cirugía y están asociadas a malos resultados con mayor reganancia de peso. Aquellos individuos que presentan 
atracones tienen menor reducción del IMC y mayor reganancia post cirugía, comparados con aquellos que no lo presentan. Tanto la pérdida del control en la alimentación como el picoteo después de la cirugía están asociados a pobre pérdida de peso con un impacto psicológico. Los atracones post cirugía tienen un impacto en la calidad de vida mayor que el relacionado al peso. En este estudio se ha encontrado relación entre ser reganador de peso post cirugía y tener el hábito de picotear o ser un comedor de dulces o sweet eater, en cambio no se ha encontrado relación con hacer atracones o ser un comedor nocturno. La mayoría de los reganadores suelen comer por ansiedad, en cambio los no reganadores sienten comer por hambre.

En las Guías de la Sociedad Americana de Cirugía Bariátrica y Metabólica y el Consenso Argentino de Nutrición en Cirugía Bariátrica recomiendan que los sujetos con Bypass Gástrico en $\mathrm{Y}$ de Roux deben abstenerse de consumir alcohol dado que el metabolismo de esta sustancia se ve alterado después de la cirugía y puede promover la reganancia de peso y deficiencias de vitaminas y minerales. (3) (51) En este estudio se ha encontrado que entre los reganadores de peso el porcentaje de consumo es más alto, respecto de los no reganadores y que existe evidencia estadísticamente significativa para relacionar este hábito y el hecho de reganar peso post cirugía bariátrica.

Un beneficio potencial de la cirugía bariátrica sobre la actividad física, es que permite a los pacientes ser más activos. Los estudios bioquímicos han demostrado que la eficiencia del músculo esquelético aumenta a medida que un paciente pierde peso, y al mismo tiempo, que la proporción de masa libre de grasa tiene una significativa correlación positiva con la tasa metabólica basal. (3) De ahí la importancia de preservar este componente corporal. En este estudio se pudo observar mayores porcentajes de realización física entre los no reganadores, aunque ni siquiera dentro de este grupo la realización de actividad física llegó a ser mayoritaria. Existe una diferencia estadísticamente significativa en la realización de actividad física respecto a no ser reganador de peso.

Según Shantavasinkul y col. (67) ser joven es predictor de reganancia de peso post cirugía, en cambio no se encontró en la bibliografía consultada una posición tomada sobre la relación entre el género, estado civil, edad de inicio del sobrepeso y escolaridad.

Continuar profundizando los conocimientos sobre las variables que influyen en la reganancia de peso post cirugía bariátrica es un reto para los profesionales para así mejorar el tratamiento y prevenir esta problemática. 


\section{Conclusiones}

A continuación se presentan las conclusiones obtenidas para una muestra de 254 pacientes operados de cirugía bariátrica con una antigüedad mayor o igual a cinco años en la que el $44 \%$ ha reganado peso al momento de ser evaluada, siendo la muestra estudiada mayormente mujeres, operadas de bypass gástrico, con un nivel escolar del secundario completo. En cuanto a la evaluación de factores de riesgo que se asocian a la reganancia de peso podemos concluir que:

Tanto la niñez como la adultez son las etapas de la vida donde se registran los mayores porcentajes de comienzo de las situaciones de sobrepeso.

Muchos equipos de cirugía bariátrica, como parte de la preparación preoperatoria, solicitan al paciente perder un porcentaje discreto de peso. (51) Este descenso de peso registrado entre la evaluación inicial y el momento del ingreso a quirófano resulta estadísticamente significativo.

Se sabe que, de acuerdo a la exhaustiva recopilación bibliográfica, un porcentaje importante de pacientes recupera peso después de la cirugía bariátrica. Los resultados de este estudio muestran una diferencia entre el peso mínimo alcanzado después de la cirugía y el peso actual de los pacientes y es significativamente diferente de cero, es decir, el aumento de peso promedio observado entre ambas instancias resulta estadísticamente significativo. A pesar de esto, los resultados obtenidos después de estos procedimientos son muy favorables para los pacientes si se los mide por pérdida de peso y mejoría de la calidad de vida. Se observa que la mayoría de los pacientes alcanzaron el peso mínimo entre los 6 y los 18 meses.

En cuanto a la prevalencia de reganancia de peso en la muestra estudiada, un $44,09 \%$ es considerada reganadora bajo el criterio que establece como reganadores a aquellos pacientes que registren un incremento de peso superior al $15 \%$ respecto del peso mínimo alcanzado posoperatorio (nadir).

La muestra en estudio no refleja diferencias estadísticamente significativas entre reganadores y no reganadores respecto a las siguiente variables: la edad, el género, tipo de técnica quirúrgica realizada, nivel educativo, momento de inicio del exceso de peso, situación de convivencia, descenso de peso adecuado preoperatorio, frecuencia de control de peso, persona responsable del control de peso, concurrencia a grupos de apoyo durante el primer año después de operado, frecuencia de consumo del desayuno, merienda, colación de media mañana, tarde y noche, tener el hábito de hacer atracones, ser un comedor nocturno, la intensidad con la que realiza actividad 
física, dormir por lo menos $7 \mathrm{~h}$ diariamente, tomar la suplementación de vitaminas y minerales sugerida por el equipo quirúrgico, frecuencia del consumo de alcohol, realización después de operado psicoterapia durante 6 meses o más, consumo de medicación psiquiátrica durante 6 meses o más, presentar un diagnóstico de trastorno mental antes de la cirugía y sentirse mejor después de la cirugía según el cuestionario BAROS.

Se han encontrado diferencias significativas respecto de ser reganador o no serlo respecto de las siguientes variables. como por ejemplo la frecuencia de consulta con un profesional de la nutrición, esto demuestra la importancia que tiene el control por parte de los profesionales nutricionistas después de dicho procedimiento a favor del mantenimiento de peso.

En cuanto a hábitos alimentarios, la frecuencia de realización del almuerzo y la cena, que su comida principal sea antes de las $15 \mathrm{~h}$, considerar comer de forma saludable, no tener el hábito de picotear, no ser un comedor de dulces o sweet eater y no consumir alcohol. Esto quiere decir que tener comidas programadas como el almuerzo y/o cena, preferentemente en las primeras comidas del día, que las mismas que sean saludables, y no tener conductas negativas son hábitos de la conducta alimentaria a mantener después de la cirugía para obtener resultados exitosos mantenidos a largo plazo.

También, como era esperable, tener el hábito de realizar actividad física, no tener diagnóstico de un trastorno mental después de la cirugía, no haber padecido algún evento traumático después de la cirugía, participar más en actividades físicas, participar más en actividades sociales, trabajar mejor y tener más actividad sexual después de la cirugía según la cuestionario BAROS son variables estadísticamente significativas.

En cuanto a la hipótesis planteada se niega que exista alguna relación con la edad, género, nivel educativo, edad de inicio del sobrepeso, IMC inicial preoperatorio, tener apoyo psicológico, descansar por lo menos $7 \mathrm{~h}$, hacer atracones y ser comedor nocturno. Se afirma el resto de las variables consideradas inicialmente. 


\section{Bibliografía}

1. Braguinsky J, De Girolami. Obesidad Bs As: El Ateneo; 1997.

2. Braguinsky Jyc. Obesidad: Saberes y Conflictos. Un tratado de Obesidad Buenos Aires: Editorial Médica A.W.W.E; 2007.

3. Garvey WT, Garber A, Mechanick J, Bray G, Dagogo-Jack S, Einhorn D, et al. American association of clinical endocrinologists and american college 0 endocrinology. Position statemen on the 2014 framework for a new diagnosis of obesity as a chronic disease. Endrocrine Practice. 2014; 20(9): p. 977-989.

4. Tounian P. Programming towards childhood. Obesity Ann Nutr Metab. 2011; 58: p. $30-41$.

5. Junnila $R$, Aromaga $M$, Heinonen $O$, Lasgström $H$, Liuksila $P$, Vahlberg $T$. The weighty matter intervention: a family-centered way to tackle an overweight childhood. $\mathrm{J}$ Community Health Nurs. 2012; 29.

6. Hernández Cordero S. Prevention of infant obesity. Gac Med Mex. 2011; 147: p. 4650.

7. Serene TE, Shamarina S, Mohd NM. Familial and socio-environmental predictors of overweight and obesity among primary school children in Selangor and Kuala Lumpur Malays. J Nutr. 2011; 17: p. 151-162.

8. Rankinen T, Zuberi A, Chagnon YC, Weisnagel SJ, Argyropoulos G, Walts B. The human obesity gene map: the 2005 update. Obesity. 2006; 14: p. 529-644.

9. Doo M, Kim Y. Association between ESR1 rs1884051 polymorphism and dietary total energy and plant protein intake on obesity in Korean men. Nutr Res Pract. 2011; 5: p. 527-532.

10. González-Jiménez E. Genes and obesity: a cause and effect relationship. Endocrinol Nutr. 2011; 58: p. 492-496.

11. Nativio DG. The genetics, diagnosis, and management of Prader-Willi syndrome. $J$ Pediatr Health Care. 2002; 16: p. 298-303.

12. González-Jiménez E. Obesity: etiologic and pathophysiological analysis. Endocrinol Nutr. 2013; 60: p. 17-24.

13. Deeble VJ, Roberts E, Jackson A, Lench N, Karbani G, Woods CG. The continuing failure to recognise Alstrom syndrome and further evidence of genetic homogeneity. J Med Genet.

2000; 37: p. 219.

14. Marshall JD, Beck S, Maffei P, Naggert JK. Alström syndrome. Eur J Hum Genet. 2007; 15: p. 1193-1202.

15. Prados-Bo A, Gómez-Martínez S, Nova E, Marcos A. El papel de los probióticos en el manejo de la obesidad. Nutr Hosp. 2015; 31(supl ): p. 10-18. 
16. Tehrani AB, Nezami BG, Gewirtz A, Srinivasan S. Obesity and its associated disease: a role for microbiota? Neurogastroenterol Motil. 2012; 20.

17. Cani PD, Bibiloni R, Knauf C, Waget A, Nevrinck AM, Delzenne NM. Changes in gut microbiota control metabolic endotoxemia-induced inflammation in high-fat dietinduced obesity and diabetes in mice. Diabetes. 2008; 57: p. 1470-1481.

18. Turnbaught R, Mahowald M, Magrini V, Mardis E, et al.. An obesity-associated gut microbiome with increased capacity for energy harvest. Nature. 2006; 444: p. 10271031.

19. Le RE, Trunbaugh P, Klein S, Gordon J. Microbial ecology: Human gut microbes associated with obesity. Nature. 2006; 444: p. 1022-1023.

20. Sato K, Uzu T, Yoshida EM, Hamad H, Kawakami H, Marsuyama. Effects of milk fermented by Lactobacillus gasseri SBT2055 on adipocyte size in rats. Br J Nutr. 2008; 99: p. 1013-1017.

21. Ma X, Hua J, Li Z. Probiotics improve high fat diet-induced hepatic steatosis and insulin resistance by increasing hepatic NKT cells. J Hepatol. 2008; 49: p. 821-830.

22. Everard A, Belzer C, Geurts L, Ouwerkerk J, Druart C, Bindels L, et al. Cross-talk between Akkermansia muciniphila and intestinal epithelium controls diet-induced obesity. Proc Natl Acad Sci USA. 2013; 110(22): p. 9066-71.

23. Skinner J, Carruth B, Moran J. Fruit juice intake is not related to childrens growth. Pediatrics. 1999; 103: p. 58-64.

24. Cavadini C, Siega-Riz A, Popkin B. US adolescent food intake trends from 1965 to 1996. Arch Dis Child. 2000; 83: p. 18-24.

25. González-Jiménez E. Evaluación de la eficacia de una intervención educativa sobre nutrición y actividad física en niños y adolescentes escolares con sobrepeso y obesidad de Granada y provincia. 2010.

26. Viner R, Segal T, Lichtarowicz-Krynska E, Hindmarsh P. Prevalence of the insulin resistence syndrome in obesity. Arch Dis Child. 2005; 90: p. 10-14.

27. Welsh J, Cogswell M, Rogers S, Rockett H, Mei Z, Grummer S. Overweight among low-income preschool children associated with the consumption of sweet drinks: Missouri, 1999-2002. Pediatrics. 2005; 115: p. 223-229.

28. Salmon J, Timperio A, Teldford A, Carver A, Crawford D. Crawford Association of family environment with childrens television viewing and with low level of physical activity. Obes Res. 2005; 13: p. 1939-1951.

29. Jeffcogle W. Obesity is a disease: food for thought. Lancet. 1998; 351: p. 903-904.

30. Najjar MF, Rowland M. Anthropometric reference data and prevalence of overweight, United States, 1976-80. Vital Health Stat. 1987; 11: p. 1.

31. Salas-Salvadó J, Rubio M, Barbany M, Moreno B, y col. Consenso SEEDO 2007 
para la evaluación del sobrepeso y la obesidad y el establecimiento de criterios de intervención terapéutica. Med Clin. 2007; 128(5): p. 184-96.

32. Sociedad Americana de Cirugía Bariátrica. Obesity Morbide. Obes Surg. 1997; 7.

33. Garvey WT, Mechanick J, Brett E, Garber A, Hurley D, Jastreboff A, et al. American association of clinical endocrinologists and american college of endocrinology clinical practice guidelines for comprehensive medical care of patients with obesity. Endocrine Practice. 2016; 22(Suppl 3).

34. Rodota L, Castro ME. Nutrición clínica y dietoterapica: Panamericana; 2012.

35. Bouchard C, et al. Basal and clinical aspects of regional fat distribution. Am J Clin Nutr.1990; p. 52.

36. Bouchard C. Current understanding of the etiology of obesity: genetic and nongenetic factors. Am J of Clin Nutr. 1991; 53: p. 1561s-1565s.

37. Torresani ME, Somoza I. Lineamientos para el cuidado nutricional Bs As: Eudeba; 2016.

38. Rodríguez Scull LE. Obesidad: fisiología, etiopatogenia y fisiopatología, Enfoque actual. Rev Cubana Endocrinol. 2003; 14(2).

39. Organización Mundial de la Salud (OMS) Junio 2016, http://www.who.int/es/.

40. Kellum JM, Demaria E], Sugerman H]. The Surgical Treatment Of Morbid Obesity. Current Problems In Surgery 1998 ;35: 796-851.

41. Sapala Ja, Wood Mh, Sapala Ma, y Colab.: Marginal Ulcers Following Gastric Bypass: A Prospective 3 Years Study Of 173 Patients. Obes Surg 1998;8:505-16.

42. Schauer Pr, Ikaramuddin S, Gourash W, y Colab: Outcomes After Laparoscopic Roux-En-Y Gastric Bypass For Morbid Obesity. Ann Surg 2000;232:515-29.

43. Wittgrove Ac, Clark Gw, Tremblay Lj: Laparoscopic Gastric Bypass, Roux-En-Y: Preliminary Report Of Five Vases. Obes Surg 1994; 4: 353-357.

44. LANGER FB, BOHDJALIAN A, FELBERBAUER FX, y colab. Does gastric dilatation limit the success of sleeve gastrectomy as a sole operation for morbid obesity? Obes Surg 16:166-171, 2006.

45. Hollanda A, Ruiz T, Jiménez A, Flores L, Lacy A, Vidal J. Patterns of weight loss response following gastric bypass and sleeve gastrectomy. Obes Surg. 2015; 25: p. 1177-1183.

46. Sjoostrom L. Review of the key results from the Swedish Obese Subjects (SOS) trial - a propective controlled intervention stydy of bariatric surgery. J of Int Med. 2013; 273: p. 219-234.

47. Odom J. ZKC,WTL. Behavioral Predictors of Weight Regain after Bariatric Surgery.. Obes Surg. 2010; 20: p. 349-356.

48. Rossner EK. Who succeds in maintaining weight loss? A conceptual review of 
factors associated with weight loss maintenance and weight regain. Obes Rev. 2005; 6: p. 67-85.

49. Stoklossa CJ, Atwal S. Nutrition care for patients with weight regain after bariatric surgery. Hindawi Publishing Corp Gastroent Res and Pract Vol. 2013.

50. Leite Faria S, de Oliveira Kelly E, et al. Nutritional Management of Weight Regain After Bariatric Surgery. Obes. Surg. 2010; 20: p. 135-139.

51. Pampillón N, Reynoso C, Sánchez M, Aguirre Ackerman M, De Rosa $P$, Coqueugniot $\mathrm{M}$, et al. Actualización del consenso argentino de nutrición en cirugía bariátrica. Actualización en nutrición. 2016; 17(1): p. 19-32.

52. Papapietro V K. Evaluación alejada de los obesos mórbidos sometidos a cirugía bariátrica. Revista Hospital Clínico Universidad de Chile. 2005; 16 (4).

53. Rubio , Ballesteros. Causas y manejo clínico de la recuperación de peso tras cirugía bariátrica.

54. Colleen M. Cook CE. Success Habits of Long-Term Gastric Bypass Patients. Allied Health. Obesity Surgery. 1999; 9: p. 80-82.

55. Karmali S, Brar B, Shi X, Sharma A, de Gara C, Birch D. Weight Recidivism PostBariatric Surgery: A Systematic Review. Obes Surg. 2013; 23: p. 1922-1933.

56. Papapietro V K. Reganancia de peso después de la cirugía bariátrica. Rev. Chilena de Cirugía. 2012 Febrero; 64 (1): p. 83-87.

57. Rutledge T, Groessz L, Savu M. Psychiatric factors an weight loss patterns following gastric bypass surgery in a veteran population. Obes Surg. 2011; 21(1): p. 29-35.

58. Leite Faria S KEFO. Energy Expenditure and Weight Regain in Patients Submitted to Roux-en-Y Gastric Bypass. Obes Surg. 2009; 19: p. 856-9.

59. MacLean PS. Enhanced metabolic efficiency contributes to weight regain after weight loss in obesity-prone rats.. Am J Physiol Regul Integr Comp Physiol. 2004 ; 287: p. 1306-15.

60. Bastos E. BE,SG. Determinants of Weight Regain after Bariatric Surgery. ABCD Arq Bras Cir Dig. 2013; 26(1): p. 26-32.

61. Shen R, Dugay G, Rajaram K, Cabrera I, Siegel N, Ren CJ. Impact of patient follow-up on weight loss after bariatric surgery. Obes Surg. 2004; 14: p. 514-19.

62. Vidal P.Ramón J. M. GA,PA,CX,TLPMea. Lack of Adherence to Follow-Up Visits After Bariatric Surgery: Reasons and Outcome. Obes. Surg. 2014; 24: p. 179-183.

63. Fazylov R SEMS. Laparoscopic Roux en Y Gastric Bypass in morbidly obese patients >55 years old. OBES SURG. 2008; 18: p. 656- 659.

64. Svetkey L. Comparison of Strategies for Sustaining Weight Loss The Weight Loss Maintenance Randomized Controlled Trial, JAMA, 2008, Vol 299, No. 10. 
65. Oliveira Magro D., Geloneze B. Delfini R., Contini B. Long-term Weight Regain after Gastric Bypass: A 5-year Prospective Study, obes surg (2008) 18:648-651 DOI 10.1007/s11695-007-9265-1.

66. Sarwer D. B., Dilks R., West Smith L. Review article Dietary intake and eating behavior after bariatric surgery: threats to weight loss maintenance and strategies for success. Surgery for Obesity and Related Diseases 7 (2011) 644-65.

67. Shantavasinkul P. C., Omotosho P. Corsino L. Portenier D. Predictors of weight regain in patients who underwent Roux-en-Y gastric bypass surgery. Surgery for Obesity and Related Diseases (2016) 00-00 5859.

68. Sociedad Internacional para el Avance de la Cineantropometría (ISAK). Protocolo internacional para la valoración antropométrica. Segunda revision, 2011. United Kingdom.

69. Organización Mundial de la Salud (OMS), Obesidad y Sobrepeso, Nota descriptiva N³11, Agosto de 2014 [acceso: 1 de diciembre de 2014]. Disponible en: http://www.who.int/mediacentre/factsheets/fs311/es/.

70. Oria, H.E. \& Moorehead, M.K. Bariatric Analysis and Reporting Outcome System (BAROS) obes surg (1998) Volume 8: 487-499 DOI10.1381/096089298765554043 
